\title{
Streptococcus milleri : relevance of species
}

Citation for published version (APA):

Jacobs, J. A. (1996). Streptococcus milleri : relevance of species. [Doctoral Thesis, Maastricht University]. Universiteit Maastricht. https://doi.org/10.26481/dis.19960619jj

Document status and date:

Published: 01/01/1996

DOI:

10.26481/dis.19960619jj

Document Version:

Publisher's PDF, also known as Version of record

\section{Please check the document version of this publication:}

- A submitted manuscript is the version of the article upon submission and before peer-review. There can be important differences between the submitted version and the official published version of record.

People interested in the research are advised to contact the author for the final version of the publication, or visit the DOI to the publisher's website.

- The final author version and the galley proof are versions of the publication after peer review.

- The final published version features the final layout of the paper including the volume, issue and page numbers.

Link to publication

\footnotetext{
General rights rights.

- You may freely distribute the URL identifying the publication in the public portal. please follow below link for the End User Agreement:

www.umlib.nl/taverne-license

Take down policy

If you believe that this document breaches copyright please contact us at:

repository@maastrichtuniversity.nl

providing details and we will investigate your claim.
}

Copyright and moral rights for the publications made accessible in the public portal are retained by the authors and/or other copyright owners and it is a condition of accessing publications that users recognise and abide by the legal requirements associated with these

- Users may download and print one copy of any publication from the public portal for the purpose of private study or research.

- You may not further distribute the material or use it for any profit-making activity or commercial gain

If the publication is distributed under the terms of Article $25 \mathrm{fa}$ of the Dutch Copyright Act, indicated by the "Taverne" license above, 


\title{
STREPTOCOCCUS MILLERI: RELEVANCE OF SPECIES
}

\section{PROEFSCHRIFT}

\author{
Ter verkrijging van de graad van doctor \\ aan de Rijksuniversiteit Limburg te Maastricht, \\ op gezag van de Rector Magnificus, Prof. Mr. M.J.Cohen, \\ volgens het besluit van het College van Dekanen, \\ in het openbaar te verdedigen op \\ woensdag 19 juni 1996 om 16.00 uur
}

door:

Jan Adriaan Jacobs

geboren te Leuven 
Promotor:

Co-promotores

Beoordelingscommissie:
Prof. Dr. P.B.Soeters

Dr. E.E. Stobberingh

Dr. J.L. Verhaegen (Katholieke Universiteit Leuven, Belgié)

Prof. Dr. F.C.S. Ramaekers (voorzitter)

Prof. Dr. J. Dankert (Universiteit van Amsterdam)

Prof. Dr. E.F.M. Wouters

Prof. Dr. H.F.P. Hillen

Prof. Dr. J. C.M. Ratus (Limburgs Universitair Centrum, België)

ISBN: D/1996/1430/1

Druk: Drukkerij Bessemans, Eigenbilzen

Ontwerp omslag: J. Kellens / W. Vriese 


\section{CONTENTS}

Introduction

Chapter I Review of the literature

Aims of the study.

Chapter II Viridans streptococci isolated from the bloodstream.

Relevance of species identification.

Diagnostic Microbiology and Infectious Diseases 1995; 22: 267-273.

Chapter III Bacteremia involving the "Streptococcus milleri" group:

analysis of 19 cases

Clinical Infectious Diseases 1994; 19: 704-713.

Chapter IV Streptococcus anginosus, Streptococcus constellatus and Streptococcus

intermedius. Clinical relevance, hemolytic and serologic characteristics.

American Journal of Clinical Pathology 1995; 104: 547-553.

Chapter V Species identification of "Streptococcus milleri"

with the Rapid ID 32 Strep system.

Medical Microbiology Letters 1994; 3: 315-322.

Chapter VI Rapid species identification of "Streptococcus milleri" strains by

line blot hybridization: identification of a distinct $16 \mathrm{~S}$ ribosomal population closely related to Streptococcus constellatus.

Journal of Clinical Microbiology, accepted with minor modification.

Chapter VII Hydrolytic enzymes of Streptococcus anginosus, Streptococcus constellatus and Streptococcus intermedius in relation to infection.

European Journal of Clinical Microbiology and Infectious Diseases 1995;

14: $818-820$.

Chapter VIII In-vitro antimicrobial susceptibility of the "Streptococcus milleri"

group (Streptococcus anginosus, Streptococcus constellatus and

Streptococcus intermedius)

Journal of Antimicrobial Chemotherapy 1996; 37: 371-375.

Chapter IX General Discussion

Summary

Samenvatting

Dankwoord.

List of publications 


\section{INTRODUCTION}

\section{General Background}

"In microbiology, a name denotes an organism's place in the world and connotes its significance in the clinic" (Turck, 1989).

The taxonomy of "Streptococcus milleri" strains has been debated for many years. "S. milleri" strains, known for their association with purulent infections, have been repeatedly classified and reclassified until they were finally reallocated into three distinct species, Streptococcus anginosus, Streptococcus constellatus and Streptococcus intermedius (Whiley, 1991). The changes in classification and nomenclature of these organisms have hampered their recognition and identification in the diagnostic laboratory. Further identification problems arose from the phenotypic heterogeneity of these organisms. In addition, the reference phenotypic identification scheme includes tests that are not traditional for viridans streptococci (Whiley, 1990). By consequence, little is known about the precise ecology of the three "S. milleri" species, and only scanty information is available about the clinical picture they

\section{References}

Piscitelli SC, Shwed J, Schreckenberger P, Danziger LH. Streptococcus milleri group: renewed interest in an elusive pathogen. Eur J Clin Microbiol Infect Dis 1992; 11: 491-498.

Ruoff KL. Streptococcus anginosus ("Streptococcus milleri"): the unrecognized pathogen. Clin Microbiol Rev 1988; 1: 102-108.

Turck M. The new taxonomy in infections. Hosp Pract 1989; 24: 109-121. are associated with. Furthermore, data on the antimicrobial susceptibilities and the pathogenicity of the three species are rarely found in the literature. Appealing names, such as "insidious pathogen" (Spertini, 1987), "unrecognized pathogen" (Ruoff, 1988), and "elusive pathogen" (Piscitelli, 1992), have expressed both the difficult recognition and the poorly documented pathogenic role of the organism.

At the University Hospital Maastricht, we collected "S. milleri" strains recovered from clinical specimens routinely submitted for culture. We designed several studies to provide further information on the ecology, the clinical picture, the classification and identification, the antimicrobial susceptibilities and the pathogenicity of the three "S. milleri" species as they are currently described.

Whiley RA, Fraser H, Hardie JM, and Beighton D. Phenotypic differentiation of Streptococcus intermedius, Streptococcus constellatus, and Srreptococcus anginosus strains within the "Streptococcus milleri" group. J Clin Microbiol 1990; 28: 1497-1501.

Whiley RA and Beighton D. Emended descriptions and recognition of Streptococcus constellatus, Streptococcus intermedius and Streptococcus anginosus as distinct species. Int I Syst Bacteriol $1991 ; 41: 1-5$. 


\section{Outline of this thesis}

The literature on "S. milleri" and on S. anginosus, $S$. constellatus and $S$. intermedius is reviewed in Chapter I. The taxonomic history of these organisms is reviewed. Clinical picture, pathogenicity and antimicrobial susceptibilities of the organisms are discussed, based on data reported on the three distinct species and on "S. milleri" as a whole.

In Chapters II and III, episodes of bacteraemia due to "S. milleri" organisms are described. The clinical significance and the blood culture characteristics of the $S$. viridans strains recovered from the blood stream can be found in Chapter II, as well as information regarding the performance of two commercial identification systems (the API 20 Strep and the Rapid ID 32 Strep systems) in identification of the viridans streptococci. Chapter III reports the detailed clinical and microbiological findings of 19 episodes of bacteraemia due to "S. milleri" strains. In Chapter IV, the serologic and haemolytic properties of the three species in a collection of consecutively isolated strains are presented. Information is provided on the anatomic distribution and the clinical significance of the three species.

In Chapter V, the "S. milleri" species identifications obtained by the Rapid ID 32 Strep system are compared to those obtained by the reference phenotypic identification scheme. Chapter VI explores the genetic interrelationships on the $16 \mathrm{~S}$ ribosomal RNA level between the three species by use of species-specific oligonucleotide probes in a line blot assay.

In Chapter VII, the three "S. milleri" species are tested for the presence of hydrolytic enzymes, and the activities detected are related to the clinical significance of the strains.

The three "S. milleri" species are tested for susceptibilities to a panel of currently used antimicrobial agents in Chapter VIII.

Chapter IX overviews the results presented in the previous Chapters with greatest emphasis put on issues of classification and identification. 
CHAPTER I. Review of the literature Aims of the study 


\section{Streptococcus anginosus, Streptococcus constellatus and Streptococcus intermedius versus "Streptococcus milleri"}

The "Streptococcus milleri" strains form a biochemically and serologically heterogeneous collection of strains included in the Streptococcus viridans group. They encompass organisms listed in the 1986 edition of Bergey's Manual (Hardie, 1986) as $S$. anginosus, Streptococcus $M G, S$. constellatus, S. intermedius "S. milleri" and minute $B$-haemolytic streptococci of Lancefield groups $F$ and $G$ (Withworth, 1990). Their normal habitat includes the oropharynx, the gastrointestinal tract, and the female genital tract (Poole, 1977; Poole, 1979; Gossling, 1988). The "S. milleri" strains share a common link in the clinical setting: a striking association with endogenous pyogenic infections sharply delineates them from the other viridans streptococci (Parker, 1976; Gossling, 1988). At present, three species are recognised within the "S. milleri" group: $S$. anginosus, S. constellatus and S. intermedius (Whiley, 1991).

The epithet "S. milleri" is not included in the Approved Lists of Bacterial Names (amended edition) (Skerman 1980) neither in the Index of the Bacterial and Yeast Nomenclatural Changes Published in the International Journal of Systematic Bacteriology since the 1980 Approved Lists of Bacterial Names (1 January 1980 to I January 1989) (Moore, 1989) and not validly described in the validation lists and articles published in the International Journal of Systematic Bacteriology since 1 January 1989. By consequence, the epithet is not a formal name, and the name has to be enclosed in quotation marks. Because of its association with purulent infection, the name " $S$. milleri" continues to be used in the medical literature.

In this Chapter, a compact review of the taxonomic history of the "S. milleri" strains will be offered.
Their identification in the diagnostic laboratory will be discussed as well as their epidemiology, the clinical picture they are associated with, their pathogenicity, their antimicrobial susceptibility and the therapy of the infections they are involved in. Where available, data on the three distinct species as currently described are presented. If species-associated data are not available, the epithet "S. milleri" will be used. For reasons of legibility, the quotation marks of this epithet will be omitted.

\section{The confusing taxonomic history of $S$. anginosus, $S$. constellatus and S. intermedius}

The name Streptococcus milleri was first used by Guthof (1956), following the isolation of a nonhaemolytic and non-groupable streptococcus from a dental root abscess. The name was given to honour Dr.W.D.Miller (1853-1907), who is looked upon as the father of oral microbiology (Anonymous, 1985). In 1962, Ottens and Winkler isolated a biochemically similar group of non-haemolytic streptococci from dental root canals, which they named "indifferent" streptococci (Ottens, 1962). However, over half of their strains belonged to Lancefield groups F, G or C. In 1972, Colman and Williams demonstrated that, based on cultural characteristics and cell wall analysis, these organisms belonged to the same species as Guthof's S. milleri and expanded the species further to include other streptococci. Some of these strains displayed $\beta$-haemolysis: nevertheless, they included $S$. milleri in the viridans group of streptococci (Colman, 1972). Support for this phenotypic classification has been provided by British authors (Ball, 1979; Poole, 1979). 
Meanwhile, Facklam (Facklam, 1977; Facklam, 1984) from the Centers for Disease Control and Prevention (CDC) in the USA favoured the separation of $S$. milleri into distinct species, which were named (in the final version) S. anginosus, S. constellatus and $S$. intermedius. By consequence, two classification and nomenclature schemes (one American and one British) coexisted from 1977 to 1987. The CDC scheme has been the basis of most commercial identification kits.

In the 1980s, DNA-DNA reassociation studies yielded conflicting results with regard to the taxonomy of the S. milleri group. Some authors proposed unification of the $S$. milleri strains into a single DNA homology group (Welborn, 1983; Ezaki, 1986; Coykendall, 1987) while others demonstrated several distinct DNA homology groups (KilpperBälz, 1984; Knight, 1988). It has been acknowledged that the difference in these results is attributable to variations in experimental hybridisation stringencies (Whiley, 1989). The unification of all S. milleri strains into a single species was validly published in 1987 (Coykendall, 1987). According to the rules of nomenclature, this single species was named Streptococcus anginosus, which is the eldest approved name for these bacteria (Andrewes, 1906) and therefore had precedence over the name Streptococcus milleri.

Some years later, Whiley and Beighton identified on the basis of DNA-DNA reassociation studies and different phenotypic properties three homology groups within the $S$. milleri group. These homology groups corresponded to the type strains of $S$. anginosus, S. constellatus and $S$. intermedius and were consistent with distinct species. The authors published an emended description of the three species and consequently reinstated the nomenclature $S$. anginosus, S. constellatus and S. intermedius (Whiley, 1991). It should be noticed that the species described by Whiley and Beighton do not necessarily encompass the same strains as did their homonyms of the Facklam scheme.

The phylogenetic validity of the current taxonomy has been confiimed by comparisons of rRNA gene restriction patterns (Doit, 1994) and of $16 \mathrm{~S}$ rRNA sequences (Bentley, 1991), but the tumultuous taxonomic tale probably will not end here. Within the $S$. anginosus species, Bergman and coworkers recognised distinct rRNA populations (Bergman, 1995). Small-subunit rRNA gene sequencing, as used by Bergman, currently represents one of the most powerful methods for elucidating phylogenetic interrelationships of microorganisms (Woese, 1987). Ribosomal RNA molecules contain segments that are evolving very slowly, these regions are called highly conserved regions. Certain of these sequences are found in all known bacteria, and "broad range" PCR primers have been designed to recognise these sequences (Wilson, 1990). On the other hand, there are other segments of the rRNA that have evolved much faster, these segments show high variability and are appropriate targets of genus-, species- and subspecies-specific bybridisation probes. Study of the three $S$. milleri species by this refined molecular tool will probably contribute to further insights in their genetic interrelationships.

\section{S. milleri strains: phenotypic characteristics}

Strains belonging to the $S$. milleri group form at primary isolation small ("minute") colonies (less than $0.5 \mathrm{~mm}$ in diameter) and may require carbon dioxide for isolation. Many of them have a characteristic caramel odour when cultured on agar plates (Gossing, 1988). On Gram stain, they appear as spherical or ovoid cells which form chains or pairs in broth culture. 
Although they are part of the viridans streptococci, the $S$. milleri strains may display all three haemolytic patterns ( $\alpha-$, $\beta$ - or $y$-haemolysis). Beta-haemolytic strains accounted for $25-29 \%$ of the strains described (Ball, 1979; Poole, 1979; Kambal, 1987). S. milleri strains may carry four Lancefield group antigens (A, $\mathrm{C}, \mathrm{F}$ or $\mathrm{G}$ ) or may be non-groupable. Group $\mathrm{F}$ accounted for some $30-55 \%$ of the strains examined, $25-30 \%$ of the strains were non-groupable and groups $\mathrm{C}, \mathrm{G}$ and $\mathrm{A}$ were observed in decreasing frequency (Ball and Parker, 1979; Poole and Wilson, 1979; Miller, 1983). Beta-haemolytic strains tended to carry more frequently a Lancefield group antigen than non-haemolytic strains (Poole and Wilson, 1979; Shlaes, 1981), but this observation was not confirmed in a collection of consecutively isolated strains (Van der Auwera, 1985). The proportions of B-haemolytic $S$. milleri strains compared to the large-colony $ß-$ haemolytic pyogenic streptococci for a given Lancefield group are listed in Table 1.

Table 1. Proportions in percentages of B-haemolytic S. milleri strains compared to the large-colony B-haemolytic pyogenic streptococci for a given Lancefield group (data according to Ruoff, 1985 and Lawrence, 1985).

\begin{tabular}{|l|c|c|c|c|c|}
\hline Lancefield group & A & C & F & G & no group \\
Colony type & $<10$ & $56-75$ & 100 & $12-15$ & 75 \\
\hline Minute* & $>90$ & $25-44$ & 0 & $85-88$ & 25 \\
\hline Large** & & & & \\
\hline
\end{tabular}

* Minute colony: S. milleri; ** Large colony: S. pyogenes (A), S. dysgalactiae (C, G), S. equi (C), S. equi subspecies zooepidemicus (C), S. canis $(\mathrm{G})$.

All S. milleri strains produce acetoin in the VogesProskauer test with the Coblentz method, hydrolyse arginine (method according to Moeller) and fail to use sorbitol. The positive reaction in the VogesProskauer tests distinguishes $S$. milleri from the largecolony pyogenic streptococci (Bucher, 1984). Alternatively, rapid differentiation can be performed with an assay for $B-D$-glucuronide activity, which is only present in the large-colony streptococci (Cimolai, 1991).

\section{Identification to the species level:}

$S$. anginosus, $S$. constellatus,

\section{$S$. intermedius}

S. milleri strains are phenotypically identificd to the species level on the basis of the scheme of Whiley and coworkers (Whiley, 1990), which detects glycosidase enzyme activities by use of 4methylumbelliferyl-linked substrates and hyaluronidase production. Key reactions for the identification of the three species are listed in table 2. 
Table 2. Phenotypic differentiation of Streptococcus anginosus, Streptococcus constellatus and Streptococcus intermedius (+: $85 \%$ or more of the strains are positive, $-: 85 \%$ or more of the strains are negative, d: 16 to $84 \%$ of the strains are positive) (Whiley 1990).

\begin{tabular}{|l|c|c|c|}
\hline Test & S. anginosus & S. constellatus & S. intermedius \\
\hline$B$-D-fucosidase & - & - & + \\
\hline B- $N$-acetylglucosaminidase & - & - & + \\
\hline$B$ - $N$-acetylgalactosaminidase & - & - & + \\
\hline Sialidase & - & - & + \\
\hline B-galactosidase & - & - & + \\
\hline B-glucosidase & + & + & $\mathrm{d}$ \\
\hline -glucosidase & $\mathrm{d}$ & + & + \\
\hline hyaluronidase & - & + \\
\hline
\end{tabular}

Recently, a commercial system (Fluo-Card Milleri, KEY Scientific, Round Rock, Texas, USA) has been marketed in North-America. The system, which consists of filter paper strips with circles containing 4-methylumbelliferyl(MU)- -D-glucoside, 4-MU-B$D$-glucoside and 4-MU-B-D-fucoside, is an abbreviated version of the phenotypic identification scheme. The system is simple and easy to use and has been evaluated favourably in comparison with the reference scheme (Flynn, 1995). It should be noticed that both the reference scheme and the FluoCard Milleri only identify to the species level those strains that have been identified to the S. milleri level in an earlier step. However, an enlarged version of the scheme of Whiley also includes the other viridans streptococcal species (Beighton 1991) and the most recently updated version (Version 5.1) of the API 20 Strep System (API system, bioMérieux, Marcyl'Etoile, France) claims to identify the three S. milleri species, as does the recently released Rapid ID 32 Strep system from the same manufacturer. Regarding the species identification of $S$. milleri, the latter system seemed promising as it incorporates assays for $B$-glucosidase, $B$-galactosidase and $B-N$ acetylglucosaminidase activities (Freney, 1992).

Whiley and coworkers identified 157 S. milleri strains to the species level and found the vast majority of the $S$. intermedius strains to be non-haemolytic, whereas $38 \%$ of the S. constellatus strains and $12 \%$ of the $S$. anginosus strains showed B-haemolysis. In their study, both $S$. anginosus and $S$. constellatus strains displayed serological heterogeneity, and $S$. intermedius strains were mostly non-groupable (Whiley, 1992). Taketoshi and coworkers (Taketoshi, 1993 ) slightly modified the identification scheme. Their findings were comparable to those of Whiley et al. (Whiley, 1992)

\section{Difficulties in recognition and identification of the $S$. milleri strains}

Traditionally, microbiologists are reluctant to group streptococci across haemolytic boundaries (Shlaes, 1981) and little interest is paid to those viridans streptococci that are not associated with a welldefined clinical picture such as infective endocarditis (Ruoff, 1988, Hamoudi, 1989). As a result, a Bhaemolytic $S$. milleri strain may be reported as a $B$ haemolytic streptococcus with a given Lancefield group while an -haemolytic S. milleri strain risks to be identified only to the S. viridans level (Ruoff, 1988; Piscitelli, 1992). Alternatively, because of the confusion over the nomenclature, less formal descriptive names tend to be used: $S$. milleri strains 
have been described according to their growth and culture characteristics (microaerophilic streptococci, indifferent streptococci, group F Streptococcus) or according to their presumed origin (oral streptococci) (Gossling, 1988).

Conventional species identification of the viridans streptococci is laborious and time-consuming and therefore clinical laboratories often rely upon commercial systems for streptococcal identification. Unfortunately, several systems perform poorly in species identification of viridans streptococci in general and of S. milleri in particular (Hinnebusch, 1988). Moreover, apart from the above cited FluoCard Milleri and Rapid ID 32 Strep system, commercial systems do not incorporate key tests for differentiation of the three S. milleri species. Many of them were originally designed according to the Facklam classification scheme (Facklam, 1984). As already mentioned, the $S$. milleri species as currently described do not always comprise the same strains as their homonyms of the Facklam scheme: for example, in the latter scheme B-haemolytic strains were exclusively categorised as $S$. anginosus (Facklam, 1984), while in the new scheme they are mostly classified as S. constellatus (Whiley, 1991, Taketoshi, 1993).

\section{The epidemiology and clinical picture of Streptococcus milleri}

Apart from numerous case reports and excellent reviews on the subject (Ruoff, 1988; Gossling, 1988; Withworth, 1990, Piscitelli, 1992), few studies have investigated the epidemiology of $S$. milleri (Bannatyne, 1976; Poole, 1979). In addition, problems arise when the data reported in the literature are studied: the composition of strain collections from reference laboratories may be influenced by the referral pattern, e.g. they may include predominantly strains clearly associated with infection (Parker, 1979) or strains that originate from a particular anatomic site such as the oral cavity (Whiley, 1990). Moreover, both reference and clinical strain collections may include a preponderance of $\beta$ haemolytic strains as a result of a selection process during the isolation and identification steps (Ball, 1979; Spertini, 1987).

\section{Demographic data}

The overall incidence of serious infections with $S$. milleri in a 600-bed general hospital in Belgium was five cases per 1,000 admissions (Van der Auwera, 1985). S. milleri strains were the most frcquently isolated species in a series of consecutively isolated clinical S. viridans strains (Ruoff, 1983). Their proclivity for abscess formation was first noticed by Parker and Ball (Parker, 1976) who compared the distribution of streptococcal species recovered from purulent lesions. A male-to-female ratio of 1: 0.3 was noted by Gossling who reviewed 192 cases of suppurative infections with $S$. milleri and excluded those cases in which trauma and alcoholism were predisposing factors (Gossling, 1988). The age distribution of infected patients in the above-cited review was Gaussian (Gossling, 1988).

Clinical spectrum of infections caused by S. milleri The overall distribution of serious infections with $S$. milleri reflects the natural habitat of these organisms, (Ball, 1979; Shlaes, 1981). Abdominal infections accounted for $7-40 \%$ of all significant infections with S. milleri (Gossling, 1988). S. milleri has been recovered from the abdominal cavity after gastrointestinal surgery, colonic perforation and appendectomy (Gossling, 1988; Libertin, 1985). Hepatic abscesses have been described following gastrointestinal perforation in Crohn's disease, perirectal abscesses, carcinoma of the colon and abdominal surgery (Chua, 1989). S. milleri organisms have been isolated from $56-81 \%$ of bacterial brain 
abscesses either in pure or mixed culture (Gossling, 1988). The organism has also been recovered from acute spinal epidural abscesses and subdural empyema (Gosh, 1988; Gelfand, 1991). The intrathoracic cavity has been recognised as another important location of infection, with $S$. milleri as part of the offending flora in aspiration pneumonia, pleural empyema and lung abscess (Shlaes, 1981; Libertin, 1985; Spertini, 1987; Brook, 1988; Plump, 1983). S. milleri accounted for $8 \%$ of Streptococcus viridans endocarditis (Murray, 1978). A high incidence of suppurative metastatic lesions has been reported in this condition, including vertebral osteomyelitis and abscess formation in liver, joints, myocardium and spleen (Murray, 1978; Levandowski, 1985; Barnham, 1989). Reports on obstetrical and neonatal infections with S. milleri are anecdotal (Poole, 1979; Miller, 1983; Cox, 1987). S. milleri strains have been recovered in pure culture from subcutaneous abscesses in drug addicts (Müller, 1987; Stocker, 1994) and the implication of S. milleri in bone and joint infections has been reported in isolated cases (Meyes, 1990; Jacobs, 1993). Bacteraemia due to Streptococcus milleri has been rarely described (Gossling, 1988; Van der Auwera, 1985; Libertin, 1985) but this condition should alert the clinician to the possible existence of a pyogenic focus (Kambal, 1987; Gossling, 1988; Shlaes, 1981).

Culture characteristics and phenotypic properties in relation to the clinical picture

When recovered from purulent infections, S. milleri strains were reported to be part of polymicrobial infections in 39 to $98 \%$ of cases, the highest proportion was found in abdominal infections. The accompanying flora included anaerobes, various Enterobacteriaceae, and other streptococcal species (Spertini, 1987; Shlaes, 1981; Edminston, 1991). A peculiar association between Eikenella corrodens and S. milleri has been noticed (Stone, 1992; Jacobs, 1993).
In several studies, B-haemolytic S. milleri strains were reported to be more frequently associated with purulent disease as compared to non-haemolytic $S$. milleri strains (Spertini, 1987; Shlaes, 1981; Kambal, 1987; Whiley, 1990). This association was not confirmed in a large study of consecutively isolated strains (Van der Auwera, 1985). Beta-haemolytic strains were more frequently recovered from the throat and the respiratory tract (Ruoff, 1985; Spertini, 1987) and strains displaying wide carbohydrateutilisation profiles have been associated with the female genital tract (Ball, 1979; Ruoff, 1982) and have occasionally been implicated in cases of neonatal sepsis (Cox, 1987).

The potential properties of $S$. milleri strains belonging to Lancefield group $\mathrm{C}$ will be discussed in the section 'pathogenicity'.

\section{The epidemiology of $S$. anginosus, $S$. constellatus and $S$. intermedius}

Despite the increasing awareness of the clinical significance of $S$. milleri, little is known about the association between the particular species and specific sites of isolation and disease conditions (Piscitelli, 1992). At the time our investigations started, only one report gave data on the clinical correlation of the three distinct species as they are currently defined (Whiley, 1992). In 1994, a Spanish group (Gómez-Garcés, 1994) described 70 S. milleri strains that were identified to the species level by the Rapid ID 32 Strep system, and additional data on this subject were recently reported by Flynn and Ruoff (Flynn, 1995).

Whiley and coworkers (Whiley 1992) examined 153 strains from a reference collection and noted that $S$. intermedius was associated with brain and liver abscesses. S. anginosus was the predominant species recovered from gastrointestinal and genitourinary sites while $S$. constellatus was prevalent in all 
anatomic sites. The data reported by Gómez-Garcés and colleagues confirmed the above-mentioned association between liver abscesses and $S$. intermedius, as well as the association of gastrointestinal abscesses and S. anginosus (GómezGarcés, 1994). Their study included consecutively isolated strains which made it possible to establish the relative proportions of the three species: $S$. anginosus was the most frequently recovered species (approximately 60\%), followed by $S$. constellatus (approximately 30\%) and S. intermedius. However, all strains in their study were infection-related and no colonising strains recovered from superficial sites were included for comparison. By consequence, it remained conjectural whether the high prevalence of S. anginosus reflected more widespread colonisation by $S$. anginosus, or indicated enhanced pathogenic mechanisms of this species.

The collection of Flynn and Ruoff (Flynn, 1995) represented 93 clinically documented infection-related strains. Again, S. anginosus (51\% of the strains) was more frequently isolated than the two other species combined. S. anginosus was more commonly found in the genitourinary tract as previously noted, and $S$. constellatus was recovered as frequently as $S$. anginosus from the abdomen. Again, epidemiological conclusions regarding the pathogenic potential of the three species could not be drawn.

\section{Pathogenicity}

Infections with S. milleri strains are thought to arise by local invasion from their natural habitats (Shlaes, 1981; Miller, 1983). Compromised systemic host defences such as malignancy, diabetes mellitus or immunosuppression are predisposing factors but local disruption of the mucosal barrier appears to be an at least as important factor: ulceration or perforation, inflammation or surgery frequently preceded purulent infections (Shlaes, 1981; Libertin, 1985; Barnham, 1989).
The exact mechanisms by which $S$. milleri strains are able to cause purulent infection once they have gained access to deep tissues and organs are not yet understood (Gossling, 1988). Several factors can be offered as explanation, they are briefly discussed: the presence of hydrolytic enzymes, protection against phagocytosis and the host's immune system, haemagglutinating activity, aggregation of human platelets, glycosidase activities and a selective advantage due to inappropriate antimicrobial prophylaxis in surgery.

Hydrolytic enzymes are generally considered to be potentially virulence factors (Homer, 1993). It is thought that these extracellular enzymes contribute to pathogenicity by facilitating liquefaction of pus (deoxyribonuclease, ribonuclease) or by facilitating the spread of the organisms through tissue planes (hyaluronidase, chondroitin sulfatase) (Ruoff, 1987). Production of ribonuclease, deoxyribonuclease, gelatinase, chondroitin sulfatase and collagenase has been demonstrated in S. milleri (Pulliam, 1980; Marshall, 1981; Steffen, 1981; Osano, 1987; Homer, 1993), but protein and lipid-degrading activities were not found (Ruoff, 1987). Hyaluronidase activity was observed mainly in B-haemolytic strains (Poole and Wilson, 1979; Unsworth, 1989). Only one of the cited studies evaluated the correlation between the enzyme activity tested for and the clinical significance of the strains examined (Unsworth, 1989). Regarding the three species, Whiley and coworkers (Whiley, 1990; Whiley, 1992) noted hyaluronidase activity almost exclusively to be linked to $S$. constellatus and $S$. intermedius.

The presence of a polysaccharide capsule preventing phagocytosis has been suggested to play a role in suppurative infection caused by S. milleri (Brook and Walker 1985), but this was not confirmed in other observations (Lewis 1993). An immunosuppressive substance released by $S$. milleri has been described 
and characterized (Arala-Chaves, 1979, Lima, 1992). Recently, synergy between S. milleri and Prevotella intermedia was demonstrated by both in-vitro and animal studies (Shinzato 1994). Haemagglutinating activity was demonstrated in $66 / 148(44.6 \%)$ of oral S. intermedius strains (Yamagushi 1993) and the presence of glycosidase enzymes has been postulated to favour persistence of the strain once it has entered the blood stream (Homer, 1994).

Over the past few years, studies performed by Willcox and coworkers contributed to further insights in the pathogenesis of $S$. milleri infections. These authors demonstrated that S. milleri strains of Lancefield group $\mathrm{C}$, irrespective of the species they belonged to, aggregated human platelets (Willcox, 1994). They suggested that this phenomenon, which did not occur in S. milleri strains belonging to other Lancefield groups, might be an important factor in the initiation and progression of infective endocarditis. The platelet-interacting substance on the surface of the Lancefield group C S. milleri strains appeared to be proteinaceous (Willcox, 1994). In addition, the authors reported that S. milleri strains of Lancefield group $C$ were the only $S$. milleri strains that were able to bind large amounts of albumin on their surface (Willcox, 1990, Willcox, 1994). They explained this finding as another mechanism of streptococcalplatelet interaction or, alternatively, as a protection from intracellular killing by abscess-derived neutrophils. Finally, they demonstrated that the albumin receptor on the $S$. milleri strains of Lancefield group C was related to the albumin receptor of $S$. equisimilis, a species that forms part of the large-colony group C streptococci (Willcox, 1994). Interestingly, a recent numerical taxonomic study allocated $S$. milleri strains of Lancefield group C to a distinct group (Winstanley, 1992).

Lastly, the prophylactic use in surgery of antibiotic regimens which lack activity against $S$. milleri has been postulated as a factor possibly promoting the emergence of $S$. milleri as a significant pathogen, by giving it an ecologic advantage. One such regimen is the combination of gentamicin and metronidazole, which is used in colorectal surgery. (Tresadern, 1983; Madden, 1985).

\section{Antimicrobial susceptibility - therapy of serious infections with $S$. milleri}

Only one report gives details on the antimicrobial susceptibilities of the three species as currently described (Gómez-Garcés, 1994). The literature on antibiotic susceptibility of $S$. milleri as a whole has been extensively reviewed (Gossling, 1988; Piscitelli, 1992). The authors noted a wide variety in susceptibility test systems, making comparisons difficult. S. milleri strains are generally susceptible to penicillin, ampicillin, penicillinase-resistant semisynthetic penicillins, cephalosporins and other antibiotics frequently used against grampositive bacteria (Gossling, 1988; Piscitelli, 1992). Recently, an increasing antimicrobial resistance among viridans streptococci has been noted (Potgieter, 1992) and anecdotally, penicillin-resistant strains among $S$. milleri were demonstrated (Quinn, 1988). The above cited Spanish study reported alarming resistance rates that contrasted with previously reported data: for erythromycin, clindamycin and tetracycline, resistance rates of respectively $14.3 \%, 12.8 \%$, and $37.1 \%$ were found. Tetracycline resistance was most obvious in the S. anginosus strains, with a MIC 50 of $>8 \mathrm{mg} / \mathrm{L}$ (Gómez-Garcés, 1994) .

As for Streptococcus pneumoniae, the antibiotic resistance determinants are located on the chromosome. These chromosomal antibiotic resistance is conjugative and the determinants (except the determinant for penicillin resistance) transfer en bloc at low frequencies $\left(10^{-5}\right.$ to $10^{-9}$ per donor $)$ (Clermont, 1990). Nor resistance markers on plasmids have been found. The antibiotic resistance genes are 
frequently found in streptococci, enterococci and aerococci (Clermont, 1990; Charpentier, 1994).

The pronounced tendency of $S$. milleri to cause abscesses precludes effective therapy with antibiotics alone: combined medial-surgical therapy is warranted. In-vitro synergism between an aminoglycoside and a penicillin has been reported once (Francioli, 1985), but clinical evidence that proves the benefit of this regimen has not yet been reported.

\section{Aims of the study}

Despite the rather extensive literature on the subject, it is clear that many open questions remain, particularly regarding the clinical relevance of species identification of S. milleri.

Therefore, we used a collection of consecutively isolated "S. milleri" strains recovered from clinical specimens. We wanted to establish the possible clinical significance of species identification of these organisms in the diagnostic microbiological laboratory. For this purpose, we investigated the prevalence, the anatomic distribution, the clinical spectrum, the culture characteristics, the phenotypic properties and the antimicrobial susceptibilities of the three species in the present setting. In addition, we attempted an evaluation of the Rapid ID 32 Strep system for phenotypic identification of the three $S$. milleri species, and an exploration of the possible genotypic diversity within the $S$. milleri species at the level of the $16 \mathrm{~S}$ ribosomal RNA sequence. Furthermore, we wanted to provide epidemiological evidence for the production of hydrolytic enzymes as possible factors of pathogenicity. 


\section{References}

Andrewes FW and Horder TJ. A study of the streptococci pathogenic for man. Lancet 1906; ii: $703-$ 713.

Anonymous: Streptococcus milleri, pathogen in various guises. Lancet 1985: ii: 1403-1404.

Arala-Chaves MP, Higerd T, Porto MT, Munoz J, Goust J, Fugdenberg HH and Boyd Loadholt C. Evidence for the synthesis and reledse of strongly, immunosupressive, noncytotoxic substances by Streptococcus intermedius. J Clin Invest 1979; 64: 871-883.

Ball LC and Parker MT. The cultural and biochemical characters of Streptococcus milleri strains isolated from human sources. J Hyg (Camb) 1979; 82: 6378.

Bannatyne RM and Randall C. Ecology of 350 isolates of group F streptococcus. Am J Clin Pathol 1977; 67: 184-186.

Beighton D, Hardie JM and Whiley RA. A scheme for the identification of viridans streptocncci. J Med Microbiol 1991; 35: 367-372.

Bentley RW, Leigh JA, and Collins MD. Intrageneric structure of Streptococcus based on comparative analysis of small-subunit rRNA sequences. Int J Syst Bacteriol 1991; 41: 487-494.

Bergman S, Selig M, Collins MD, Farrow JAE, Baron EJ, Dickersin GR and Ruoff KL. "Streptococcus milleri" strains displaying a gliding type of motility. Int J Syst Bacteriol 1995; 45: 235-239.

Brook MG, Lucas RE and Pain AK. Clinical features and management in two cases of Streptococcus milleri chest infection. Scand J Infect Dis 1988; 20: 345-346.

Brook I and Walker RI. The role of encapsulation in the pathogenesis of anaerobic gram-positive cocci. Can J Microbiol 1985; 31: 176-180.

Bucher $\mathrm{C}$ and von Graevenitz. A. Differentiation in throat cultures of group $\mathrm{C}$ and $\mathrm{G}$ streptococci from Streptococcus milleri with identical antigens. Eur J Clin Microbiol 1984; 3: 44-45.
Charpentier E, Gerbaud G and Courvalin P. Presence of Listeria tetracycline resistance gene tet $(S)$ in Enterococcus faecalis. Antimicrob Agents Chemother 1994; 38: 2330-2335.

Chua D, Reinhart HH and Sobel JD. Liver abscess caused by Streptococcus milleri. Rev Infect Dis 1989; 11: 983-987.

Cimolai C, Mah D. B-D-Glucuronidase activity for rapid differentiation of species within $\beta$-haemolytic group C and G streptococci. J Clin Pathol 1991; 44: 824-825.

Clermont $\mathrm{D}$ and Horaud T. Identification of chromosomal antibiotic resistance genes in Streptococcus anginosus ("S. milleri"). Antimicrob Agents Chemother 1990; 34: 1685-1690.

Colman G and Williams REO. Taxonomy of some human viridans streptococci. In:

Wannamaker LW, Matsen JM, eds. Streptococci and streptococcal diseases. London,

Academic Press, 1972, pp.281-299.

Cox RA, Chen AL, Coykendall P, Wesbecher P and Herson VC. Fatal infection in neonates of 26 weeks' gestation due to Streptococcus milleri: report of two cases. J Clin Pathol 1987; 40: 190-193.

Coykendall A, Wesbecher PM and Gustafson KB. "Streptococcus milleri", Streptococcus constellatus, and Streptococcus intermedius are later synonyms of Streptococcus

anginosus. Int J Syst Bacteriol 1987; 37: 222-228.

Doit C, Grimont F, Whiley RA, Regnault B, Grimont PAD, Hardie JM and Bouvet A. Ribotypes of the "Streptococcus milleri-group" allow discrimination between Streptococcus constellatus, Streptococcus intermedius and Streptococcus anginosus. In A.Totolian (ed.), Pathogenic Streptococci: present and future. Lancer Publication, St.Petersburg, Russia, 1994: pp 531-532.

Edminston CE, Walker AP, Krepel CJ, Gohr MC, Seabrook GR and Frantzides CT. Streptococcus milleri group (Streptococcus anginosus): recovery from intra-abdominal and soft tissue sites. Ann Clin Lab Sci 1991; 21: 56-61. 
Ezaki T, Facklam R, Takeuchi $\mathrm{N}$ and Yabuuchi E. Genetic relatedness between the type strains of Streptococcus anginosus and minute-colonyforming-beta-haemolytic streptococci carrying different Lancefield grouping antigens. Int J Syst Bacteriol 1986; 36: 345-347.

Facklam RR. Physiological differentiation of viridans streptococci. J Clin Microbiol 1977; 5: 184-201.

Facklam RR. The major differences in the American and British Streptococcus taxonomy schemes with special reference to Streptococcus milleri. Eur J Clin Microbiol 1984; 3: 91-93.

Flynn CE and Ruoff KL. Identification of "Streptococcus milleri" group isolates to the species level with a commercially available rapid test system. J Clin Microbiol 1995; 33: 2704-2706.

Francioli P, Moreillon P and Glauser MP. Comparison of single doses of amoxicillin or of amoxicillingentamicin for prevention of endocarditis caused by Streptococcus faecalis and by viridans streptococci. J Infect Dis 1985; 152: 83-89.

Freney J, Bland S, Etienne J, Desmonceaux M, Boeufgras JM and Fleurette J. Description and evaluation of the semi-automated 4-hour rapid ID 32 Strep method for identification of streptococci and members of related genera. J Clin Microbiol 1992; 30: 2657-2661.

Gossling J. Occurrence and pathogenicity of the Streptococcus milleri group. Rev Infect Dis 1988; 10: 257-285.

Gelfand MS, Bakhtian BJ and Simmons BP. Spinal sepsis due to Streptococcus milleri: two cases and review. Rev Infect Dis 1991; 13: 559-563.

Ghosh K, Duncan R and Kennedy PG. Acute spinal epidural abscess caused by Streptococcus milleri. J Infection 1988; 16: 303-304.

Gómez-Garcés JL, Alós JI, Cogollos R. Bacteriologic characteristics and antimicrobial susceptibility of 70 clinically significant isolates of Streptococcus milleri group. Diagn

Microbiol Infect Dis 1994; 19: 69-73.
Guthof O. Über pathogene "vergrunende Streptockokken". Streptockokken-Befunde bei dentogenen Abszessen und Infiltraten im Bereich der Mundhöhle. Zentralbl Mikrobiol 1956; 166: 553-564.

Hamoudi AC, Hribar MM, Marcon MJ and Cannon HJ. Clinical relevance of viridans and nonhemolytic streptococci isolated from blood and cerebrospinal fluid in a pediatric population. Am J Clin Pathol 1990; 93: 270-272.

Hardie JM. Oral streptococci. In Krieg NR, Holt JG (eds) Bergcy's Manual of systematic bacteriology, vol.2. Baltimore, MD, Williams and Wilkins, 1986: 1054-1063.

Hinnebusch CJ, Nikolai DM and Bruckner DA. Comparison of API Rapid Strep, Baxter MicroScan Rapid Pos ID panel, BBL Minitek Differential Identification System, IDS RapID STR System and Vitek GPI to conventional biochemical tests for identification of viridans streptococci. Am J Clin Pathol 1991;91:459-63.

Homer KA, Dendow L, Whiley RA and Beighton D. Chondroitin sulfate depolymerase and hyaluronidase activities of viridans streptococci determined by a sensitive spectrophotometric assy. J Clin Microbiol 1993; 31: 1648-1651.

Homer KA, Whiley RA and Beighton D. Production of specific glycosidase activities by Streptococcus intermedius strain UNS35 grown in the presence of mucin. J Med Microbiol 1994; 41: 184-190.

Jacobs JA, Algie GD, Sie GH and Stobberingh EE. Association between Eikenella corrodens and streptococci. Clin Infect Dis 1993; 16: 173.

Jacobs JA, Pietersen HG, Walenkamp GHIM, Stobberingh EE and Soeters PB. Intervertebral infection caused by Streptococcus milleri. A case report. Clin Orthop Rel Res 1994; 302: 183-188.

Kambal AM. Isolation of Streptococcus milleri from clinical specimens. J Infection 1987; 14: 217-223.

Kilpper-Bälz R, Williams BL, Lütticken R and Schleifer KH. Relatedness of "Streptococcus milleri" with Streptococcus anginosus and Streptococcus constellatus. Syst Appl Microbiol 1984; 5: 494-500. 
Kitada K, Yakushiji T and Inoue M. Immunochemical characterization of the carbohydrate antigens of serotype c/Lancefield group C "Streptococcus milleri". Oral Microbiol Immunol 1993; 8: 161-166.

Knight RG and Shlaes DM. Physiological characteristics and deoxyribonucleic acid relatedness of Streptococcus intermedius strains. Int J Syst Bacteriol 1988; 38: 19-24.

Lawrence J, Yajko DM and Hadlay WK. Incidence and characterisation of beta-hemolytic Streptococcus milleri and differentiation from $S$. pyogenes (group A), S. equisimilis (group C) and Large-colony group G streptococci. J Clin Microbiol 1985; 22: 772-777.

Levandowski RA. Streptococcus milleri endocarditis complicated by myocardial abscess. South Med J 1985: 78: 892-893.

Lewis MAO, Milligan SG, MacFarlane TW and Carmichael FA. Phagocytosis of bacterial strains isolated from acute dentoalveolar abscess. J Med Microbiol. 1993; 38: 151-154.

Libertin CR, Hermans PE and Washington JA II. Beta-hemolytic group F streptococcal bacteremia: a study and a review of the literature. Rev Infect Dis 1985;7:498-503.

Lima M, Bandeira A, Portnoi D, Ribeiro A and Arala Chaves M. Protective effect of a T-cell dependent immunosuppressive, B-cell-mitogenic protein (F3'EP-Si, or P90) produced by Streptococcus intermedius. Infect Immun 1992; 60: 3571-3578.

Madden NP and Hart CA. Streptococcus milleri in appendicitis in children. J Ped Surg 1985: 20: 6-7.

Marshall R and Kaufman AK. Production of deoxyribonuclease, ribonuclease, coagulase and hemolysins by anaerobic gram-positive cocci. J Clin Microbiol 1981; 13: 787-788.

Meyes E, Flipo R-M, Van Bosterhout B, Mouligneau G, Duquesnoy B and Delcambre B. Septic Streptococcus milleri spondylodiscitis. J Rheumatol 1990; 17: 1421-1423.

Miller SD, Mauff AC and Koornhof HJ. Streptococcus milleri causing infection in man. S Afr Med J 1983; 63: 684-686.
Moore WEC, Moore LVH. Index of bacterial and yeast nomenclatural changes-1989. Washington DC: American Society for Microbiology, 1989.

Müller F, von Graevenitz $A$ and Ferber $T$. Streptococcus milleri subcutaneous abscesses in drug addicts. Infection 1987; 15: 201.

Murray HW, Gross KC, Masur H and Roberts RB. Serious infections caused by Streptococcus milleri. Am J Med 1978; 64: 759-764.

Osano E, Hibi E, Ozeki M, Fujii Y and Moriyama T: Chondroitin sulfate-depolymerizing activity in Streptococcus intermedius and other streptococci. Microbiol Immunol 1987; 31: 1127-1113.

Ottens $\mathrm{H}$ and Winkler KC. Indifferent and haemolytic streptococci possessing group-antigen F. J Gen Microbiol 1962; 28: 181-191.

Parker MT and Ball LC. Streptococci and aerococci associated with systemic infections in man. J Med Microbiol 1976; 9: 275-302.

Piscitelli SC, Shwed J, Schreckenberger P, Danziger LH. Streptococcus milleri group: renewed interest in an elusive pathogen. Eur J Clin Microbiol Infect Dis 1992; 11: 491-498.

Plump DH and Haponik EJ. Streptococcus milleri empyema. South Med J 1983; 76: 1321-1322.

Poole PM and Wilson G. Occurrence and cultural features of Streptococcus milleri in various body sites. J Clin Pathol 1979; 32: 764-768.

Poole PM and Wilson G. Infection with minutecolony-forming B-haemolytic streptococci. J Clin Pathol 1976; 29: 740-745.

Potgieter E, Carmichael M. Koornhof HJ and Chalkley LJ In vitro antimicrobial susceptibility of viridans streptococci isolated from blood cultures. Eur J Clin Microbiol Infect Dis 1992; 11, 453-456.

Pulliam L, Porschen RK, Hadley WK. Biochemical properties of $\mathrm{CO}_{2}$-dependent streptococei. J Clin Microbiol 1980; 12: 27-31. 
Quinn JP, DiVincenzo CA, Lucks DA, Luskin RL, Shatzer KL and Lenner SA. Serious infections due to penicillin-resistant strains of viridans streptococci with altered penicillin-binding proteins. J Infect Dis 1988; 157: 764-769.

Ruoff KL, Fishman JA, Calderwood SB, Kunz LJ. Distribution and incidence of viridans streptococcal species in routine clinical specimens. Am J Clin Pathol 1983; 80: 854-858.

Ruoff KL, Kunz LJ, Ferraro MJ. Occurrence of Streptococcus milleri among beta-hemolytic Streptococci isolated from clinical specimens. J Clin Microbiol 1985; 22: 149-151.

Ruoff Kl, Ferraro MJ. Hydrolytic enzymes of "Streptococcus milleri". J Clin Microbiol 1987; 25: 1645-1647.

Ruoff KL. Streptococcus anginosus ("Streptococcus milleri"): the unrecognized pathogen. Clin Microbiol Rev 1988; 1: 102-108.

Shlaes DM, Lerner PI, Wolinsky E and Gopalakrinshna KV. Infections due to Lancefield group F and related streptococci (S. milleri, $S$. anginosus). Medicine 1981; 60: 197-207.

Shinzato T and Saito A. A mechanism of pathogenicity of "Streptococcus milleri group" in pulmonary infection: synergy with an anaerobe. J Med Microbiol 1994; 40: 118-123.

Skerman VBD, McGowan V and Sneath PHA. Approved lists of bacterial names. Int J Syst Bacteriol 1980; 30: 225-240.

Spertini F, Baumgartner JD and Bille J. Spectre clinique d'un pathogène commun et insidieux: le Streptococcus milleri. Schweiz med Wschr 1988; 118: 1393-1397.

Stocker E, Cortes E, Pema K, Meza A and Verghese A. Streptococcus milleri as s cause of antecubital abscess and bacteremia in intravenous drug abusers. South Med J 1994; 87: 95 -96.

Stone DR. Eikenella corrodens and group C streptococci. Clin Infect Dis 1992; 14: 789.
Taketoshi M. Kitada K, Yakushiji T and Inoue M. Enzymatic differentiation and

biochemical and serological characteristics of the clinical isolates of Streptococius

anginosus, S. intermedius and S. constellatus. Microbios 1993; 76: 115-129.

Tresadern JC, Farrand RJ, Irving MH. Streptococcus milleri and surgical sepsis. Ann R Coll Surg 1983; 65: 78-79.

Unsworth PF. Hyaluronidase production in Streptococcus milleri in relation to infection. J Clin Pathol 1989; 42: 506-510.

Van der Auwera P. Clinical significance of Streptococcus milleri. Eur J Clin Microbiol 1985; 4: 386-370

Welborn PP, Hadley WK, Newbrun E, Yajko DM. Characterization of strains of viridans streptococci by deoxyribonucleic acid hybridization and physiological tests. Int J Syst Bacteriol 1983; 33: 293299.

Whiley RA and Hardie JM. DNA-DNA hybridization studies and phenotypic characteristics of strains within the "Streptococcus milleri" group. J Gen Microbiol 1989; 135: 2623-2633.

Whiley RA, Fraser H, Hardie JM, and Beighton D). Phenotypic differentiation of Streptococcus intermedius. Streptococcus constellatus, and Streptococcus anginosus strains within the "Streptococcus milleri" group. J Clin Microbiol 1990; 28: 1497-1501.

Whiley RA and Beighton D. Emended descriptions and recognition of Streptococcus constellatus, Streptococcus intermedius and Streptococcus anginosus as distinct species. Int J Syst Bacteriol $1991 ; 41: 1-5$.

Whiley RA, Beighton D. Winstanley TG, Frazer HY and Hardie IM. Streprococcus intermedius, Sireptococcus constellatus, and Sireptococcus anginosus (the Streptococcus milleri group): association with different body sites and clinical infections. J Clin Microbiol 1992; 30: 243-244.

Whithworth JM. Lancefield group F and related streptococci. J Med Microbiol 1990; 33: 135-151. 
Willcox MDP and Knox KW. Surface-associated properties of Streptococcus milleri group strains and their potential relation to pathogenesis. J Med Microbiol 1990; 31: 259-270.

Willcox MDP, Patrikakis M, Loo CY and Knox KW. Albumin-binding proteins on the surface of the Streptococcus milleri group and characterization of the albumin receptor of Streptococcus intermedius. J Gen Microbiol 1993; 139: 2451-2458.

Willcox MDP, Oakey HJ, Harty DWS, Patrikakis M and Knox KW. Lancefield group C Streptococcus milleri strains aggregate human platelets. Microbial Pathogenesis 1994; 16: 451-457.

Wilson KH, Blitchington RB and Greene RC. Amplification of bacterial $16 \mathrm{~S}$ ribosomal DNA with polymerase chain reaction. J Clin Microbiol 1990; 28: 1942-1946.

Winstanley TG, Magee JT, Limb DI, Hindmarch JM, Spencer RC, Whiley RA, Beighton D and Hardie JM. A numerical taxonomic study of the "Streptococcus milleri" group based upon conventional phenotypic tests and pyrolysis mass spectrometry. J Med Microbiol 1992; 36: 149-155.

Woese CR. Bacterial evolution. Microbiol Rev 1987; 51: 221-271.

Yamagushi T, Taketoshi M, Eifuku-Koreeda $\mathrm{H}$, Yakushiji $\mathrm{T}$ and Inoue M. Haemagglutinating activities of oral strains of Streptococcus milleri group. Microbios 1993; 75: 249-259. 


\section{CHAPTER II Viridans streptococci isolated from the bloodstream Relevance of species identification}

J.A. Jacobs, H.C.Schouten, E.E.Stobberingh and P.B. Soeters.

Diagnostic Microbiology and Infectious Diseases 1995; 22: 267-273. 


\title{
Viridans streptococci Isolated from the Bloodstream
}

\section{Relevance of Species Identification}

\author{
J.A. Jacobs, H.C. Schouten, E.E. Stobberingh, \\ and P.B. Soeters
}

Over a 4-year-period, 104 isolates belonging to the viridans streptococci were recovered from the blood and identified to the species according to Beighton and co-workers. Streptococcus oralis was the species most frequently recovered from patients in the hematology unit [29 of $39(74 \%)]$. Streptococcus mitis ranked second [seven of $39(18 \%)]$. Both species were associated with oromucositis. Isolates presently identified as S. oralis are mainly those previously identified as S. mitis or Streptococcus sanguis II. Streptococcus milleri was most frequently isolated in the patients from the general hospital

\section{INTRODUCTION}

Viridans streptococci (VS) are oral inhabitants well known for their involvement in infective endocarditis and dental caries (Coykendall, 1989). A decade ago, Streptococcus sanguis and Streptococcus mitis emerged as a leading cause of bacteremia in neutropenic patients (Cohen et al., 1983). The Streptococcus milleri group, which includes the newly described species Streptococcus anginosus, Streptococcus constellatus, and Streptococcus intermedius (Whiley and Beighton, 1991), has been associated with purulent disease (Gossling, 1988). However, clearer delineation of the pathogenic potential of individual viridans species has been hampered by difficulties in

From the Departments of Medical Microbiology (J.A.J. E.E.S.), Internal Medicine (H.C.S.), and Surgery (P.B.S.), University Hospital Maastricht, The Netherlands.

Address reprint requests to Dr. J.A. Jacobs, Department of Medical Microbiology, University Hospital Maastricht, P.O. Box 5800, 6202 AZ Maastricht, The Netherlands.

This study was presented in part at the 94th General Meeting of the American Society of Microbiolog", Las Vegas, Nevada, May 1994 (Abstr. no. C109). 1995

Received 8 February 1995; revised and accepted $31 \mathrm{MaV}$ population [28 of $65(43 \%)$ isolates]: Streptococcus anginosus ( $\mathrm{n}=20$ ), Streptococcus constellatus $(\mathrm{n}=4)$, and Streptococcus intermedius $(n=4)$. In 14 episodes from the general hospital population, clinical significance was judged questionable. From this part of the laboratory, clinical significance could not be predicted from the number of blood cultures grown, nor from the delay of growth detection. The Rapid ID 32 Strep system agreed well with the identifications according to the scheme of Beighton et al., whereas the API 20 Strep system did not.

taxonomy and identification (Beight:on et al., 1991), and species identification of VS has been judged valuable only in well-defined clinical conditions such as infective endocarditis and immunosuppression (Hamoudi et al., 1989). Beighton and Coworkers (1991) recently proposed an identification scheme based on fluorogenic detection of glycosidic enzyme activities and conventional fermentation tests. This scheme enabled differentiation of all currently recognized viridans species.

In this study, we wanted to trace possible associations between distinct viridans species isolated from blood on the one hand, and specific diseases on the other. In addition, we wanted to evaluate the number of blood cultures grown and the delay of growth detection as possible criteria to predict the clinical significance of VS isolated from the blood. We retrospectively identified 104 consecutive isolates to the species according to the method of Beighton and co-workers (1991), and looked for clinical relevance. We compared the identifications to those obtained with two commercial identification systems: the API 20 Strep and the Rapid ID 32 Strep systems (BioMérieux, Marcy-L'Etoile, France). 


\section{MATERIALS AND METHODS}

Information concerning blood cultures performed at the University Hospital of Maastricht over a 4-yearperiod (June 1990-June 1994) was obtained from the report forms of the microbiology laboratory. We consulted the hospital information system for information regarding those patients for whom one or more blood cultures were positive for VS. Gender, age, underlying disease, and diagnosis were recorded. If these data were lacking, the medical record of the patient was reviewed. According to Centers for Disease Control (CDC) criteria (Garner et al., 1988), judgment on clinical significance of the isolate was based on the opinion of the clinician treating the patient at the time of the bacteremia and was noted as (a) clinically significant or (b) of questionable significance. For each isolate, the growth characteristics were recorded: number of blood cultures grown and delay of growth detection.

Organisms were isolated from an infrared $\mathrm{CO}_{2}$ detection blood culture system (BACTEC 9240; Becton Dickinson, Cockeysville, MD, USA). Streptococcal isolates were presumptively identified at the VS level by their colony morphology and pattern of hemolysis on $5 \%$ sheep blood agar, their resistance to optochin- and bacitracin-coated disks, and (except for Streptococcus bovis) their negative reaction in the bile-esculin test. The isolates were maintained at $-70^{\circ} \mathrm{C}$ on porous beads in cryopreservative (Microbank; Pro-Lab Diagnostics, Richmond Hill, Ontario, Canada). They were retrieved on blood agar base (Oxoid, Basingstoke, UK) supplemented with sheep blood $5 \% \mathrm{v} / \mathrm{v}$, checked for purity, and subsequently streaked on secondary plates for identification.

Species identification was performed on the basis of the scheme described by Beighton and co-workers (1991), supplemented with the reaction scheme for $S$. bovis provided by Douglas and co-workers (1993). Isolates were tested for the production of $\beta$-D-fucosidase, $N$-acetyl- $\beta$-Dgalactosaminidase, sialidase, $\alpha-\mathrm{L}$-fucosidase, $N$-acetyl- $\beta$-D-glucosaminidase, $\alpha$-D-glucosidase, $\beta$-D-glucosidase, and $\alpha$-L-arabinosidase with 4methylum belliferyl-linked substrates (Sigma, St. Louis, MO, USA). The bacteria were grown for $24 \mathrm{~h}$ on blood agar base (Oxoid) supplemented with sheep blood $(5 \% \mathrm{v} / \mathrm{v})$ at $35^{\circ} \mathrm{C}$ under enhanced $\mathrm{CO}_{2}$ tension. They were removed from the plates with swabs and suspended in $1 \mathrm{ml}$ of $50 \mathrm{mM}$ Hepes buffer (Sigma), pH 7.5, to an optical density (at 620 $\mathrm{nm}$ ) of $\sim 0.1$. The 4-methylumbelliferyl-linked substrates were dissolved in a small volume of dimethyl sulfoxide (Sigma) and further diluted in $50 \mathrm{mM}$ Hepes buffer to a concentration of $100 \mu \mathrm{g} / \mathrm{ml}$. To 50 $\mu \mathrm{l}$ of each substrate solution, $100 \mu \mathrm{l}$ of the bacterial suspension was added. The tests were performed in flat-bottomed microtitration trays (Hospidex, Nieuwkoop, The Netherlands), which were incubated for $4 \mathrm{~h}$ at $35^{\circ} \mathrm{C}$. Substrate hydrolysis resulted in release of 4-methylumbelliferone and was considered positive as a distinct blue fluorescence, by placing the microtitration trays on an ultraviolet light box. For assessment of the production of acid from carbohydrates (amygdalin, inulin, mannitol, raffinose, and $N$-acetylglucosamine), sugars $(1 \% \mathrm{w} / \mathrm{v})$ were included in a basal medium composed of Purple Broth Base (Difco, Detroit, MI, USA), 16 g/liter and thioglycollate broth without dextrose or indicator (Difco), 24 g/iter, $\mathrm{pH}$ 7.0. Bacteria were grown for $48 \mathrm{~h}$ in $2-\mathrm{ml}$ vol of Todd-Hewitt broth (Oxoid). Flat-bottomed microtitration trays were inoculated with $200 \mu \mathrm{l}$ of medium and $50 \mu \mathrm{l}$ of culture, incubated with an oil overlay at $35^{\circ} \mathrm{C}$, and assessed after 24,48 , and $72 \mathrm{~h}$. Formation of ammonia from arginine was determined with Møeller decarboxylase medium (Nash and Krenz, 1991). We compared test reactions of the isolates with the identification tables published (Beighton et al., 1991; Douglas et al., 1993), with the greatest emphasis put on those reactions reported as $100 \%$ for particular species. When an isolate could not be identified to within three test reactions, we labeled it as "no identification." We did not distinguish among the three biotypes of S. sanguis.

The isolates were also identified by the API 20 Strep system and the Rapid ID 32 Strep system (API System), according to the manufacturer's instructions. From the inoculation suspension, a $0.01-\mathrm{ml}$ suspension was streaked onto blood agar to check for purity. A reading of the API 20 Strep system was obtained after 4 and $24 \mathrm{~h}$ of incubation. The Rapid ID 32 Strep strips were read visually. Interpretation of the numeric profiles was performed with the APILAB computer program supplied with API 20 Strep data base version 5.1 and Rapid ID 32 Strep data base version 1.1. No distinction was made between the API biotypes S. mitis 1 and S, mitis 2 . Identifications were compared using the method of Beighton and co-workers and classified as (a) correct for species (corresponding to excellent, very good, good, or acceptable identifications as provided by the ApIlab data base); (b) good likelihood but low selectivity (GLLS), which included a correct identification among a spectrum of possibilities (the first of a list of likelihoods was still taken as GLLS); (c) incorrect identifications and those quoted as doubtful by the APILAB computer program; or (d) no or unacceptable identifications as provided by the ApILAB computer program.

The reference strains used in this study were type strains of S. oralis (ATCC 10557), S. sanguis (ATCC 10556), S. constellatus (ATCC 27823), S. intermedius (ATCC 27335), and S. anginosus (ATCC 33397). We 
assessed the reproducibility of the systems by testing five isolates on 5 consecutive days. Proportions were compared statistically by means of $x^{2}$ test.

\section{RESULTS}

A total of 116 isolates were recovered, representing an incidence of $1.3 / 1000$ admissions (5.9\% of all bacteremias). Twelve isolates were no longer viable and were removed from the study, resulting in a collection of 104 isolates recovered in 100 patients. In one patient two distinct isolates grew from the same culture, whereas in three other patients two isolates were recovered during separate bacteremic episodes. The male-to-female ratio was 1:1. For male patients, the mean age \pm SD was $48.2 \pm 24.2$ years, and the median age was 51 years (range 1 day to 86 years). The mean age \pm SD for female patients was $52.6 \pm 20.2$ years; their median age was 55 years (range 1 day to 90 years).

\section{Test Systems}

All three test systems proved to be reproducible. The reference strains were correctly identified by the three systems except for the type strains of $S$. sanguis and $S$. anginosus, which were identified respectively as S. mitis and S. constellatus by the API 20 Strep system.

For the scheme of Beighton and co-workers, nearly half of the isolates [ $49(47 \%)$ ] fit the identification scheme exactly. The remaining isolates were identified to within one $(n=48)$ or two $(n=4)$ test reactions except for three isolates for which no identification could be assigned. Table 1 compares the results of the three identification systems. The identifications obtained with the Rapid ID 32 Strep system agreed reasonably when identifications with low specificity (GLLS) were included [83 of 101 (83\%)]. The API 20 Strep system performed less satisfactorily: Of those isolates identified as $S$. oralis according to the scheme of Beighton et al., 17 of 43 (40\%) were incorrectly identified. A total of 14 of these isolates were designated as $S$. mitis and three as $S$. sanguis. Discrepancies were also noted for $S$. anginosus and $S$. constellatus, which were mostly identified as $S$. intermedius.

\section{Species Distribution and Relevance}

We recovered 39 isolates from patients in the hematology unit and 65 isolates from the general hospital population, including three from neonates.

In 36 of 39 patients from the hematology unit $(92.3 \%)$, the white blood cell count was $<0.510^{9} /$ liter. A total of 21 patients passed through the neutropenic phase after bone marrow transplantation. All patients received amphotericin B or nystatin in combination with ciprofloxacin as selective decontamination of gut flora. All isolates were considered clinically significant. Growth was detected within 2 days in 33 isolates $(85 \%)$ and within 3 days in the remaining isolates. We recovered 10 isolates $(26 \%)$ from a single blood culture: $S$. oralis $(n=7), S$. anginosus, S. mitis, and S. sanguis (one isolate each). In six of these isolates, one or multiple other blood cultures remained sterile. According to the identifi-

TABLE 1 Comparison of Identifications According to Beighton and Co-workers with Those of the Rapid ID 32 Strep and API 20 Strep Systems ${ }^{a}$

\begin{tabular}{|c|c|c|c|c|c|c|c|c|c|}
\hline \multirow{2}{*}{$\begin{array}{l}\text { Streptococcus } \\
\text { Identification } \\
\text { According to Beighton } \\
\text { and Co-workers }\end{array}$} & \multirow[b]{2}{*}{ N } & \multicolumn{4}{|c|}{ Rapid ID 32 Strep } & \multicolumn{4}{|c|}{ API 20 Strep } \\
\hline & & Correct & GLLS & $\begin{array}{l}\text { Incorrect/ } \\
\text { Doubtful }\end{array}$ & None & Correct & GLLS & $\begin{array}{l}\text { Incorrect/ } \\
\text { Doubtful }\end{array}$ & None \\
\hline S. bovis & 3 & 2 & - & - & 1 & 3 & - & - & - \\
\hline S. gordonii & 1 & - & -- & - & 1 & - & - & 1 & - \\
\hline S. mitis & 10 & 3 & 5 & 2 & - & 6 & 2 & 2 & - \\
\hline S. mutans & 3 & 1 & - & 2 & - & 2 & - & 1 & _- \\
\hline S. anginosus & 21 & 17 & 3 & 1 & - & - & - & 20 & 1 \\
\hline S. constellatus & 4 & 2 & 2 & - & - & - & 1 & 3 & - \\
\hline S. intermedius & 4 & 2 & 1 & 1 & - & 3 & 1 & _- & - \\
\hline S. oralis & 43 & 27 & 13 & 2 & 1 & 14 & 11 & 17 & 1 \\
\hline S. parasanguis & 1 & $\ldots$ & - & 1 & - & - & - & 1 & - \\
\hline S. salivarius & 5 & 1 & 1 & - & 3 & 3 & 2 & - & - \\
\hline S. sanguis & 6 & 1 & 2 & - & 3 & 2 & 3 & 1 & - \\
\hline Total & $101^{b}$ & 56 & 27 & 9 & 9 & 33 & 20 & 46 & 2 \\
\hline
\end{tabular}

${ }^{a}$ For definition of the categories, see MATERials and MrThods.

${ }^{\prime}$ Three isolates remained unidentified. 
cation scheme of Beighton and co-workers (1991), S. oralis was the most prevalent species [29 of 39 isolates $(74 \%)$ ] and occurred significantly more in this patient group than in the patients of the other wards $(P<.001)$. Streptococcus mitis was second in rank of frequency $(n=7 ; 18 \%)$, followed by $S$. sanguis ( $n=$ 2 ) and $S$. anginosus $(n=1)$. Bacteremia due to $S$. oralis was associated with oromucositis in 19 of $29 \mathrm{~S}$. oralis isolates $(66 \%)$ and in all seven S. mitis isolates.

In the general hospital population, isolates belonging to the $S$. milleri group were the most frequently isolated; they occurred significantly more in these patients than in the patient group from the hematology unit $(P<.001)$ and included S. anginosus $(n=20), S$. constellatus $(n=4)$, and S. intermedius $(n=4)$. They were all considered to be clinically significant, and 24 of $28(85.7 \%)$ of them were associated with deep-seated infections: In 14 of isolates, an identical one was recovered from an associated site of infection; in the other isolates, an associated site of infection was obvious by X-ray examination $(n=3)$ and/or during surgical intervention $(n=7)$. In 11 isolates, growth occurred from only one blood culture: In six, a culture-confirmed source of infection was disclosed; in four, the source of infection was identified by surgery and/or X-ray examination; and in one, significance was established by the symptoms of fever and chills, which resolved promptly after the installation of empirical antibiotic treatment. Nine S. milleri isolates $(31 \%)$ were detected only after 3 or more days of incubation. In two patients, recurrent bacteremia originated from abdominal abscesses. In each patient, two similar isolates were recovered within a $>2$-week time interval. Except for two, all isolates recovered from the blood in patients with bacterial endocarditis ( $n$ $=9$ ) grew in multiple blood cultures within 2 days of incubation. The offending organisms were identified as S. oralis $(n=3)$, S. mutans $(n=2)$, S. sanguis $(n=2), S$. mitis $(n=1)$, and S. salivarius $(n=1)$. Streptococcus bovis was isolated from multiple blood cultures in three patients and considered to be clinically significant: Colonic malignancy was present in two patients and cholecystitis with peritonitis in a third.

We recovered three isolates from blood in neonates: In one patient, the organism (S. oralis) was considered to be of questionable clinical significance. The second isolate (S. oralis) grew from the blood of an 8-day-old premature boy with hypothermia and respiratory distress. No species identification could be assigned to the third isolate; it grew together with Escherichia coli from the blood of a newborn delivered by cesarean section to a woman with premature rupture of membranes.

Table 2 lists the clinical presentations and blood culture results associated with the 22 remaining isolates from the general hospital population. Nine of
21 isolates for which clinical data were available were considered significant. In 12 episodes, clinical significance was questionable: Although all of these isolates were recovered from only one blood culture, this criterion lacked specificity to differentiate them from the significant isolates. In addition, the delay of growth detection of the isolates did not differ from the detection delay of the clinically significant isolates.

\section{DISCUSSION}

Until recently, the VS seemed to be refractory to taxonomy. Two classification schemes coexisted: a European (Colman and Williams, 1972) and an American one. The latter scheme, from the CDC (Facklam, 1977) has been the basis of several commercial identification kits. During the past decade, taxonomic relationships among VS have been clarified by the application of molecular techniques, and several new species have been described (Kilian et al., 1989, Whiley and Beighton 1991).

\section{Test Systems}

We found the scheme of Beighton and co-workers to be reproducible and managed to identify the majority of clinical isolates. Isolates assigned to the S. oralis and $S$. intermedius species produced strongly positive results with clearly distinguishable patterns. Isolates identified as $S$. mitis produced less discernible patterns, and in our opinion, the scheme lacked discriminating power to distinguish clearly between S. mutans and S. bovis and between S. anginosus and S. sanguis. Three of 104 strains could not be identified; similar proportions have been reported in previous studies (Douglas et al., 1993; Beighton et al., 1994). However, the method is somewhat timeconsuming and laborious. Faced with the demand for speed and standardization, the clinical laboratory often relies on commercial kits for streptococcal identification. For these reasons, we elected to use the API 20 Strep and Rapid ID 32 Strep systems without complementary tests. The API 20 Strep system performed poorly in this collection. Its revised data base (version 5.1) includes S. anginosus, S. constellatus, and S. intermedius, but the biochemical gallery appeared not to include appropriate tests to discriminate among the three species. Streptococcus oralis represented the other species responsible for the high number of incorrect identifications. Although the number of isolates tested was too low to reach significant conclusions, it was clear that the Rapid ID 32 Strep system performed reasonably well for the species tested. Difficulties with species such as $S$. oralis and $S$. mitis have been reported (Freney et al., 1992), and the system was found to 
TABLE 2 Streptococcal Isolates Not Described in the Text: Growth Characteristics and Clinical Data

\begin{tabular}{|c|c|c|c|c|c|c|c|c|}
\hline \multirow[b]{2}{*}{ No. } & \multirow[b]{2}{*}{ Gender } & \multirow[b]{2}{*}{ Age } & \multirow[b]{2}{*}{ Presentation } & \multirow[b]{2}{*}{ Identification $^{a}$} & \multicolumn{3}{|c|}{ Blood Cultures $^{b}$} & \multirow{2}{*}{$\begin{array}{c}\text { Clinical } \\
\text { Significance }\end{array}$} \\
\hline & & & & & $\mathrm{P}$ & $\mathrm{T}$ & $\mathrm{D}$ & \\
\hline 1 & F & 69 & Congestive heart failure & S. oralis & 1 & 4 & 2 & Q \\
\hline 2 & F & 18 & Idiopathic proctocolitis-ileoanal & & & & & \\
\hline & & & anastomosis & S. oralis & 1 & 2 & 2 & $S$ \\
\hline 3 & $\mathrm{~F}$ & 63 & Multiple myeloma, cerebrovascular & & & & & \\
\hline & & & accident & S. mitis & 3 & 3 & 1 & $S$ \\
\hline 4 & F & 11 & ND & S. oralis & 1 & 2 & 3 & ND \\
\hline 5 & F & 69 & $\begin{array}{l}\text { Polytrauma, abdominal lesions, } \\
\text { splenectomy }\end{array}$ & S. mitis & 1 & 1 & 2 & $\mathrm{Q}$ \\
\hline 6 & M & 74 & Cerebrovascular accident, oesophagitis & S. oralis & 1 & ND & 4 & Q \\
\hline 7 & M & 83 & Urinary bladder carcinoma & S. mutars & 2 & 2 & 2 & $S$ \\
\hline 8 & M & 67 & $\begin{array}{l}\text { Cardiac surgery-aortic/mitral valve } \\
\text { replacement }\end{array}$ & S. oralis & 1 & ND & 3 & Q \\
\hline 9 & F & 65 & Cardiac failure-respiratory failure & S. salivarius & 1 & 3 & 3 & $Q$ \\
\hline 10 & $\mathrm{M}$ & 65 & $\begin{array}{l}\text { Cerebrovascular accident-aspiration } \\
\text { pneumonia }\end{array}$ & S. salivarius & 1 & 1 & 2 & $Q$ \\
\hline 11 & M & 73 & Pneumonia & S. parasanguis & 1 & 3 & 1 & $Q$ \\
\hline 12 & F & 78 & $\begin{array}{l}\text { Pneumothorax after pacemaker } \\
\text { implantation }\end{array}$ & None & 1 & 3 & 2 & Q \\
\hline 13 & M & 73 & Obstruction pneumonia & S. oralis & 1 & 3 & 1 & S \\
\hline 14 & M & 17 & Cystic fibrosis & S. salivarius & 1 & 1 & 1 & $Q$ \\
\hline 15 & $\mathrm{~F}$ & 39 & Postpartum fever & S. oralis & 1 & 2 & 1 & $S$ \\
\hline 16 & $\mathrm{~F}$ & 75 & Non-Hodgkin lymphoma, diverticulitis & S. gordonit & 2 & 3 & 2 & $\mathrm{~S}$ \\
\hline 17 & $\mathrm{~F}$ & 69 & Acute asthma attack, respiratory failure & S. salivarius & 1 & 1 & 1 & $\mathrm{~S}$ \\
\hline 18 & M & 3 & Pneumonia & S. sanguis & 1 & 2. & 1 & $S$ \\
\hline 19 & $\mathrm{~F}$ & 78 & Myocardial infarction & S. oralis & 1 & 3 & 5 & Q \\
\hline 20 & M & 2 & Tonsillectomy & S. oralis & 1 & 2 & 3 & $\mathrm{~S}$ \\
\hline 21 & M & 48 & $\begin{array}{l}\text { Pickwickian syndrome, respiratory } \\
\text { failure }\end{array}$ & None & 1 & 2 & 1 & $Q$ \\
\hline 22 & M & 62 & $\begin{array}{l}\text { Cardiac surgery: coronary artery bypass } \\
\text { graft }\end{array}$ & S. sanguis & 1 & 3 & 1 & $Q$ \\
\hline
\end{tabular}

${ }^{a}$ Identification: method according to the method of Beighton and co-workers (1991).

bBlood cultures: $P$, number of blood cultures grown; $T$, total number of blood cultures drawn; $D$, days of incubation before detection

'Clinical significance: $S$, considered clinically significant; $Q$, questionable significance; ND, no data available.

perform well when challenged with a collection of clinical S. milleri isolates (Jacobs and Stobberingh, 1994).

\section{Species Distribution and Relevance}

Isolates identified as $S$. oralis accounted for the majority of those recovered in patients of the hematology unit. This agrees with a previous study that, using the same scheme, identified 14 of 23 VS (61\%) isolated from the blood of neutropenic patients as $S$. oralis (Beighton et al., 1994). Bacteremia involving VS occurs frequently in leukemic patients and bone marrow transplant recipients (Valteau et al., 1991; Elting et al., 1992; Burden et al., 1991; van der Lelie et al., 1991; McWhinney et al., 1991; Bochud et al., 1994). Most of these studies used the CDC scheme and found $S$. mitis and $S$. sanguis to be the most frequently isolated organisms. Some authors reported associations of $S$. sanguis II with oromucositis and $S$, mitis with adult respiratory distress syndrome (ARDS) (McWhinney et al., 1991; Arning et al., 1990). The absence of $S$. oralis in these studies is remarkable but may be explained by the fact that the emended description of S. oralis (Kilpper-Bälzz et al., 1985, Kilian et al., 1989) has only recently been published. The species has been included only in the most recent version of the API 20 Strep data base, version 5.1. We looked for the API 20 Strep profiles corresponding to the isolates presently identified as $S$. oralis according to the scheme of Beighton et al. and decoded them with the previous API 20 Strep data base (version 4.0 ); most of these profiles encoded for S. mitis or S. sanguis II. As the taxonomy used in these reports is now superseded, we feel that possible associations between VS, oromucositis, and ARDS are to be reassessed. In the present study, both $S$. mitis and $S$. oralis were associated with oromucositis.

The preponderance of $S$. miller in the nonhema- 
tologic patient group is interesting. Within the VS, these heterogeneous strains are particularly prone to misidentification (Ruoff, 1988). In the present collection, the three species could be discriminated unambiguously. Their fastidious growth as compared with the other viridans species is noteworthy. No clear association between one particular species and a distinct clinical presentation was obvious. As many as 19 of the present episodes have been described in detail elsewhere (Jacobs et al., 1994).

Douglas and co-workers (1993) collected 42 VS isolates from patients with bacterial endocarditis. They identified these isolates according to the method of Beighton et al. (1991) and found S. sanguis, S. oralis, and S. gordonii to be the most prevalent species. The latter species was not found among the present isolates recovered from patients with infective endocarditis.

Because of the retrospective nature of this study, it was difficult to establish clinical relevance. In a pediatric population, Hamoudi and co-workers (1989) found the majority of VS isolated from the blood not to be significant. In the present population, the majority of isolates was considered to be clinically relevant by the physician or surgeon treating the patient. Clinical significance of the isolates could not be predicted from their growth character-

\section{References}

Arning M, Gehrt A, Aul C, Runde V, Hadding U, Schneider W (1990) Septicemia due to Streptococcus mitis in neutropenic patients with acute leukemia. Blut 61:364 368

Beighton D, Hardie JM, Whiley RA (1991) A scheme for the identification of viridans streptococci. / Med Microbiol 35:367-372.

Beighton D, Carr AD, Oppenheim BA (1994) Identification of viridans streptococci associated with bacteraemia in neutropenic cancer patients. I Med Microbiol 40:202-204.

Bochud PY, Eggiman P, Calandra T, Van Melle G, Saghafi L, Francioli P (1994) Bacteremia due to viridans streptococcus in neutropenic patients with cancer: clinical spectrum and risk factors. Clin Infect Dis 18:25-31.

Burden AD, Oppenheim BA, Crowther D, Howell A, Morgenstern GR, Scarffe JH, Thatcher N (1991) Viridans streptococcal bacteraemia in patients with haematological and solid malignancies. Eur ] Cancer 27:409411.

Cohen J, Donnelly JP, Worsley AM, Catovsky D, Goldman JM, Galton DAG (1983) Septicemia caused by viridans streptococci in neutropenic patients with leukemia. Lancet 329:1452-1454.

Colman G, Williams REO (1972) Taxonomy of some human viridans streptococci. In Streptococci and Streptococcal Diseases. Eds, LW Wannaker and JM Matsen. London: Academic Press, pp 281-299.

Coykendall AL (1989) Classification and identification of the viridans streptococci. Clin Microbiol Rev 2:315-328. istics; although isolates with questionable clinical significance only grew from a single blood culture, this criterion was not specific. Neither was the delay of growth detection a clearcut distinction, as isolates of the S. milleri group (which were all considered clinically significant) tended to be detected after a longer delay. Species identification, however, revealed $S$. oralis, $S$. bovis, and the $S$. milleri group to be linked to a well-defined clinical picture.

In conclusion, the majority of isolates in this study were considered to be clinically significant. For the species tested, the Rapid ID 32 Strep system performed well, the API 20 Strep system not. Streptococcus oralis was the most prevalent species among the isolates collected in the hematology unit; the species of the S. milleri group were most prevalent among the isolates from general hospital population. Clinical significance could not be predicted from the number of blood cultures grown, nor from the delay of growth detection. The present data provide further insight into the search for the link between species and the diseases they can cause.

The authors thank Dr. J. Verhaegen, University Hospital Leuven, Belgium, for his critical review of the manuscript.
Douglas CWI, Heath J, Hampton KK, Preston FE (1993) Identity of viridans streptococci isolated from cases of infective endocarditis. J Med Microbiol 39:179-182.

Elting LS, Bodey GP, Keefe BH (1992) Septicemia and shock syndrome due to viridans streptococci: a casecontrol study of predisposing factors. Clin Infect Dis 14:1201-1207.

Facklam RR (1977) Physiological differentiation of viridans streptococci. J Clin Microbiol 5:184-201.

Freney J, Bland S, Etienne J, Desmonceaux M, Boeufgras JM, Fleurette J (1992) Description and evaluation of the semiautomated 4-hour rapid ID 32 Strep method for identification of streptococci and members of related genera. J Clin Microbiol 30:2657-2661.

Garner JS, Jarvis WR, Emori TG, Horan TC, Hughes JM (1988) CDC definitions for nosocomial infections, 1988. Am J Infect Control 16:128-140.

Gossling J (1988) Occurrence and pathogenicity of the Streptococcus milleri group. Rev Infect Dis 10:257-285.

Hamoudi AC, Hribar MM, Marcon MJ, Cannon HJ (1989) Clinical relevance of viridans and nonhemolytic streptococci isolated from blood and cerebrospinal fluid in a pediatric population. Am J Clin Pathol 93:270-272.

Jacobs JA, Pietersen HG, Stobberingh EE, Soeters PB (1994) Bacteremia due to "Streptococcus milleri": analysis of 19 cases. Clin Infect Dis 19:704-713.

Jacobs JA, Stobberingh EE (1994) Species identification of "Streptococcus milleri" with the Rapid ID 32 Strep system. Med Microbiol Lett 3:315-322. 
Kilian M, Mikkelsen L, Henrichsen J (1989) Taxonomic study of viridans streptococci: description of Streptococcus gordonii sp. nov. and emended descriptions of Streptococcus sanguis (White and Niven 1946). Streptococcus oralis (Bridge and Sneath 1982) and Streptococcus mitis (Andrewes and Horder 1906). Int J Syst Bacteriol 39:471-484.

Kilpper-Bälz R, Wenzig P, Schleifer KH (1985) Molecular relationships and classification of some viridans streptococci as Streptococcus oralis and emended descriptions of Streptococcus oralis (Bridge and Sneath 1982). Int J Syst Bacteriol 35:482-488.

McWhinney PHM, Gillespie SH, Kibbler CC, Hoffbrand AV, Prentice HG (1991) Streptococcus mitis and ARDS in neutropenic patients. Lancet 337:429.

Nash P, Krenz MM (1991). Culture media. In Manual of Clinical Microbiology. Eds, A Balows, WJ Hausler, KL Herrmann, HD Isenberg, and HJ Shadomy. Washing- ton, DC: American Society for Microbiology, pp 12261288.

Ruoff KL (1988) Streptococcus anginosus ("Streptococcus milleri'): the unrecognized pathogen. Clin Microbiol Rev 1:102-108.

Valteau D, Hartmann O, Brugieries L, Vassal G, Benhamou E, Andremont A, Kalifa C, Lemerle J (1991) Streptococcal septicaemia following autologous bone marrow transplantation in children treated with highdose chemotherapy. Bone Marrow Transplant 7:415-419.

van der Lelie $H$, van Ketel RJ, von dem Borne AEGK, Vanoers RHJ, Thomas BLM, Goudsmit R (1991) Incidence and clinical epidemiology of streptococcal septicemia during treatment of acute myeloid leukemia. Scand I Infect Dis 23:163-168.

Whiley RA, Beighton D (1991) Emended descriptions and recognition of Streptococcus constellatus, Streptococcus in termedius and Streptococcus anginosus as distinct species. Int J Syst Bacteriol 41:1-5. 


\section{CHAPTER III Bacteremia involving the "Streptococcus milleri" group: analysis of 19 cases}

Jan A.Jacobs, Henk G.Pietersen, Ellen E.Stobberingh and Peter B.Soeters Clinical Infectious Diseases 1994; 19: 704-713. 


\title{
Bacteremia Involving the "Streptococcus milleri" Group: Analysis of 19 Cases
}

\author{
Jan A. Jacobs, Henk G. Pietersen, Ellen E. Stobberingh, \\ From the Departments of Medical Microbiology and Surgery. University \\ and Peter B. Soeters \\ Hospital of Maasiricht. Maastricht, The Netherlands
}

\begin{abstract}
During a 3-year study period, 19 patients at the University Hospital of Maastricht developed bloodstream infections with species of the "Streptococcus milleri" group, for an incidence of 0.33 per 1,000 admissions. The patients' median age was 48 years; the male-to-female ratio was 2.8 . Eleven patients $(57.9 \%)$ had underlying diseases, among which malignancy was predominant. Local trauma to the mucosal barrier was an important risk factor. An associated site of infection was found most frequently in the abdominal and thoracic cavities (nine and five cases, respectively). Bacteremia was polymicrobial in four of 19 episodes. The 20 infecting $S$. milleri strains were identified to the species level; Streptococcus anginosus was the most prevalent (16 strains). Eight strains carried Lancefield group C. The isolates were sensitive to most antibiotics. Abscess formation was documented in nine cases $(47.3 \%)$; repeated drainage procedures were required in half of these episodes. Mortality was high (five of 19 patients, or $26.3 \%$ ).
\end{abstract}

Streptococcus intermedius. Sireptococcus anginosus, and Sireptococcus constellatus are collectively referred to as the "Streptococcus milleri" group and are components of the flora of the mouth, gastrointestinal tract, and urogenital tract. These species share a common denominator in the clinical setting: their marked tendency to cause abscess formation [1]. Because of persistent taxonomic confusion, the recognition of these organisms in the laboratory has been hampered and their clinical significance may have been underrated [2]. Recently, Whiley and Beighton [3] delineated the distinct DNA homology of the three species and discussed phenotypic tests by which they can be identified. In several reviews describing the manifestations of infections due to the $S$. milleri group, only a few cases of bacteremia were included and the three species were not differentiated [1, 4-6].

Herein we review 19 episodes of $S$. milleri bacteremia documented over a 3-year period at the University Hospital of Maastricht, a 600-bed tertiary-care center. We describe the relevant clinical features of these episodes and the distribution of species among the 20 isolated strains. In addition, we present the results of our analyses of risk factors, associated sites of infection. clinical presentation, treatment, and out come, and we discuss the microbiological characteristics of the three streptococcal species involved.

\section{Methods \\ Epidemiology}

Episodes of $S$. milleri bacteremia occurring at our institution between April 1990 and April 1993 were identified by

Received 30 November 1993; revised 17 May 1994

Reprints or correspondence: Dr. Jan A. Jacobs, Department of Medical Microbiology, University Hospital of Maastricht. P. O. Box 5800, 6202 AZ Maastricht, The Netherlands.

Clinical Infectjous Diseases 1994; 19:704-13

(C) 1994 by The University of Chicago. All rights reserved. $1058-4838 / 94 / 1904-0010 \$ 02.00$ an analysis of the report forms of the microbiology laboratory. All cases in which a member of the $S$, milleri group was isolated from the blood were included in the study, regardless of the number of blood cultures performed. We examined patients' medical records for information on gender, age, and underlying disease. Predisposing factors, including surgery, trauma, and time in the hospital before onset of bacteremia, were recorded, as were laboratory findings, treatment modalities, and outcome. Identification of the source of infection was based on culture and/or the clinical judgment of the physician or surgeon treating the patient at the time of the episode of bacteremia. Proportions were compared statistically by means of the $\chi^{2}$ test.

\section{Microbiology}

Organisms were isolated with a conventional biphasic aerobic/anaerobic blood-culture system (Vacutainer; BectonDickinson, Cockeysville. MD). One set of cultures consisted of two bottles, each containing $45 \mathrm{~mL}$ of supplemented peptone broth to which a volume of $5 \mathrm{~mL}$ of blood was added. On arrival of a set of bottles in the laboratory, an agar paddle was attached to one bottle; then both bottles were incubated at $35^{\circ} \mathrm{C}$ for 7 days. Occasionally, blood cultures were terminally subcultured on sheep blood agar and incubated in a $\mathrm{CO}_{2}$-enriched atmosphere for 48 hours. Microorganisms recovered from blood cultures were identified by standard procedures [7]. Streptococcal isolates were presumptively identified by their colonial morphology and pattern of hemolysis on $5 \%$ sheep blood agar, their sensitivity to bacitracin- and optochin-coated disks, and their reaction in the bile-esculin test. Isolates were identified as members of the $S$. milleri group by the API 20 Strep System (bioMérieux, La Balme les Grottes. France). Strains were stored at $-70^{\circ} \mathrm{C}$ on porous beads in a cryopreservative (Microbank: Pro-Lab Diagnostics, Richmond Hill, Ontario, Canada). Before a case was included in the study, each associated strain was retrieved 
and its identity confirmed. One isolate was no longer available, and the associatcd episode of bacteremia was excluded from the study. The Lancefield group was determined for all isolates. including $\alpha$-hemolytic and nonhemolytic strains: the Streptex system (Wellcome Diagnostics. Dartford. UK) was used. Hemolysis was confirmed by the observation of subsurface growth in stabbed plates [8].

Strains were identified as $S$. anginosus, $S$. constellatus, or $S$. intermedius on the basis of the identification scheme described by Whiley and Beighton [3]. In brief, each strain was tested for the production of $\alpha$-galactosidase, $\beta$-galactosidase. $\alpha$-glucosidase, $\beta$-glucosidase, $\beta$ - $N$-acetylgalactosaminidase, $\beta$ - $N$-acetylglucosaminidase, sialidase, and $\beta$-D-fucosidase, with use of 4-methylumbelliferyl-linked fluorogenic substrates in microtiter plates. The production of hyaluronidase was assessed by the rapid plate method of Smith and Willett [9]. Strains with atypical test results were sent to Dr. R. Whiley (The London Hospital Medical College, London. UK). who kindly confirmed their identities.

The antimicrobial susceptibility of the isolates was assessed by the agar dilution method [10] on Mueller-Hinton agar (Oxoid, Basingstoke, UK) supplemented with $5 \%$ sheep blood (vol/vol). The antimicrobial agents tested (obtained as standard reference powders from their respective manufacturers in the Netherlands) were penicillin (Brocades-Farma, Leiderdorp), amoxicillin (Smith-Kline Beecham, Rijswijk), cefotaxime (Hoechst-Roussel. Hoevelaken), clindamycin (Upjohn, Ede), doxycycline (Pfizer, Rotterdam), erythromycin (Abbott, Amsterdam), gentamicin (Essex-Schering. Amstelveen), teicoplanin (Brocades-Farma), vancomycin (Eli Lilly, Nieuwegein), and ciprofloxacin (Bayer. Mijdrecht). Plates were incubated in $7 \% \mathrm{CO}_{2}$ at $35^{\circ} \mathrm{C}$ for 18 hours. Recommended breakpoints for susceptibility were used [10].

\section{Results}

\section{Clinical Findings}

Relevant clinical and demographic features of the 19 episodes of $S$. milleri bacteremia are summarized in table 1.

Demographics/epidemiology. Of the 19 patients, 14 $(73.7 \%)$ were male and 5 were female (ratio. 2.8). Eleven patients ( $57.9 \%$ ) were $<60$ years of age. The patients were evenly distributed among all age groups. For the entire group the median age was 48.0 years, the mean age $\pm \mathrm{SD}$ was 48.8 \pm 22.7 years, and the age range was $2-85$ years. The mean age for males was 43.3 years (range, $2-74$ years), and that for females was 58.1 years (range, $30-85$ years). Episodes of bacteremia occurred after a median duration of hospitalization of 10 days (range, $1-65$ days).

Underlying diseases. Eleven (57.9\%) of 19 patients had systemic underlying conditions, including malignancy ( 5 cases), diabetes mellitus ( 2 cases). both diabetes mellitus and malignancy ( 1 case), paraplegia ( 2 cases), immunosuppres- sive therapy after liver transplantation ( 1 case), and Crohn's disease ( 1 case). Seventeen patients (89.5\%) had suffered local trauma to the mucosal barrier.

Hospital course. An episode of bacteremia developed postoperatively in four patients. Two of these patients had been admitted to the hospital for emergency coronary-artery surgery; and one of the two (episode 18) developed aspiration pneumonia, while the other (episode 4) had an esophageal perforation that gave rise to pleural empyema. In the latter case, blood cultures yielded $S$. anginosus and Enterococcus faecalis; despite intensive surgical and antibiotic treatment, the patient died. In the third case of postoperative bacteremia -involving a 70-year-old man (episode 7)-anastomotic dehiscence after resection of an esophageal carcinoma resulted in pleural empyema. The patient survived the episode of bacteremia; however, his empyema did not resolve despite surgical and antibiotic treatment, and he died 5 months later. In the last case, hemicolectomy in a 75-yearold man (episode 19) was complicated by an episode of bacteremia due to leakage of the anastomosis. A liver abscess developed, requiring repeated drainage.

Respiratory tract infections presented as pneumonia and lung abscess, respectively, in a 34-year-old man with disseminated carcinoma of the lung and in a previously healthy $40-$ year-old man with quadriplegia and lung contusion after a motorcycle accident (episodes 9 and 11).

In two women (episodes 2 and 6), premature rupture of membranes was complicated by $S$. milleri bacteremia. In the first case, a cesarean section preceded bacteremia and the genital tract was considered the site of entry of the pathogen. In the second, an abdominal infection (probably appendicitis) spread to the uterine cavity.

A 2.5-year-old boy (episode 12) who had undergone orthotopic liver transplantation 2 years carlier because of tyrosinemia presentul with fever $\left(38.2^{\circ} \mathrm{C}\right)$. gingival and nasal bleeding. and respiratory distress. S. incrmedius was isolated from his blood after his discharge from the hospital.

A 66-year-old man (cpisode 3 ) was admitted with fever $\left(39.0^{\circ} \mathrm{C}\right)$, chills, and a pain in the left lower quadrant of the abdomen. Serum concentrations of hepatic enzymes were clevated. Fever. symptoms, and laboratory abnormalities rapidly resolved after treatment with gentamicin and penicillin. Diverticulitis was considered the source of bacteremia.

One patient (episode l) was in the neutropenic phase of bone marrow transplantation for non-Hodgkin lymphoma. Grade 4 stomatitis developed on day 3 and fever 2 days later. After blood cultures yielded $S$. anginosus, the initial empirical regimen of piperacillin and amikacin was replaced with penicillin $G$, and the patient recovered.

Cholangitis developed in one case (episode 15) as a complication of common bile duct stones and in two others (episodes 5 and 10 ) as a complication of cholangiocarcinoma. In one of these cases (episode 10), a liver abscess developed, and Escherichia coli and Klehsiella pneumoniae were subse- 
Table 1. Clinical and demographic features of 19 episodes of S. milleri bacteremia occurring over a 3-year period at the University Hospital of Maastricht.

\begin{tabular}{|c|c|c|c|c|c|c|c|c|c|c|}
\hline Episode & $\begin{array}{l}\text { Patient's } \\
\text { age }(y) / \\
\text { sex }\end{array}$ & Underlying condition & $\begin{array}{l}\text { Reason for } \\
\text { admission }\end{array}$ & Clinical history & $\begin{array}{c}\text { Associated site/type } \\
\text { of infection }\end{array}$ & $\begin{array}{l}\text { Infecting } \\
\text { species (day* } \\
\text { of isolation) }\end{array}$ & $\begin{array}{l}\text { Antibiotic(s) } \\
\text { administered } \\
\text { (treatment } \\
\text { duration. d) }\end{array}$ & $\begin{array}{l}\text { Surgical } \\
\text { treatment }\end{array}$ & Outcome & Remarks \\
\hline 1 & $32 / \mathrm{M}$ & $\begin{array}{l}\text { Non-Hodgkin } \\
\text { lymphoma }\end{array}$ & $\begin{array}{l}\text { Bone marrow } \\
\text { transplantation }\end{array}$ & $\begin{array}{l}\text { Neutropenia, stomatitis } \\
\text { (grade 4) }\end{array}$ & Oropharynx & $\begin{array}{l}\text { S. anginosus } \\
\text { (12) }\end{array}$ & $\begin{array}{l}\text { Pip, Amik. Pen G } \\
\text { (10) }\end{array}$ & $\cdots$ & Recovery & \\
\hline 2 & $30 / \mathrm{F}$ & None & $\begin{array}{l}\text { Premature rupture of } \\
\text { membranes at } \\
\sim 35.5 w \text { of } \\
\text { gestation }\end{array}$ & $\begin{array}{l}\text { Cesarean section, } \\
\text { postoperative fever } \\
\left(39.8^{\circ} \mathrm{C}\right)\end{array}$ & Intrauterine cavity & $\begin{array}{l}\text { S. constellaturs } \\
\text { (7) }\end{array}$ & Amox. Mtz (7) & . & Recovery & $\begin{array}{l}\text { Child's Apgar score: } \\
8 / 9\end{array}$ \\
\hline 3 & $66 / M$ & None & $\begin{array}{l}\text { Anorexia, fever } \\
\left(39.0^{\circ} \mathrm{C}\right) \text {, chills. } \\
\text { abdominal pain }\end{array}$ & $\begin{array}{l}\text { Diverticulitis. elevated } \\
\text { levels of Jiver } \\
\text { enzymes }\end{array}$ & Diverticulitis & $\begin{array}{l}\text { S. interntedius } \\
\text { (1) }\end{array}$ & $\operatorname{Pen}(20), \mathrm{Gm}(5)$ & $\ldots$ & Recovery & \\
\hline 4 & $74 / \mathrm{M}$ & $\begin{array}{l}\text { Diabetes mellitus, } \\
\text { silicosis }\end{array}$ & $\begin{array}{l}\text { Myocardial } \\
\text { ischemia, } \\
\text { coronary artery } \\
\text { surgery }\end{array}$ & $\begin{array}{l}\text { Postoperative } \\
\text { esophageal } \\
\text { perforation and } \\
\text { pleural empyema }\end{array}$ & Pleural empyema & $\begin{array}{l}\text { S. anginosus } \\
(42)\end{array}$ & Pip. Gm (1) & $\begin{array}{l}\text { Percutaneous and } \\
\text { surgical } \\
\text { drainage of } \\
\text { pleural cavity }\end{array}$ & Death & $\begin{array}{l}\text { Associated organisms: } \\
\text { Enferococcus } \\
\text { faecalis recovered } \\
\text { from blood cultures }\end{array}$ \\
\hline 5 & $60 / \mathrm{F}$ & Cholangiocarcinoma & $\begin{array}{l}\text { Icterus, fever } \\
\left(39.8^{\circ} \mathrm{C}\right)\end{array}$ & $\begin{array}{l}\text { Stenosis of } \\
\text { choledochojejunal } \\
\text { anastomosis }\end{array}$ & Cholangitis & $\begin{array}{l}\text { S. anginosus } \\
\text { (25) }\end{array}$ & $\begin{array}{l}\text { Amox/CA, Gm } \\
(7)\end{array}$ & $\begin{array}{l}\text { Percutaneous } \\
\text { drainage of bile } \\
\text { ducts. ERCP\$ } \\
\text { with } \\
\text { endoprosthesis }\end{array}$ & Recovery & $\ldots$ \\
\hline 6 & $34 / \mathrm{F}$ & $\begin{array}{l}\text { Gestational diabetes } \\
\text { mellitus }\end{array}$ & $\begin{array}{l}\text { Periappendicular } \\
\text { mass. premature } \\
\text { rupture of } \\
\text { membranes at } \\
\sim 24.5 \mathrm{w} \text { of } \\
\text { gestation. fever } \\
\left(40.1^{\circ} \mathrm{C}\right)\end{array}$ & $\begin{array}{l}\text { Chorioamnionitis. } \\
\text { intrabdominal } \\
\text { abscesses }\end{array}$ & $\begin{array}{l}\text { Periappendicular } \\
\text { abscesses. }{ }^{\S} \\
\text { chorioamnionitis }{ }^{\S}\end{array}$ & $\begin{array}{l}\text { S. anginosus } \\
\text { (1) }\end{array}$ & $\begin{array}{l}\operatorname{Amox} / \mathrm{CA}, \mathrm{Gm} \\
(7)\end{array}$ & $\begin{array}{l}\text { Manual removal } \\
\text { of placenta, } \\
\text { percutaneous } \\
\text { abscess } \\
\text { drainage }\end{array}$ & Recovery & Intrauterine death \\
\hline 7 & $70 / \mathrm{M}$ & $\begin{array}{l}\text { Diabetes mellitus, } \\
\text { esophageal } \\
\text { carcinoma }\end{array}$ & $\begin{array}{l}\text { Resection of } \\
\text { esophageal } \\
\text { carcinoma }\end{array}$ & $\begin{array}{l}\text { Anastomotic } \\
\text { dehiscence and } \\
\text { pleural empyema }\end{array}$ & Pleural empyema & $\begin{array}{l}\text { S. anginosus } \\
\text { (7) }\end{array}$ & Pip, Cm (14) & $\begin{array}{l}\text { Multiple } \\
\text { percutaneous } \\
\text { and surgical } \\
\text { drainages }\end{array}$ & Death & . \\
\hline 8 & $85 / \mathrm{F}$ & None & $\begin{array}{l}\text { Acute upper- } \\
\text { abdominal pain }\end{array}$ & Perforated gastric ulcer & $\begin{array}{l}\text { Intraabdominal } \\
\text { abscesses }\end{array}$ & $\begin{array}{l}\text { S. anginosus } \\
\quad(65)\end{array}$ & Pip (4) & $\begin{array}{l}\text { Percutaneous and } \\
\text { surgical abscess } \\
\text { drainage }\end{array}$ & Death & $\begin{array}{l}\text { Associated organisms: } \\
\text { Klebsiclia oxitoca } \\
\text { recovered from } \\
\text { blood cultures }\end{array}$ \\
\hline 9 & $34 / \mathrm{M}$ & $\begin{array}{l}\text { Disseminated lung } \\
\text { carcinoma. }\end{array}$ & Hemoptysis & $\begin{array}{l}\text { Progressive respiratory } \\
\text { insufficiency }\end{array}$ & Pneumonia & $\begin{array}{l}\text { S. anginosus } \\
\text { (3) }\end{array}$ & Cfur (2) & & Death & $\ldots$ \\
\hline
\end{tabular}


Surgical exploration of Intraabdominal

\section{S. constellariss None}$$
\text { abscess }
$$

$$
\begin{aligned}
& \text { intraabdominal } \\
& \text { abscesses }
\end{aligned}
$$

Fever $\left(40.2^{\circ} \mathrm{C}\right) . \quad$ Retroperitoneal

Abdominal abscess ${ }^{8}$ S. anginosus Pen $\mathrm{G}(5)$ abdominal pain in abscess caused by

right lower appendicitis

$15 \quad 67 / \mathrm{M}$ Nonc

Abdominal pain in Cholangitis caused by

right upper common bile duct

$$
\text { quadrant stones }
$$

Stab wound to neck Ferer $\left(40.0^{\circ} \mathrm{C}\right)$

subcutaneous

emphysema.

cmphysemat
thrombus of internal
jugular vein

$17 \quad 22 / \mathrm{M}$ Paraplegia

$18 \quad 72 / \mathrm{M}$ None

$19 \quad 75 / \mathrm{M}$ Diabctes mellitus cmphysema.
thrombus of inte
jugular vein
Pain. fever $\left(39.0^{\circ} \mathrm{C}\right)$. Osteomyelitis of

Pain. fever $\left(39.0^{\circ} \mathrm{C}\right)$. Osteomyelitis or $\begin{array}{cc}\text { Coronary artery } & \begin{array}{c}\text { Postoperative } \\ \text { surgery }\end{array} \\ \text { aspiration }\end{array}$

surgery pneumonia

Adenocarcinoma in Hemicolectomy descending colon complicated by postoperative dehiscence

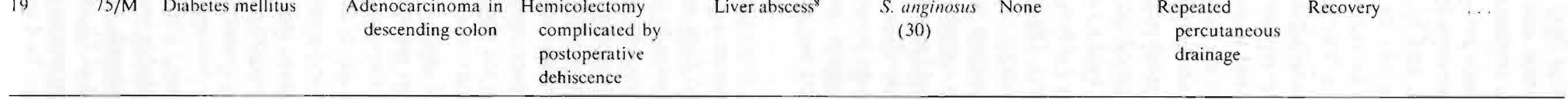

Infecied venous $S$ anginosus Amox/CA (ND) Surgery

Bone and soft

tissues

S. an

angin

S. angind

(9)

anginosus Pip. Gm (7) percutaneous drainage

ERCP with

Surgery

Recovery Two distinct strains of S. anginosus recovered

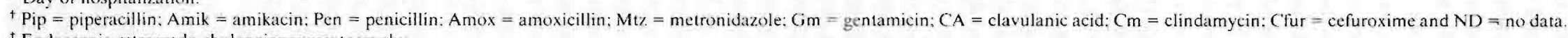
¥ Endoseopic retrograde cholangiopancreatography. 
quently isolated from the blood. The patient died despite repeated drainage and antibiotic therapy.

Bacteremia originated from multiple abdominal abscesses caused by gastric perforation in an 85 -year-old woman (episode 8), by intestinal lesions in a patient with Crohn's disease (episode 13), and by appendicitis in a previously healthy man (episode 14). In the first case, Klebsiella oxytoca was isolated from another set of cultures of blood drawn the same day as the first. The patient died of cardiorespiratory failure and diffuse intravascular coagulation. The other two patients recovered after repeated surgical and percutancous drainage.

A 36-year-old tourist (episode 16) was admitted with a stab wound to the neck. He developed fever $\left(40.0^{\circ} \mathrm{C}\right)$ within 24 hours. Radiography showed subcutaneous emphysema adjacent to the left internal jugular vein. On day 4 of hospitalization, computed tomography of the neck showed a thrombus with gas bubbles in the jugular vein. Cultures of blood drawn on day 2 of hospitalization yielded two distinct strains of $S$. anginosus. The patient left the hospital the same day against the advice of the surgical staff. We were later informed that surgery was later successfully performed in the patient's own country.

A 22-year-old man (episode 17) who had been paraplegic for 11 years developed a decubitus ulcer of the left buttock. with progression to osteomyelitis of the femoral head. In addition to surgical treatment, therapy with amoxicillin/ clavulanic acid was administered. The patient made a gradual recovery.

Associated sites of infection. In 7 (36.8\%) of the 19 episodes of bacteremia, an isolate identical to that from blood was recovered from an associated site of infection that was also considered to be the source of the bloodstream infection on clinical grounds. In another 11 episodes (57.9\%). deep infectious processes were considered to be the source of bacteremia although confirmation by culture was lacking. In the remaining episode (episode 12), no source was established at the time of bacteremia. Associated sites of infection were most often in the abdominal cavity ( 9 cases, 5 of them culture-confirmed); next most common were sites in the thoracic cavity ( 5 cases, 2 of them culture-confirmed). The bone and soft tissues accounted for two episodes, the genital tract for one, and the oropharynx for one. Endocarditis was not diagnosed in any of the 19 cases. Clear abscesses developed in 9 episodes and presented as pleural empyema or as lesions of the abdomen, pelvis, lung, or liver. We were later informed that surgery was later successfully performed the in patient's own country.

laboratory findings. The mean white blood cell (WBC) count $\pm S D$ was $13,900 \pm 2,700 / \mu \mathrm{L}$ for the 14 cases in which data were available and immunosuppressive therapy was not being administered. The differential WBC count disclosed a left shift in 8 of 12 cases. Ten of 15 patients had elevated serum concentrations of aminotransferases and $\gamma$-glutamyltranspeptidase. In 4 instances (episodes 5, 11, 15, and 19), these increases were related to underlying disease in the hepatobiliary tract; in one case (episode II), they occurred in conjunction with myocardial contusion.

Treatment. Most patients (16 of 19 ) initially received an empirical regimen including antibiotics that were later judged to be appropriate in light of in vitro susceptibility tests. The median duration of antibiotic therapy for patients who survived was 7 days.

When abscesses were documented, endoscopic, transcutaneous, or surgical drainage was undertaken. In half of these cases, repeated drainage was required to eradicate the focus of infection. Two patients (episodes 13 and 19) were successfully treated with surgery only.

Outcome. Five patients (26.3\%; three men and two women) died during hospitalization. Their mean age $\pm \mathrm{SE}$ was $68.8 \pm 5.5$ years. Three patients died within 1 week after the onset of bacteremia (episodes 4, 8, and 9); two of these individuals had debilitating disease (episodes 4 and 9). Two other patients (episodes 7 and 10) recovered from bacteremia but died later (after 152 days and 15 days, respectively) for reasons clearly related to an underlying condition. Outcome was adversely - although not significantly-affected by advanced age and by the presence of underlying conditions.

\section{Microbiological Findings}

Incidence. The 19 patients developing bacteremia represented an incidence of 0,33 per 1,000 hospital admissions. A total of 39 blood cultures yielded 20 isolates of the $S$. milleri group. (As has already been mentioned, two distinct strains of $S$. anginosus were recovered in one episode.) At our hospital, S. milleri bacteremia occurred about one-eighth as often as Staphylococcus aureus bacteremia and one-third as often as Streptococcus pneumoniae, Klebsiella species, or Pseudomonas acruginosa bacteremia. The average annual number of episodes of bloodstream infection with $S$. milleri (i.e., 6.3 episodes) exceeded that for Streptococcus agalactiae (5.3 episodes) and for the large-colony $\beta$-hemolytic streptococci of groups $\mathrm{C}$ and $\mathrm{G}$ ( 1.7 episodes).

Culture data. One set of blood cultures was performed in four episodes, two sets in 12 episodes, and three sets in three episodes. A species of the $S$. milleri group was recovered from more than one set of cultures in 10 of the 15 episodes with more than one set performed. In four of the nine episodes in which an $S$. milleri species was recovered from only one set of blood cultures (episodes 8, 14, 18, and 19), a culture-confirmed source of bacteremia was disclosed: in four of these episodes (episodes 1, 4, 9, and 13), a probable focus of infection was identified; and in one episode (episode 12), no associated site of infection was found.

The mean \pm SD time of recovery of an $S$. milleri species from blood cultures was day $3.1 \pm 1.8$ of hospitalization. Growth was detectable only after 6 days of incubation in 
Table 2. Hemolytic patterns and lancefield groups of $20 \mathrm{~S}$. milleri isolates from 19 episodes of bacteremia occurring over a 3-year period at the University Hospital of Maastricht.

\begin{tabular}{|c|c|c|c|c|}
\hline \multirow[b]{2}{*}{ Lancefield group } & \multicolumn{4}{|c|}{ No. of isolates with indicated group and hemolytic pattern } \\
\hline & $\alpha$ & $\beta$ & Nonhemolytic & Total \\
\hline $\mathrm{C}$ & $2^{*}$ & $4^{*}$ & $2^{*}$ & $8^{*}$ \\
\hline $\mathrm{F}$ & $5^{*}$ & $\mathrm{I}^{\dagger}$ & $1^{*}$ & $6^{*}+1^{\dagger}$ \\
\hline Nongroupable & $1^{*}+2^{\ddagger}$ & 0 & $1^{*}+1^{\dagger}$ & $2^{*}+2^{*}+1^{*}$ \\
\hline Total & $8^{*}+2^{\ddagger}$ & $4^{*}+1^{t}$ & $4^{*}+1^{\dagger}$ & $16^{*}+2^{\ddagger}+2$ \\
\hline
\end{tabular}

three episodes (episodes 2, 17, and 18). The organism was detected with the same frequency in aerobic and anaerobic bottles. On two occasions subcultures were prepared at the end of the incubation period: an $S$. milleri species was recovered from the anaerobic bottle on both occasions (cpisodes 17 and 19).

Four of 19 episodes were polymicrobial. The associated organisms included E. faecalis, K. oxytoca, and E. coli and $K$. pneumoniae (episodes 4. 8, and 10, respectively): in the fourth episode (episode 16) two distinct strains of S. anginosus were recovered. No episode of recurrent or persistent bacteremia was documented.

Distribution and characteristics of species. Sixteen of the 20 strains isolated were identified as $S$. anginosus, two as $S$. constellatus, and two as $S$. intermedius. The distribution of hemolytic patterns and Lancefield groups among the 20 isolates is shown in table 2 . Only five of 20 strains were $\beta$-hemolytic. while 10 were $\alpha$-hemolytic. Lancefield group $C$ accounted for eight isolates (40\%) and group $F$ for $7(35 \%)$; the remaining five strains (25\%) had no detectable Lancefield antigen. Of the seven isolates carrying Lancefield group $F$, only one (identified as $S$. constellatus) was $\beta$-hemolytic. No association was found between pattern of hemolysis, Lancefield group. and species on the one hand and associated site of infection and clinical history on the other.

Antimicrobial susceptibility: All strains exhibited predictable patterns of antimicrobial susceptibility (table 3 ). Three isolates had an MIC of $0.125 \mu \mathrm{g} / \mathrm{mL}$ for penicillin-a value equal to the breakpoint concentration for susceptibility. In terms of both the $\mathrm{MIC}_{90}$ and the $\mathrm{MIC}_{50}$, the activity of penicillin exceeded that of amoxicillin. The in vitro activity of ciprofloxacin against species of the $S$. milleri group was poor: $14(70 \%)$ of 20 strains had MIC values equal to the breakpoint concentration.

\section{Discussion}

Strains belonging to the $S$. milleri group are components of the endogenous flora of the mouth, the nasopharynx, the gastrointestinal tract. and the vagina [11]. Falling within the category of viridans streptococci, these strains, which encompass three species carrying four Lancefield groups and exhibiting three hemolytic patterns, are prone to misidentification [2.12]. Adding to the confusion was the development of two classification schemes-one European and the other American-from 1977 to 1987. The former included only one species (Streptococcus milleri), while the latter distinguished three species and has been the preferred scheme in commercial identification systems. From 1987 to 1991, all strains were unified under the species $S$. anginosus. Recently, Whiley and co-workers [3] offered an emended description of three species: $S$. anginosus. $S$. intermedius, and $S$. constellatus. It should be borne in mind that these recently established species do not always comprise the same strains as in the Facklam scheme [13]; for example, in the latter scheme $\beta$-hemolytic strains were categorized almost exclusively as $S$. anginosus [14], while in the new scheme they are usually classified as $S$. constellatus. The designation Streptococcus milleri is no longer formally approved but is still used-generally with quotation marks-because it has clinical significance.

In this study we reviewed 19 episodes of $S$. milleri bacteremia and characterized the 20 strains recovered from the blood during these episodes.

We considered the growth of an $S$. milleri species in one blood-culture bottle to be significant. This criterion is both highly sensitive and acceptably specific: comparison of episodes with single and multiple positive blood cultures revealed no differences in clinical presentation, mortality, or associated site of infection. Since no report has described the presence of $S$. milleri organisms on the skin [1], their isolation from blood cultures can hardly be attributed to skin contamination.

Although the clinical significance of $S$. milleri has recently been reviewed $[1,2,6,12,15,16]$, reports focusing on $S$. milleri bacteremia are rare and often anecdotal $[17,18]$. We compared our data with those from other series of consecutive isolates from episodes of bacteremia (table 4) [16. 19- 
Table 3. Antimicrobial susceptibility of $20 \mathrm{~S}$. milleri isolates from 19 episodes of bacteremia occurring over a 3-year period at the University Hospital of Maastricht.

\begin{tabular}{|c|c|c|c|c|c|}
\hline \multirow[b]{2}{*}{ Antimicrobial agent } & \multicolumn{3}{|c|}{$\mathrm{MIC}(\mu \mathrm{g} / \mathrm{mL})$} & \multirow{2}{*}{$\begin{array}{c}\text { Breakpoint } \\
\text { concentration } \\
(\mu \mathrm{g} / \mathrm{mL})\end{array}$} & \multirow{2}{*}{$\begin{array}{c}\text { Percentage } \\
\text { of isolates } \\
\text { susceptible at } \\
\text { breakpoint } \\
\text { concentration }\end{array}$} \\
\hline & $\mathrm{MIC}_{50}$ & $\mathrm{MKC}_{90}$ & MIC range & & \\
\hline Penicillin & 0.06 & 0.125 & $\leqslant 0.015-0.125$ & 0.12 & 100 \\
\hline Amoxicillin & 0.12 & 0.25 & $\leqslant 0.06-0.25$ & 0.12 & 70 \\
\hline Cefotaxime & 0.25 & 0.25 & $\leqslant 0.06-0.25$ & 8 & 100 \\
\hline Clindamycin & $\$ 0.06$ & 0.125 & $\leqslant 0.06-0.125$ & 0.5 & 100 \\
\hline Doxycycline & $\leqslant 0.25$ & 4 & $\leqslant 0.25-8$ & 4 & 90 \\
\hline Erythromycin & $\leqslant 0.25$ & $\leqslant 0.25$ & $\leqslant 0.25-\leqslant 0.25$ & 0.5 & 100 \\
\hline Gentamicin & 16 & 32 & $\leqslant 4-32$ & 4 & 10 \\
\hline Teicoplanin & $\leq 0.06$ & 0.125 & $50.06-0.125$ & 8 & 100 \\
\hline Vancomycin & 1 & 1 & $\leqslant 0.25-1$ & 4 & 100 \\
\hline Ciprofloxacin & 1 & 1 & $\leqslant 0.5-1$ & 1 & 90 \\
\hline
\end{tabular}

23]. S. milleri bacteremia is rare [1.6.20]. The incidence in the present study was similar to figures reported previously in the literature (table 5) [6,20,21,23]. The age distribution of our patients was Gaussian: the mean age ( 48.8 years) and the male-to-female ratio (2.8) were also similar to the figures previously reported (table 4) [1,22]. Compared with previously described patients, our patients had systemic underlying conditions with identical frequency $(\sim 60 \%)$; malignancy and immunosuppression were the most prevalent conditions. Local trauma appeared to be at least as important a predisposing factor: in the majority of past and present epi sodes of bacteremia, purulent infections were preceded by mucosal disruption, ulceration. or perforation; inflammation: or surgery [1, 19,20,22]. Endocarditis due to species of the $S$. milleri group was almost invariably associated with preexistent cardiac-valve abnormalities [16, 19, 21, 24].

The proclivity for abscess formation in $S$. milleri infection was first established by Parker and Ball [25]. Although notorious, this association is not invariable: Awada and coworkers [23], for example, found clear abscess formation in only one of eight patients. In our study, abscesses were documented in nearly half of patients: in contrast, data compiled from the literature indicated that one-quarter of episodes of bacteremia were associated with clear abscess formation (table 4). In particular, sites of empyema and liver abscesses are known to yield $S$. milleri at a high rate $[26-28]$.

The overall distribution of infectious foci associated with the reported episodes of bacteremia reffects the natural habitat of $S$. milleri. Abdominal infections accounted for $\sim 7 \%-$ $40 \%$ of all significant infections caused by $S$. milleri [12], and the gastrointestinal tract has been recognized as the most likely portal of entry for bacteremia-related strains [20]. $S$. milleri is often isolated after gastrointestinal surgery, colonic perforation, or appendectomy [1.21]. Hepatic abscesses due to $S$. milleri have been described after gastrointestinal perfo- ration in Crohn's disease, perirectal abscesses. carcinoma of the colon, and abdominal surgery [26].

Tresadern and co-workers [29] postulated that prophylactic antibiotic regimens lacking activity against $S$. milleri (such as the combination of gentamicin and metronidazole) may promote the emergence of $S$. milleri as a significant pathogen in patients who have undergone abdominal surgery. In our series, this regimen was given to only one patient (episode 10).

Intrathoracic infection represents the second important source of bacteremia: the infection arose from an esophageal fistula and leakage-a source that has been described previously-in episodes 4 and $7 \mid 19.20]$. Another route is aspiration, which was documented in episodes 11 and 18. Aspiration pneumonia with $S$. milleri as part of the offending flora is known to be associated with the complications of pleural empyema and lung abscess $[22,30,31]$.

No case of endocarditis due to $S$. milleri was found in our group. In contrast. in the series revicwed. S. milleri accounted for $8 \%$ of cases of viridans streptococcal endocarditis [16], and endocarditis was documented in the majority of episodes of bacteremia. "The lack of endocarditis in our series might have been attributable to the fact that our hospital is a referral center; thus most cascs of endocarditis are diagnosed bacteriologically in hospitals elsewhere in our region. This finding may also have been related to the decreasing incidence of preexisting valvular discase among patients at our hospital.

A high incidence of suppurative metastatic lesions has been reported in $S$. milleri infections, including vertebral osteomyelitis and abscess formation in liver. joints. myocardium, and spleen $[16,21,32]$. Reports on obstetric infections with $S$. milleri are anecdotal $[11,15.17]$. Sott-tissue infections accounted for onc-quarter of episodes of bacteremia in one study [22]. and the affinity of this group of organ- 
Table 4. Clinical and microbiological findings for previously reported series of episodes of $S$. milleri bacteremia.

\begin{tabular}{|c|c|}
\hline Finding* [references] & Value \\
\hline \multicolumn{2}{|l|}{ Demographic characteristics $(n=24)[19-21]$} \\
\hline \multicolumn{2}{|l|}{ Age: $y$} \\
\hline Mean $\pm \mathrm{SD}$ & $46.7 \pm 20.6$ \\
\hline Median & 49.5 \\
\hline Range & $3-88$ \\
\hline Male-torfemale ratio & $3: 1$ \\
\hline \multicolumn{2}{|l|}{ Underlying condition: $/(n=26)[19-21]$} \\
\hline Present & 61.5 \\
\hline Not demonstrated & 38.5 \\
\hline \multicolumn{2}{|l|}{ Associated site/type of infection: $8(n=60)[16.19-23]$} \\
\hline Endocarditis & 18.3 \\
\hline Sinus/oral cavity & 8.3 \\
\hline Lung & 6.6 \\
\hline Liver/biliary tract & 15.0 \\
\hline Urogenital tract & 5.0 \\
\hline Abdominal/pelvic cavity & 11.6 \\
\hline Bonc/soft tissues & 11.6 \\
\hline Gastrointestinal tract & 8.3 \\
\hline "No associated site of infection" & 15.0 \\
\hline Abscess formation: $5(n=60)[16,19-23]$ & 26.7 \\
\hline \multicolumn{2}{|l|}{ Outcome: 5 mean age $(n=26)[19-21]$} \\
\hline Death & $30.7,66.5 \mathrm{y}$ \\
\hline Recovery & $69.3 .39 .5 \mathrm{y}^{\dagger}$ \\
\hline Presence of associated organisms: $c(n=24)[19,22,23]$ & 41.7 \\
\hline \multicolumn{2}{|l|}{ Growth characteristics: no. of isolates $(n=18)[19,21]$} \\
\hline \multicolumn{2}{|l|}{ Lancefield group } \\
\hline $\mathrm{F}$ & 7 \\
\hline None & 5 \\
\hline No data provided & 6 \\
\hline \multicolumn{2}{|l|}{ Henolytic pattem } \\
\hline$\alpha$ & 10 \\
\hline$\beta$ & I \\
\hline$\gamma$ & 6 \\
\hline No data provided & 1 \\
\hline
\end{tabular}

- Numbers in parentheses indicate number of cases from which informa tion was available. Units of measure are shown for each category.

${ }^{+} P<.05$ vs. mean age of patienis who died.

isms for bones and joints has been emphasized [33]. Although a definite focus of infection could not be ascertained in a considerable proportion ( $15 \%$ ) of reported episodes of bacteremia, this was true for only one of the episodes in our study (episode 12). Multiple organ failure complicated bacteremia in only one instance (episode 8), and even in that instance might have been attributable to concomitantly isolated gram-negative organisms

The antimicrobial susceptibility patterns of the strains in our study conformed to those previously reported [19.3437]. Little information is available on the tolerance of $S$. milleri to penicillin: in vitro synergism between aminoglycosides and penicillins has been reported once [38]. From the present series, it is clear that surgery constitutes the cornerstone of effective treatment when abscesses are present. En- doscopic, transcutaneous, or surgical drainage can be used, depending on the clinical situation. Two of our patients (episodes 13 and 19) recovered with surgical treatment only, but the experience of other investigators indicates that long-term antibiotic therapy should be used in conjunction with surgery [29]. To our knowledge, no clinical evidence that proves the benefit of adding an aminoglycoside to a penicillin regimen exists.

The clinical outcome of $S$. milleri bacteremia varies with the group of patients considered. The mortality rate in the present study (26.3\%) corresponds with figures reported in unselected populations of patients $(30.7 \%)$. Both in our group and in previously reported series, the risk of death increased with age. The relation of outcome to underlying conditions was not statistically significant either in the present study or in previously reported series. Whether $S$. milleri bacteremia contributed to the death of a patient often remained conjectural, especially in the presence of severe underlying conditions and associated surgical pathology (e.g.. episodes 7 and 10). Apart from those who died, several patients in our series (episodes 7, 13.14. and 19) and in previously reported studies [20] developed significant morbidity due to frequently severe focal complications.

little information is available on the growth characteristics of $S$. milleri in blood cultures. A mean detection time of 1.9 days was previously reported for $\beta$-hemolytic streptococci of Lancefield group F [20]. In contrast, the detection time in our study was twice as long. with recovery of the organism only after 6 days in three episodes and only on terminal subculture in two episodes. Polymicrobial infection of the blood was reported more frequently in other studies than in ours: in previous investigations the other organisms isolated included $S$. aurets (three cases), anaerobes (five cases), Enterobacteriaceae (four cases), other streptococci (two cases), and Eikenella corrodens (one case). The distributions of hemolytic patterns and species among our 20 blood isolates was roughly the same as among the 200 strains of $S$. milleri consecutively isolated from various other clinical specimens in our laboratory during the same period: the majority of these strains were identified as $S$, anginosus and displayed no $\beta$-hemolysis. However, strains belonging to Lancefield group $C$ accounted for only $10 \%$ of the latter group. while they represented 40 \% of isolates from blood

The limited number of blood isolates and the high preponderance of $S$ anginosus among these isolates meant that it was difficult to identify meaningful associations between species and their growth characteristics on the one hand and specific sources of infection and clinical presentations on the other. The sole published report on the ecology of the three species of the $S$. milleri group in clinical specimens [39] noted associations of $S$. intermedius with infections involving the CNS, S. anginosus with infections of the gastrointestinal and genitourinary tracts, and $S$. constellatus with infections 
Table 5. Incidence of $S$. milleri bacteremia, as reported or calculated from available data.

\begin{tabular}{|c|c|c|c|c|}
\hline Years & Hospital, country & $\begin{array}{l}\text { Relative } \\
\text { incidence* }\end{array}$ & $\begin{array}{c}\text { Overall } \\
\text { incidence }^{\dagger}\end{array}$ & Reference \\
\hline $1986-1988$ & Cancer hospital, Belgium & 1.4 & 0.54 & $23]$ \\
\hline $1978-1988$ & General hospital, United Kingdom & 1.1 & $\mathrm{ND}^{\ddagger}$ & [21] \\
\hline Early 1980 s (4-year period) & General hospital, Belgium & $1-2$ & 0.17 & {$[6]$} \\
\hline $1970-1980$ & Mayo Clinics. United States & $0.05^{\$}$ & ND & {$[20]$} \\
\hline $1990-1992$ & Tertiary-care hospital, The Netherlands & 1.5 & 0.33 & Present report \\
\hline
\end{tabular}

* Percentage of all episodes of bacteremia.

+ Percentage of admissions.

* No data available.

\$Includes only $\beta$-hemolytic strains belonging to Lancefield group $F$.

of the respiratory tract. The strains isolated from obstetric infections in our study (episodes 2 and 6) did not belong to the broadly fermentative biotype of $S$. milleri that has been recognized as an inhabitant of the female genital tract [39. 40].

In summary, in this study, $S$. milleri bacteremia was a rare event that occurred in all age groups and aflected more male than female patients. Local trauma to the mucosal barrier preceded bacteremia in the vast majority of cases. Abscesses were documented in nearly half of patients and often required repeated drainage. The heterogeneity of organisms designated as $S$. milleri was confirmed, as was the potential for their fastidious grow th to delay their recovery from blood cultures. $S$. anginosus was the most frequently identified species. and most isolates were either $\alpha$-hemolytic or nonhemolytic. The large proportion of strains belonging to Lancefield group $\mathrm{C}$ was remarkable. The antimicrobial susceptibilities of the strains were consistent with previously reported patterns. $S$. milleri did not meet all the criteria for an opportunistic pathogen but did cause high mortality and significant morbidity.

\section{Acknowledgment}

The authors thank Dr. R. Whiley of the London Hospital Medical College for his help in identification of the strains.

\section{References}

1. Gossling J. Occurrence and pathogenicity of the Sireptococcus milleri group. Rev Infect Dis 1988: 10:257-85.

2. Ruofl KL. Sireptococcas anginosus ("Sireptococas milleri"): the unrecognized pathogen. Clin Microbiol Rev 1988: 1:102-8.

3. Whiley RA. Beighton D. Emended descriptions and recognition of Strepococcus constedlanus, Streprococcus intermedius, and Streprococcus anginosus as distinct species. Int J Syst Bacteriol 1991:41: J-5.

4. Poole PM. Wilson G. Infection with minute-colony-forming $\beta$-haemolytic streptococci. J Clin Pathol 1976:29:740-5.

5. Whitworth JM. Lancefield group $F$ and related streptococci. I Med Microbiol 1990; 33:135-51

6. Van der Auwera P. Clinical significance of Streptococcus milleri. Eur J Clin Microbiol 1985:4:386-90.
7. Lennette EH, Balows A, Hausler WJ Jr. Shadomy HJ eds. Manual of clinical microbiology. 4th ed. Washington. DC: American Society for Microbiology, 1985.

8. Ruoff KL. Kunz LJ. Ferraro MJ. Occurrence of Streplococcus milleri among beta-hemolytic streptococci isolated from clinical specimens. J Clin Micrubiol 1985;22:149-51.

9. Smith RF. Willett NP. Rapid plate method for screening hyaluronidase and chondroitin sulfatase-producing microorganisms. Appl Microbiol 1968: 16:1434-6.

10. National Committee for Clinical Laboratory Standards. Methods for dilution antimicrobial susceptibility test for bacteria that grow aerobically. M7-T2. Approved standard. Villanova. Pennsylvania: National Committee for Clinical Laboratory Standards. 1990.

11. Poole PM. Wilson G. Occurrence and cultural features of Streptococcus milleri in various body sites. J Clin Pathol 1979:32:764-8.

12. Piscitelli SC, Shwed J. Schreckenberger P. Danziger LH. Streplococcus milleri group: renewed interest in an elusive pathogen. Eur J Clin Microbiol Infect Dis 1992: 11:491-8.

13. Whiley RA. Fraser H. Hardie JM. Beighton D. Phenotypic differentiation of Streplocorcus intermedius. Sireptococcus constellatus. and Streprococus anginosus strains within the "Sireptococcus milleri" group. J Clin Microbiol 1990;28:1497-501.

14. Facklam RR. The major differences in the American and British Streprococcus taxonomy schemes with special reference to Streprococcus milleri [editorial]. Eur J Clin Microbiol 1984:3:91-3.

15. Miller SD. Mauff AC: Koornhof HJ. Sireptococcus milleri causing infection in man. S Afr Med J 1983:63:684-6.

16. Murray HW. Gross KC. Masur H. Roberts RB. Serious infections caused by Streptococcus milleri. Am J Med 1978:64:759-64.

17. Cox RA. Chen K. Coykendall AL. Wesbecher P. Herson VC. Fatal infection in neonates of 26 weeks gestation due to Strepiococcus milleri: repon of two cases. J Clin Pathol 1987:40:190-3.

18. Rich MW. Radwany SM. "Streprococcus milleri" septicemia in a patient with colorectal carcinoma [letter]. Eur J Clin Microbiol Infect Dis 1993: 12:225.

19. Shlaes DM, Lerner PI. Wolinsky E. Gopalakrishna KV. Infections due so Lancefield group $F$ and related streptococci (S. milleri. S. anginosus). Medicine (Baltimore) 1981:60:197-207.

20. Libertin CR. Hermans PE. Washington JA II. Beta-hemolytic group $F$ streptococcal bacteremia: a study and review of the literature. Rev Infect Dis 1985: 7:498-503.

21. Barnham $M$. Invasive streptococcal infections in the era before the acquired immune deficiency syndrome: a 10 years' compilation of patients with streptococcal bacteremia in North Yorkshire. J Infect 1989: 18:231-48.

22. Spertini F. Baumgartner J-D. Bille J. Spectre clinique d'un pathogène 
commun et insidieux: le Streptococcus milleri. Schweiz Med Wochenschr 1988: 118:1393-7

23. Awada A. Van der Auwera P. Meunier F. Daneau D. Klastersky J. Streptococcal and enterococcal bacteremia in patients with cancer. Clin Infect Dis 1992; 15:33-48.

24. Barham NJ. Flint EJ. Mifsud RP. Osteomyelitis complicating Sireprococcus milleri endocarditis. Postgrad Med J 1990;66:314-5

25. Parker MT, Ball LC. Streptecocci and aerococci associated with systemic infection in man. J Med Microbiol 1976:9:275-302.

26. Chua D. Reinhart HH, Sobel JD. Liver abscess caused by Sireprecoccus milleri. Rev Infect Dis 1989:11:197-202.

27. Gelfand MS. Hodgkiss T. Simmons BP. Multiple hepatic abscesses calused by Streptococcus milleri in association with an intrauterine device. Rev Infect Dis 1989;11:983-7.

28. Frankish PD. Kulbe J. Thoracic empyema due to Streptococcus milleri: four cases. N Z Med J 1984: 97:849-51.

29. Tresadern JC. Farrand RJ, Irving MH. Streptococcus milleri and surgical sepsis. Ann R Coll Surg Engl 1983:65:78-9.

30. Brook MC;. Lucas RE. Pain AK. Clinical features and management of two cases of Streptococcus milleri chest infection. Scand J Infect Dis 1988:20:345-6.

31. Plump DH. Haponik EF. Streptecoccus milleri empyema. South Med J 1983;76:132I-2.

32. Levandowski RA. Sireptococcus milleri endocarditis complicated by myocardial abscess. South Med J 1985:78:892-3.
33. Meyes E. Flipo R-M, Van Bosterhaut B, Mouligneau G, Duquesnoy B. Delcambre B. Septic Sireptococcus milleri spondylodiscitis. J Rheumatol 1990;17:1421-3

34. Tillotson GS, Ganguli LA. Antibiotic susceptibilities of clinical strains of Sireptococcus milleri and related streptococci [letter]. J Antimicrob Chemother 1984:14:557-8.

35. Bourgault A-M. Wilson WR. Washington JA II. Antimicrobial susceptibilities of species of viridans streptococci. J Infect Dis 1979: 140:316-21.

36. Le Pennec MP, Berardi-Grassias L. In-vitro activity of 13 antibiotics against clinical isolates of Streptococcus milleri [letter]. J Antimicrob Chemother 1989:24:618-9.

37. Teixeria LM. Facklam RR. Susceptibility of Streplococcus milleri-like strains to 16 antimicrobial agents [abstract no A4]. In: Proceedings of the annual meeting of the American Society for Microbiology. Washington. DC: American Society for Microbiology. 1985:1.

38. Francioli P. Moreillon P. Glauser MP. Comparison of single doses of amoxicillin or of amoxicillin-gentamicin for the prevention of endocarditis caused by Streptococcus faecalis and by viridans streptococci. $J$ Infect Dis 1985: 152:83-9.

39. Whiley RA. Beighton D. Winstanley TG. Fraser HY, Hardie JM. Strep tococcus intermedius. Streptococcus constellatus. and Streptococcus an gimosus (the Streprococcus milleri group): association with different body sites and clinical infections. J Clin Microbiol 1992; 30:243-4.

40. Peck G. Coe PR. Allen JB. Fatal infection in neonates caused by $S$ milleri [letter]. J Clin Pathol 1987:40:1386. 
Streptococcus anginosus, Streptococcus constellatus and Streptococcus intermedius. Clinical relevance, hemolytic and serologic characteristics 


\title{
Streptococcus anginosus, Streptococcus constellatus and Streptococcus intermedius Clinical Relevance, Hemolytic and Serologic Characteristics
}

\author{
JAN A. JACOBS, MD, ${ }^{1}$ HENK G. PIETERSEN, MD, ${ }^{2}$ ELLEN E. STOBBERINGH, PHD, ${ }^{1}$ \\ AND PETER B. SOETERS, PHD ${ }^{2}$
}

\begin{abstract}
A collection of 518 "Streptococcus milleri" isolates recovered from clinical specimens was identified to the species level according to recently established criteria. Streptococcus anginosus was the most frequently isolated species $(59.3 \%)$, followed by $S$ constellatus $(30.3 \%)$ and $S$ intermedius $(10.4 \%)$. One third (34\%) of all isolates were $\beta$-hemolytic. The majority of $S$ anginosus isolates were nonhemolytic, carried Lancefield group $\mathrm{F}$, or were nongroupable. Mast of the $S$ constellatus isolates were $\beta$-hemolytic, as well as $16.6 \%$ of $S$ intermedius strains. Streptococcus anginosus was recovered more often from the
\end{abstract}

genital and urinary tracts and $S$ constellatus was recovered from the thorax. Streptococcus intermedius was mostly found in the head and neck area, but was also isolated from the abdomen and the skin, bone, and soft tissue. Streprococcus intermedius and nonhemolytic isolates were recovered most often from abscess-related specimens. (Key words: Streptococcus milleri; Streptococcus anginosus; Streptococcus constellatus; Streptococcus intermedius; Infection; Identification; Clinica: relevance) Am J Clin Pathol 1995: 104:547-553.
Strains belonging to the "Streptococcus milleri" group form a heterogeneous group within the viridans streptococci. They encompass organisms listed in the 1986 edition of Bergey's Manual ${ }^{1}$ as $S$ anginosus, Streptococcus $M G$, S constellatus, Sintermedius, "S milleri, "and minute $\beta$-hemolytic streptococci of Lancefield groups $\mathrm{F}$ and $\mathrm{G}^{2}$. Although the name "Streptococcus milleri" is not included in the approved lists of bacterial names, ${ }^{3}$ the term remains popular because it conveys clinical significance. It refers to those viridans streptococci that may be associated with abscesses or other purulent infections. ${ }^{4}$

Recent molecular studies clarified taxonomic relationships within the "Streptococcus milleri" group and Whiley and coworkers ${ }^{5}$ redefined three species: $S$ anginosus, $S$ constellatus and $S$ intermedius. In addition, they developed biochemical tests that allow for phenotypic differentiation between the three species. ${ }^{6}$

In this study, we were interested in the clinical relevance of the three species within the "S milleri" group. We retrospectively identified a collection of 518 " $\mathrm{S}$ mil-

From the Department of ${ }^{1}$ Medical Microbiology and ${ }^{2}$ Surgery, University Hospital of Maastricht. Maastricht. the Netherlands

Manuscript received February 28. 1995; revision accepted May 30. 1995.

Address reprint requests to Dr. Jacobs: Department of Medical Microbiology, University Hospital of Maastricht, P.O. Box $5800.6202 \mathrm{AZ}$ Maastricht, the Netherlands. leri" isolates to the species according to Whiley and coworkers. ${ }^{6}$ The collection consisted of mainly consecutive isolates from clinical specimens. We tried to establish possible associations between the distinct species, their anatomic distribution, and the relation with infection and abscesses. In addition, we described the hemolytic and serologic characteristics of the three species.

\section{MATERIALS AND METHODS}

The streptococci studied were collected over a period of almost 3 years (July 1991-June 1994), and were consecutively recovered from clinical specimens routinely submitted for culture at the microbiological laboratory of the University Hospital of Maastricht (azM), a 600. bed tertiary care center. Streptococci were grown on blood agar base (Oxoid, Basingstoke, UK) containing 5\% (v/v) sheep blood and on the same plates supplemented with nalidixic acid $(5 \mathrm{mg} / \mathrm{L})$ and polymixin $\mathrm{B}(10 \mathrm{mg} / \mathrm{L})$. These plates were incubated in a $\mathrm{CO}_{2}$-enriched atmosphere and inspected for growth after 1 and 2 days. Blood was cultured with a conventional biphasic aerobic/anaerobic blood culture system (Vacutainer, Becton Dickinson, Sparks, MD) during the first year of the study, and thereafter with an infrared $\mathrm{CO}_{2}$-detection system (Bactec 9240. Becton Dickinson).

Streptococcal colonies were selected for further identification if they were grown in any quantity from nor- 
mally sterile body fluids or when they were recovered in moderate, predominant, or pure culture from other specimens. Colonies were selected regardless of their hemolytic behavior. They were identified to the "Streptococcus viridans" level by colony morphology, negative catalase reaction, sensitivity to vancomycin, resistance to bacitracin $(0.04 \mathrm{U})$ and optochin-coated disks, and a negative reaction in the bile-esculin test. They were identified and reported as "Streptococcus milleri" if they produced acetoin in the Voges-Proskauer (VP) test with the Coblentz test method, ${ }^{7}$ hydrolyzed arginine (method according to Moeller ${ }^{7}$ ), and failed to use sorbitol (Rosco Diagnostica, Taastrup, Denmark).

The isolates were stored at $-70^{\circ} \mathrm{C}$ on porous beads in cryopreservative (Microbank, Pro-Lab Diagnostics, Richmond Hill, Ontario, Canada). Before inclusion in the study, they were retrieved and the identification was confirmed with the API 20 Strep system supplied with the database 4.0 (bioMérieux, Marcy-l'Etoile, France). Hemolysis was assessed by observation of the subsurface growth in sheep blood agar plates. ${ }^{7}$ Both $\alpha$ - and $\beta$-hemolysis were recorded as "nonhemolytic." Lancefield grouping was performed on all isolates (Streptex, Wellcome Diagnostics, Dartford, UK).

Assignment of strains to either $S$ anginosus, $S$ constellatus, or $S$ intermedius was determined by the identification scheme described by Whiley and coworkers. ${ }^{6}$ Briefly, strains were tested for production of $\alpha$-galactosidase, $\beta$-galactosidase, $\alpha$-glucosidase, $\beta$-glucosidase, $N$ acetyl- $\beta$-D-galactosaminidase, $N$-acetyl- $\beta$-D-glucosaminidase, sialidase and $\beta$-D-fucosidase by using 4-methylumbelliferyl-linked fluorogenic substrates (Sigma, St. Louis, MO) in flat-bottomed microtiter plates (Hospidex. Nieuwkoop, the Netherlands). Hyaluronidase production was assessed by the rapid plate method of Smith and Willett. ${ }^{8}$ Reference strains were the type strains of the three species: $S$ anginosus: ATCC 33397 , S constellatus: ATCC 27823 and S intermedius: ATCC 27335. Reproducibility of the identification method was assessed by testing five isolates on 5 consecutive days.

Strains isolated from brain abscesses $(n=9)$, blood ( $n$ =9) and other body parts (abdomen: 9; oral cavity: 3; skin and soft tissues: 3 ; genital tract: 1 ; and thoracic cavity: 8) were kindly provided by Dr. J. Verhaegen (University Hospital, Leuven, Belgium) and Dr. M. Visser (University Hospital, Utrecht, the Netherlands). In both laboratories, methods for isolation were similar to those used in the azM. The identification of these isolates was confirmed by the API 20 Strep system before they were included in the collection.

Strains were assigned to one of the following broad anatomic categories: (1) head and neck (including the oral cav- ity); (2) thoracic cavity (including the respiratory tract); (3) abdomen; (4) genital tract; (5) urinary tract; (6) skin, bone and soft tissues; and (7) blood. Isolates recovered from neonatal skin cultures or neonatal gastric aspirates were separately classified. According to Centers for Disease Control and Prevention (CDC) definitions, ${ }^{9}$ isolates were considered infection-related based on the opinion of the clinician treating the patient. Specimens obtained from abscesses were separately recorded. If clinical evidence was not conclusive or if the specimen might have been contaminated by saprophytic flora, the culture result was labelled as of questionable significance.

One isolate per species per patient was included, unless the isolates differed in hemolytic pattern or Lancefield group or unless they were recovered from distinctive body sites. The accompanying flora recovered with the "S milleri" strains was recorded. For statistical evaluation, proportions were compared by means of the chisquare test.

\section{RESULTS}

During the study period, 561 isolates were collected. Eleven isolates were no more viable at retrieval. The API 20 Strep system did not confirm another 32 isolates as " $S$ milleri." The profiles of 16 of these strains corresponded with unacceptable identifications or identifications of low probability. Among the other 16 strains, profiles coding for $S$ sanguis $(\mathrm{n}=5)$ and Lactococcus spp. were noted. The final collection consisted of 518 isolates. The method of Whiley and coworkers proved to be reproducible. When tested with this method, $294(56.8 \%)$ isolates fit the identification scheme exactly. One hundred eighty $(34.7 \%)$ were identified to within 1 test reaction. Most of them $(n=128)$ were $S$ anginosus isolates that produced $\beta$-galactosidase. More than half of these isolates were recovered from the urogenital tract or from neonates. Isolates that differed in two or three test results from the method of Whiley and coworkers ${ }^{6}$ were assigned to the species on the basis of those tests reported as $100 \%$ positive for a particular species. These isolates $(\mathrm{n}=44,8.5 \%)$ were mostly designated as $S$ constellatus and Sintermedius.

Information on age and gender was available in 511 isolates. These isolates were recovered from 483 patients. Two distinct isolates recovered from the same culture specimen were seen in nine patients. In 19 patients, isolates of the same species were recovered from distinct body sites: among them, 11 blood culture isolates with corresponding focus-related strains. Overall, the mean age ( \pm standard deviation [SD]) of the patient population was $46.7 \pm 22.2$ years, ranging from 1 day to 92 years. The mean age for males was $46.9 \pm 20.3$ years (range 1 
$S$ anginosus, $S$ constellatus and $S$ intermedius

TABLE 1. DEMOGRAPHIC DATA ACCORDING TO CLINICAL SIGNIFICANCE OF THE ISOLATES*

\begin{tabular}{|c|c|c|c|c|c|c|}
\hline \multirow[b]{2}{*}{ Age Group (yr) } & \multicolumn{2}{|c|}{ Questionable } & \multicolumn{2}{|c|}{ Infection-rclated } & \multicolumn{2}{|c|}{ Abscess-related } \\
\hline & Male & Female & Male & Female & Male & Female \\
\hline $0-9$ & 5 & 13 & 3 & 3 & 1 & 4 \\
\hline $10-19$ & 9 & 4 & 2 & 3 & 11 & 4 \\
\hline $20-29$ & 7 & 20 & 7 & 7 & 17 & 8 \\
\hline $30-39$ & 9 & 24 & 18 & 10 & 17 & 8 \\
\hline $40-49$ & 11 & 12 & 11 & 5 & 15 & 9 \\
\hline $50-59$ & 19 & 11 & 13 & 6 & 15 & 10 \\
\hline $60-69$ & 17 & 16 & 12 & 7 & 10 & 6 \\
\hline $70-79$ & 12 & 27 & 11 & 3 & 10 & 7 \\
\hline$>80$ & 4 & 9 & 1 & 4 & 2 & 2 \\
\hline Total & 93 & 136 & 78 & 48 & 98 & 58 \\
\hline Mean & 49.3 & 47.6 & 47.5 & 16.1 & 44.3 & 45.1 \\
\hline $\mathrm{SD}$ & 21.8 & 25.4 & 19.8 & 22.6 & 19.3 & 21.2 \\
\hline Median & 53 & 45 & 49 & 44 & 44 & 43 \\
\hline Male to female ratio & \multicolumn{2}{|c|}{$1: 1.5$} & \multicolumn{2}{|c|}{$1: 0.6$} & \multicolumn{2}{|c|}{$1: 0.6$} \\
\hline
\end{tabular}

- From seven isolates no data were available.

day-87 years), and for females, $46.4 \pm 24.2$ years (range 1 day-92 years). The demographic data according to the clinical significance of the isolates are listed in Table 1.

Table 2 represents the anatomic distribution of the strains with the clinical category they were assigned to. The head and neck area included. 13 isolates recovered from the central nervous system (CNS): 12 isolates from brain abscesses and 1 from subdural empyema. The highest proportion of abscess-related isolates was found in the abdomen. These isolates were frequently recovered from abscesses in the anal region $(n=19)$ or related to appendicitis $(n=13)$. The urinary and genital tracts accounted for a majority of strains with questionable clinical significance. Most strains from the thorax group were isolated in mixed cultures from sputum specimens and not considered infection related. Among abscesses in the skin, bone and soft tissue group, eight subcutaneous abscesses in intravenous drug abusers were included.

The results of the species identification, the hemolytic reaction, and Lancefield group are listed in Table 3 . The relative proportions of the three strains were not affected when the isolates provided by the other laboratories were subtracted. $\beta$-hemolytic strains carried more frequently a Lancefield antigen than the nonhemolytic strains $(P<.001)$, particularly groups $\mathrm{C}$ and $\mathrm{G}$. The majority of strains identified as $S$ anginosus were nonhemolytic, and they were nongroupable or belonged to Lancefield group F. Although only $23(7.5 \%)$ of $S$ anginosus strains carried group $\mathrm{G}$, they encompassed the majority 123 of 26 , $88.5 \%)$ of the strains carrying this Lancefield group. The majority of $\beta$-hemolytic strains ( 117 of $176,66.5 \%$,) were identified as $S$ constellatus. Although most isolates identified as $S$ intermedius were nonhemolytic, a proportion ( 9 of $54,16.7 \%$ ) displayed $\beta$-hemolysis.

Table 4 represents the anatomic distribution of the three species, matched with their Lancefield group. The genital and urinary tracts most frequently harbored $S$ anginosus $(P<.001)$, whereas proportionally more $S$ constellatus strains were recovered from the thorax $(P<.001)$. The highest proportion of $S$ intermedius

TABLE 2. ANATOMICAL DISTRIBUTION OF THE S MILLERI STRAINS IN RELATION TO CLINICAL SIGNIFICANCE

\begin{tabular}{|c|c|c|c|c|}
\hline Anatomic Site & Questionable & Infection-related & Abscess-related & Total $(\%)$ \\
\hline Abdomen & 31 & 55 & 75 & $161(31.1)$ \\
\hline Head and neck & 22 & 12 & 32 & $66(12.7)$ \\
\hline Thorax & 69 & 7 & 6 & $82(15.8)$ \\
\hline Skin, bone, and soft tissues & 13 & 16 & 26 & $55(10.6)$ \\
\hline Blood & 0 & $2 !$ & 15 & $36(6.9)$ \\
\hline Genital tract & 47 & 8 & 4 & $59(11.4)$ \\
\hline Neonate & 11 & 2 & 0 & $13(2.5)$ \\
\hline Total $\left({ }^{(1)}\right)$ & $229(44.2)$ & $121(23.3)$ & $168(32.4)$ & 518 \\
\hline
\end{tabular}


TABLE 3. SPECIES DISTRIBUTION, HEMOLYTIC REACTION, AND LANCEFIELD GROUP OF THE $S$ MILLERI ISOLATES

\begin{tabular}{|c|c|c|c|c|c|c|c|}
\hline \multirow[b]{2}{*}{ Hemolysis } & \multicolumn{2}{|c|}{ S anginosus } & \multicolumn{2}{|c|}{$S$ constellatus } & \multicolumn{2}{|c|}{$S$ intermedius } & \multirow[b]{2}{*}{ Total $(\%)$} \\
\hline & - & + & - & + & - & + & \\
\hline \multicolumn{8}{|c|}{ Lancefield group } \\
\hline A & 2 & 0 & 0 & 1 & 0 & 0 & $3(0.6)$ \\
\hline$C$ & 18 & 22 & 0 & 14 & 2 & 4 & $60(11.6)$ \\
\hline $\mathrm{F}$ & 144 & 3 & 7 & 75 & 18 & 2 & $249(48.1)$ \\
\hline$G$ & 9 & 14 & l & 2 & 0 & 0 & $26(5.0)$ \\
\hline Nogroup & 84 & 11 & 32 & 25 & 25 & 3 & $180(34.7)$ \\
\hline Subtotal & 257 & 50 & 40 & 117 & 45 & 9 & 518 \\
\hline Total (\%) & \multicolumn{2}{|c|}{$307(59.3)$} & \multicolumn{2}{|c|}{$157(30.3)$} & \multicolumn{2}{|c|}{$54(10.4)$} & \\
\hline
\end{tabular}

strains were found in the head and neck area $(P<.001)$, with 9 of 13 strains isolated from the CNS identified as $S$ intermedius (the other central nervous system strains were identified as Sanginosus: $[\mathrm{n}=1$ ] and $S$ constellatu. $[n=3])$. Three isolates recovered from liver absccsses were identified as $S$ anginosus $(\mathrm{n}=2)$ and $S$ intermedius $(n=1)$. $\beta$-hemolytic strains were most frequently found in the thorax $(P<.001)$, nonhemolytic strains were most prevalent in the genital tract $(P<.001)$, the urinary tract $(P<.05)$ and the blood $(P<.05)$. Strains carrying Lancefield group $C$ were proportionally more often recovered from the blood $(P<.05)$.

From the three species, $S$ intermedius was more often recovered from infections and abscesses $(P<.001$. Table 5). Nonhemolytic isolates were more associated with infections and abscesses than $\beta$-hemolytic strains $(P<.001)$. No relationship could be established between Lancefield group and clinical significance.

Information on accompanying flora was available for 133 of the abscess-related isolates. In 83 (62.4\%) abscesses, accompanving flora was present. Members of the Enterohacteriaceas (with a marked predominance of
Escherichia coli) accounted for nearly half (48.7\%) of the accompanying organisms, and anaerobes accounted for $27.7 \%$. Abscesses with polymicrobial flora were found more often in the abdomen (57 of $68, P<.001$ ). "Streptococcus milleri" was recovered more frequently in pure culture from abscesses in the head and neck area ( 9 of $2 \mathrm{I}, P<.05$ ) and in the skin, bone, and soft tissues ( 9 of $25, P<05)$. Coinfection with more than one "S milleri" strain occurred in two abscesses.

\section{DISCUSSION}

Strains belonging to the "S milleri" group have been resistant to uniform classification and unequivocal nomenclature until recently. Two classification schemes cocxisted from 1977 to 1987: a British scheme that unified all strains into the spccics "S milleri" ican scheme (from Facklam at the $C D C^{\prime \prime}$ ) that distinguished between three species, that were named (in the final version), S anginosus, Sconstellatus, and Sintermedius. From 1987 to 1991 , all strains were considered to belong to one single species, $S$ anginosus." Recently,

TABLE 4. ANATOMICAL DISTRIBUTION OF THE $S$ MILLERI SPECIES IN RELATION TO LANCEFIELD GROUP

\begin{tabular}{|c|c|c|c|c|c|c|c|c|c|c|c|c|c|}
\hline \multirow[b]{2}{*}{ Anatomic Site } & \multicolumn{5}{|c|}{ S anginosus $(\mathbf{n}-307)$} & \multicolumn{5}{|c|}{$\mathbf{S}$ constellatus $(\mathbf{n}=157)$} & \multicolumn{3}{|c|}{$\begin{array}{l}S \text { intermedius } \\
(\mathbf{n}=54)\end{array}$} \\
\hline & $A$ & C. & $F$ & $G$ & NG & $A$ & $C$ & $F$ & $G$ & $N G$ & C & $F$ & NG \\
\hline Abdomen & 1 & 18 & 48 & 10 & 27 & 0 & 2 & 20 & 0 & 14 & 2 & 11 & 8 \\
\hline Head and neck & 1 & 2 & 7 & 4 & 3 & l & 2 & 16 & 0 & 15 & 1 & 4 & 10 \\
\hline Thorax & 0 & II & 5 & 3 & 14 & 0 & 6 & 24 & 1 & 14 & 2 & 0 & 2 \\
\hline Skin, bone, and soft tissues & 0 & 2 & 15 & 2 & 9 & 0 & 1 & 11 & 1 & 6 & 0 & 4 & 4 \\
\hline Blood & 0 & 7 & 14 & 1 & 3 & 0 & 1 & 3 & 0 & 2 & 1 & 0 & 4 \\
\hline Genital tract & 6) & 0 & 30 & 1 & 19 & 0 & 1 & 4 & 1 & 3 & 0 & 0 & 0 \\
\hline Urinary tract & 0 & 0 & 21 & 2 & 15 & 0 & 1 & 4 & 0 & 2 & 0 & 1 & 0 \\
\hline Neonate & 0. & 0 & 7 & 0 & 5 & 0 & 0 & 0 & 0 & 1 & 0 & 0 & 0 \\
\hline Total & 2 & 40 & 147 & 23 & 95 & 1 & 14 & 82 & 3 & 57 & 6 & 20 & 28 \\
\hline
\end{tabular}

A. C. T. anc $\mathrm{C} i=1$ ancelicld groups: $\mathrm{NG}=$ no lancefield group 
$S$ anginosus, $S$ constellatus and $\mathrm{S}$ intermedius

TABIE 5. CLINICAL SIGNIFICANCE OF THE $S$ MILLERI SPECIES IN RELATION TO THEIR HEMOLYTIC PATTERN

\begin{tabular}{|c|c|c|c|c|c|c|c|c|c|}
\hline \multirow[b]{2}{*}{ Hemolysis } & \multicolumn{3}{|c|}{$S$ anginosus } & \multicolumn{3}{|c|}{$S$ constellatus } & \multicolumn{3}{|c|}{$S$ intermedius } \\
\hline & - & + & Tolal $(\%)$ & - & + & Total $(\%)$ & - & + & Total $(\%)$ \\
\hline Abscess-related & 75 & 8 & $83(27)$ & 18 & 28 & $46(31)$ & 26 & 3 & $29(54)$ \\
\hline Infection-related & 71 & 9 & $80(26)$ & 13 & 23 & $26(18)$ & 13 & 2 & $15(28)$ \\
\hline Questionable significance & 111 & 33 & $144(47)$ & 9 & 66 & $75(51)$ & 6 & 4 & $10(18)$ \\
\hline Total & 257 & 50 & 307 & 40 & 117 & 157 & 45 & 9 & 54 \\
\hline
\end{tabular}

molecular techniques delineated three species, which for reasons of nomenclature were given the same names as those used by the Facklam scheme. ${ }^{5}$ The designation "Streptococcus milleri" is not formally approved but is still in use-generally with quotation marks. Recognition of " $S$ milleri" isolates in the clinical laboratory is difficult, 4.13 and in the traditional diagnostic approach, species identification of viridans streptococci is generally considered unnecessary. ${ }^{13}$ Moreover, the three species as redefined by Whiley and coworkers ${ }^{5}$ do not overlap their homonyms of the Facklam classification scheme. ${ }^{4}$ For these reasons, little is known about "S milleri" in gen$\mathrm{eral}^{1,3}$ and about the association between the individual species and specific sites of isolation or clinical relevance in particular. ${ }^{6.15 .16}$

We used the scheme described by Whiley and coworkers. ${ }^{6}$ The key tests include detection of several glycosidase activities using fluorogenic substrates. Although not traditional for the viridans streptococci, this approach has been enlarged to include all species within the "Streptococcus viridans" group ${ }^{17}$ and has proved to be reliable in other collections. ${ }^{14}$ As in the present study, Whiley and coworkers ${ }^{15}$ reported a high proportion of $S$ anginosus producing $\beta$-galactosidase in their collection, largely because of the inclusion of isolates from urogenital sources.

The demographic data in this study showed an obvious male predominance when infection- and/or abscessrelated isolates were compared. This male predominance was similar to the ratio of 1:0.6 that was noted in a collection consisting mainly of infection-related isolates, ${ }^{18}$ but was not as marked as the 1:0.3 ratio quoted in a review of 192 cases of suppurative infections. ${ }^{19}$ The patients in our study were evenly distributed among all age groups. This finding corresponds with the age distribution compiled by Gossling ${ }^{19}$ and this distinguishes " $\mathrm{S}$ milleri" strains from truly opportunistic bacteria.

The distribution of the isolates and their clinical significance refiected the patient population at our hospital. The overall distribution of clinical "S milleri" isolates was comparable to data reviewed from the literature, ${ }^{13.19}$ except for the absence of strains isolated from dental plaque or odontogenic abscesses in the present collection. It should be noted that along with the progression of the study period, the isolation rate of " $S$ milleri" in our laboratory gradually increased. This probably reflected increased microbiological experience. It influenced the ultimate composition of the collection by adding more strains of questionable clinical significance (eg, strains isolated in mixed flora from sputum or urogenital specimens).

The relative proportions of the three species agree with those reported by Gómez-Garcés and coworkers. ${ }^{16}$ In their study, 75 consecutive "S milleri" isolates were identified to the species level by use of the Rapid ID 32 Strep system (bioMérieux, Marcy-l'Etoile, France) that is in agreement with the method of Beighton and coworkers. ${ }^{20}$ The hemolytic reaction and Lancefield groups of the isolates in this study were similar to the patterns recorded in two reference collections. ${ }^{6.14}$ However, the $S$ intermedius isolates described in the cited reports were virtually all nonhemolytic and nongroupable. However, in these collections. the vast majority of the Sintermedius isolates originated in the oral cavity, whereas in the present study, they were mainly recruited from the abdomen and the skin, bone, and soft tissue group. For $S$ constellatus, and to a lesser degree for $S$ anginosus, we found more $\beta$-hemolytic and groupable strains compared to the previous reports. ${ }^{6.14}$ As for $S$ intermedius, the previously described collections included for both species a considerable number of strains isolated from the oral cavity, ${ }^{14}$ dental plaque and dental abscesses, ${ }^{6}$ which are sites represented in our collection.

We observed a wide anatomic distribution of $S$ anginosus and $S$ constellatus strains, with a high prevalence of $S$ anginosus (nonhemolytic, nongroupable) in the genitourinary tract. These observations are consistent with those previously reported. ${ }^{6,15}$ Gómez-Garcés and coworkers ${ }^{1 / 1}$ recovered most of their isolates from the abdomen, but their study did not include isolates from the genitourinary tract. If isolates from the thoracic cavity and the genitourinary tract in our population were subtracted, the relative distri- 
bution of the isolates was in agreement with those reported by Gómez-Garcés and coworkers. ${ }^{16}$ Contrary to previous observations, ${ }^{6.14 .15}$ we found the distribution of $S$ intermedius strains not exclusively limited to the head and neck area. In addition to this area, we recovered the species in considerable proportions from the skin, bone, and soft tissue group, as well as from the abdomen and the thorax. We confirmed the involvement of $S$ intermedius in central nervous system infections, ${ }^{15}$ but the number of isolates recovered from liver abscesses in our study was too low to confirm the reported association between $S$ intermedius and liver abscesses. ${ }^{15,16}$ Twenty isolates recovered from the bloodstream have been described in detail, ${ }^{2 !}$ the additional isolates exhibited the same species and Lancefield group distribution.

From the three species, Sintermedius was proportionally more associated with infection and abscesses (Table 5). Factors that might contribute to its pathogenicity are its broad range of glycosidase activities: $N$-acetyl- $\beta$-D-galactosaminidase, $N$-acetyl- $\beta$-D-glucosaminidase, and sialidase (substrates for these glycosidases are incorporated in the identification scheme). These glycosidases are specific to acetylamino sugars, which are important constituents of naturally occurring polysaccharides and glycoproteins. ${ }^{26}$ In addition, $S$ intermedius produces hyaluronidase, an enzyme that has been related to abscess formation. ${ }^{27}$ Among infection- and abscess-related specimens, we found a higher isolation rate of nonhemolytic strains compared to $\beta$-hemolytic strains. Two studies reported $\beta$-hemolytic strains to be associated with suppurative infections. ${ }^{18.24}$ However, the implicated numbers in both studies were limited. In one study, the possibility of selective isolation of $\beta$-hemoJytic strains was mentioned. ${ }^{18}$ In a larger collection, no relationship between hemolytic pattern or Lancefield group and clinical spectrum was found.$^{23}$ In view of the high proportion of nonhemolytic strains recovered from abscessrelated specimens, we recommend more biochemical testing of all viridans strains isolated from those specimens, regardless of their hemolytic pattern. The presumptive screening tests we used (VP test, hydrolysis of arginine, fermentation of sorbitol) are suggested.

When recovered from purulent infections, "S milleri" strains were reported to be part of polymicrobial infections in $39 \%$ to $98 \%$ of cases. The accompanying organisms in our study were consistent with those reported. ${ }^{18,22-25}$ In one study, polymicrobial infections were found more frequently in abdominal infections than in supradiaphragmatic infections. ${ }^{25}$

In summary, in the present study, we analyzed serologic and hemolytic patterns of the three species of the "S milleri" group. The study provided information on the ecology of the three "S milleri" species in the clinical setting and their relation to infection. The different pattern of clinical infections and abscess formation suggests that "S milleri" isolates recovered in the diagnostic laboratory be designated to the species level. Future investigations concerning the pathogenic properties of " $S$ milleri" strains may build upon the findings of this study.

\section{REFERENCES}

1. Hardie JM. Oral streptococci. In: Krieg NR. Holt JG, eds. Berge'y's Manual of Systematic Bacteriology: Baltimore: Williams and Wilkins, 1986, pp 1054-1063.

2. Whithworth JM. Lancefield group $F$ and related streptococci. $J$ Med Microbiol 1990:33:135-151.

3. Skerman VBD, McGowan V. Sneath PHA. Approved lists of bacterial names. Int I Syst Bacteriol 1980:30:225-240.

4. Ruoff KL. Streprococcus anginosus ("Sireptococcus milleri"): the unrecognized pathogen. Clin Microbiol Rev 1988:1:102-108.

5. Whiley RA, Beighton D. Emended descriptions and recognition of Sireptococcus constellatus, Sireptococcus intermedius, and Streptocrecus anginosus as distinct species. Int J Syst Bacturiol $1991: 41: 1-5$.

6. Whiley RA. Fraser H, Hardie JM, et al. Phenotypic differentiation of Streptococcus intermedius, Sireplococcus constellatus, and Strepococrus anginosus strains within the "Streplococcus milleri" group. J Clin Microbiol 1990;28:1497-1501.

7. Facklam RR, Washington JA II. Streptococcus and related cata lase-negative gram-positive cocci. In: Balows A. Hausler WJ, Herrmann KL, Isenberg HD. Shadomy HS, eds. Manual of Clinical Microbiology. ed 5. Washington DC: American Socicty for Microbiology, 1991. pp 238-257.

8. Smith RF. Willett NP. Rapid plate method for screening hyal uronidase and chondroitin sulfatase-producing microorganisms. Appl Microbiol 1968:16:1434-1436.

9. Garner JS. Jarvis WR. Emori TG, et al. CDC definitions for nosocomial infections. Am J Infect Control 1988; 16:128-140

10. Colman $G$, Williams REO. Taxonomy of some human viridans streptococci. In: Wannaker LW, Matsen JM, eds. Streptococci and Streptococcal Diseases. London: Academic Press, 1972, pp 281-299.

11. Facklam RR. The major differences in the American and British Streplococcus taxonomy schemes with special reference to Streptococcus milleri. Eur J Clin Microbiol 1984:3:91-93.

12. Coykendall A. Wesbecher PM. Gustafson KB. "Streptococculs milleri. "Streptococcus conviellatus, and Streptococcus intermedius are later synonyms of Streptococcus anginosus. JnI J Sist Bacteriol 1987;37:222-228.

13. Piscitelli SC, Shwed J, Schreckenberger P, et al. Streptococcus milleri group: Renewed interest in an elusive pathogen. Eur J Clin Microbiol Infect Dis 1992:11:491-498.

14. Taketoshi M, Kitada K. Yakushiji T. el al. Enzymatic differentiation and biochemical and serological characteristics of the clinical isolates of Streptococcus conginosus, S intermedius, and $S$. constellatus. Microbios 1993:76:115-129.

15. Whiley RA. Beighton D. Winstanley TG, et al. Streptococcus intermedius, Sireptococcus constellatus, and Streptococcus anginosus (the Sireptococcus milleri group): Association with different body sites and clinical infections. J Clin Microbiol 1992;30: 243-244.

16. Gómez-Garcés JL, Alós $J 1$, Cogollos R. Bacteriologic characteristics and antimicrobial susceptibility of 70 clinically significant isolates of Streptococcus milleri group. Diagn Microhiol Infect Dis 1994;19:69-73.

17. Beighton D. Hardie JM. Whiley RA. A scheme for the identification of viridans streptococci. $J$ Med Microhiol 1991:35:367372. 
$S$ anginosus, $S$ constellatus and $S$ intermedius

18. Spertini F. Baumgartner JD. Bille J. Spectre clinique d'un pathogène commun et insidieux: le Streptococus milleri. Schweiz med Wich 1988:118:1393-1397.

19. Gossling J. Occurrence and pathogenicity of the Streplococcus mitleri group. Rer Infec Dis 1988;10:257-265.

20. Jacobs JA. Stobberingh EE. Species identification of "Sireptococctos milleri" with the Rapid ID 32 Strep system. Med Microbiol Lefl 1994:3:315-322

21. Jacobs JA. Pietersen HG. Stobberingh EE Soeters PB. Bacteremia involving the "Sirephococcus milleri" group: Analysis of 19 cases. Clin Infect Dis 1994;29:704-713.

22. Shlaes DM. Lerner PI. Wolinsky E, et al. Infections due to Lancefield group $\mathrm{F}$ and related streptococci ( $S$ inilleri, $S$ anginosus). Medicine 1981:60:197-207.
23. Van der Auwera P. Clinical significance of Streptococeus milleri. Eur J Clin Microbiol 1985:4:386-390.

24. Kambal AM. Isolation of Sireprococrus milleri from clinical specimens. J Infection 1987:14:217-223.

25. Edminston CE, Walker AP, Krepel C, et al. Strentococcus millerigroup (Streptococius anginosus): Recovery from intra-abdominal and soft tissue sites. Anri Clin Lab Sci 1991:21:5661.

26. Manafi M, Kneifel W, Bascomb S. Fluorogenic and chromogenic substrates used in bacterial diagnostics. Microbiol Rev 1991:55: $335-348$.

27. Unsworth PF. Hyaluronidase production in Streptococcus milleri in relation to infection. J Clin Pathol 1989;42:506-510. 


\section{CHAPTER V}

\section{Species identification of "Streptococcus milleri" with the Rapid ID 32 Strep system}

Jan A.Jacobs and Ellen E.Stobberingh

Medical Microbiology Letters 1994; 3: 315-322.

Reprinted with permission 


\section{SPECIES IDENTIFICATION OF "STREPTOCOCCUS MILLERI" WITH THE RAPID ID 32 STREP SYSTEM}

Jan A.Jacobs* and Ellen E.Stobberingh

University Hospital of Maastricht, Dpt. of Medical Microbiology, P.O. Box 5800, NL-6202 AZ Maastricht, The Netherlands

\section{Summary}

A total of 250 "Streptococcus milleri" strains were identified to species according to Whiley et al. (J.Clin.Microbiol.1990;28:1497-501) and with the Rapid ID 32 Strep system (bioMérieux, France). Both systems agreed in $56.4 \%$ of all identifications, a value that increased to $70.2 \%$ when doubtful Rapid ID profiles were included. The best agreement: was reached with S.anginosus, most discrepancies occurred with. S.intermedius.

\section{Introduction}

Streptococcus intermedius, Streplococcus anginosus and Streptococcus constellatus are collectively referred to as the "Streptococcus milleri" group. They are part of the flora of the oropharynx, the gastrointestinal tract, and the vagina (5), and are known for their proclivity to cause abscess formation ( 9 ). Their turbulent taxonomic history witnessed the coexistence of two classification schemes: a European and an American one. The latter (Facklam) scheme distinguished three species and has been 
the basis of commercial identification kits while the former scheme recognised one species named "Streptoccocus milleri" (2).

Although no longer approved, this term continues to be used because it conveys clinical significance. From 1987 to 1991, "S.milleri" strains were considered to belong to one species, S.anginosus. Based on DNA homology studies, Whiley et al. (12) recognised three species and identified them phenotypically by detection of glycosidase activities using fluorogenic substrates (11). It should be noted that these recently described species do not overlap their homonyms of the Facklam scheme.

The Rapid ID 32 Strep system (bioMérieux, La Balme les Grottes, France) allows the identification within $4 \mathrm{~h}$ of most streptococci and related genera of medical importance. We identified 250 "S.milleri" strains using this system and compared the results of speciation to those obtained with the scheme of Whiley and coworkers (11).

\section{Materials and Methods}

Bacterial strains. During a 2 -year period, 250 strains belonging to the "S.milleri" group were collected from clinical specimens: blood (n, 30), head and neck $(n, 28)$, skin and soft tissues $(n, 34)$, urogenital tract $(n, 48)$, abdomen $(n, 82)$, and thorax, i.e., strains isolated from sputum $(n, 20)$, pleural fluid $(n, 4)$ and bronchial aspirate $(n, 6)$. Ninety-one $(36 \%)$ strains were associated with abscess formation. Distribution of hemolysis and Lancefield groups are depicted in Table 1.

Streptococcal isolates were tentatively identified by Gram stain, colony morphology, pattern of hemolysis on $5 \%(\mathrm{v} / \mathrm{v})$ sheep blood agar, negative catalase reaction, susceptibility to vancomycin ( $30 \mu \mathrm{g}$ disk), resistance to optochin and bacitracin (0.04U disk), and a negative bile-esculin test. 
Table 1. Lancefield group and hemolysis of the "S.milleri" strains.

\begin{tabular}{lcccc}
\hline $\begin{array}{l}\text { Lancefield } \\
\text { group }\end{array}$ & 6-hemolysis & $\begin{array}{l}\text { no } \beta \text { hemolysis } \\
(\alpha \text { or } \gamma)\end{array}$ & Total (\%) \\
\hline $\mathrm{A}$ & 1 & 0 & 1 & $(0.4)$ \\
\hline $\mathrm{C}$ & 12 & 14 & $26 \quad(10.4)$ \\
\hline $\mathrm{F}$ & 28 & 80 & $108 \quad(43.2)$ \\
\hline $\mathrm{G}$ & 6 & 2 & 8 & $(3.2)$ \\
\hline NG (no group) & 26 & 81 & $107(42.8)$ \\
\hline Total (\%) & $73(29.2)$ & $177(70.8)$ & 250 \\
\hline \hline
\end{tabular}

Identification on the "S.milleri" level was reached by a positive VogesProskauer (VP) test (Coblentz method(3)). In addition, Lancefield grouping was performed (Streptex, Wellcome Diagnostics, U.K.). In doubtful cases, identification was confirmed with the API 20 Strep system (bioMérieux, La Balme les Grottes, France). The strains were stored at $-70^{\circ} \mathrm{C}$ on porous beads (Microbank, Pro-Lab Diagnostics, Canada). They were retrieved on sheep blood agar. Identification reactions were repeated before entry in the study. Reference strains used in the study were S.anginosus (ATCC 33397), S.constellatus (ATCC 27823) and S. intermedius (ATCC 27335).

Identification according to Whiley et al (11). Assignment of strains to either S.anginosus, S.constellatus or S.intermedius was made according to Whiley et al. (11). Briefly, strains were tested for production of $\alpha$-galactosidase, $\beta$-galactosidase, $\alpha$-glucosidase, $\beta$-glucosidase, $N$-acetyl-B-D-galactosaminidase, $N$-acetyl- $\beta$-D-glucosaminidase, sialidase and $\beta$-D-fucosidase by using 4-methylumbelliferyl-linked fluorogenic 
substrates (Sigma, U.S.A.) in flat-bottomed microtiter plates (Hospidex, The Netherlands). After incubation for $3 \mathrm{~h}$ at $35^{\circ} \mathrm{C}$, hydrolysis of substrates was visualized as a distinct fluorescence by placing the microtiter plates on an ultraviolet light box. Hyaluronidase production was assessed by the plate method of Smith and Willett (10), with hyaluronic acid obtained from Sigma (U.S.A).

API Rapid ID32 Strep System. The rapid ID 32 Strep strip includes 32 wells containing dehydrated substances which enable the performance of 7 osidase reactions, 3 arylamidase reactions, alkaline phosphatase, 4 conventional biochemical tests (arginine dihydrolase, Voges-Proskauer, hippurate hydrolysis, and urease) and 17 carbon substrate fermentations. After growth on Columbia agar with $5 \%(\mathrm{v} / \mathrm{v})$ sheep blood, a suspension was prepared in $2 \mathrm{ml}$ of demineralized water and adjusted to a McFariand 4.0 standard turbidity. Of this suspension, $55 \mu \mathrm{l}$ per well were deposited with an electronic pipette. After a 4 -h incubation at $35^{\circ} \mathrm{C}$, reagents (API System, France) were added: VP A and B reagents for the VP reaction, FB reagent for the arylamidases, $\beta$-galactosidase, and $N$-acetyl- $\beta$ glucosaminidase, and NIN reagent for the hippurate hydrolysis test. Within the prescribed reading time, the color of the wells was visually compared to the reading table. The resulting 11-digit numerical profile was decoded from the Rapid ID 32 Strep data base in its version 1.1 by use of the APILAB computer program. A 0.01-ml sample from the inoculated suspension was streaked onto blood agar to check for purity. Reproducibility of the systems was assessed by testing three different strains on five consecutive days. 


\section{Results}

Table 2 lists the identifications according to Whiley et al. (11).

Table 3 compares these results with those obtained by the Rapid ID 32

Strep system.

Table 2. Identification of the "S.milleri" strains according to Whiley et al. (11)

\begin{tabular}{lccccccc}
\hline \hline & \multicolumn{3}{c}{ Lancefield group } & & \multicolumn{2}{c}{ Total ( \% ) } \\
& $\mathrm{A}$ & $\mathrm{C}$ & $\mathrm{F}$ & $\mathrm{G}$ & none & & \\
\hline S.anginosus & 1 & 16 & 69 & 4 & 55 & 145 & $(58.0)$ \\
\hline S.constellatus & 0 & 3 & 28 & 0 & 23 & 54 & $(21.6)$ \\
\hline S.intermedius & 0 & 7 & 11 & 4 & 29 & 51 & $(20.4)$ \\
\hline \hline
\end{tabular}

Table 3. Comparison of results obtained by the scheme of Whiley et al.(11) and those obtained by the Rapid ID 32 Strep system.

\begin{tabular}{lcccc}
\hline \hline Rapid ID 32 Strep & \multicolumn{3}{c}{ Whiley et al. } & \\
& SA & SC & SI & Total \\
\hline S.anginosus* & 104 & 9 & 10 & 123 \\
\hline SA doubtful profile & 15 & - & - & 15 \\
\hline S.constellatus* & 4 & 23 & 1 & 28 \\
\hline SC doubtful profile & - & 13 & - & 13 \\
\hline S.intermedius* & - & - & 14 & 14 \\
\hline SI doubtful profile & - & - & 8 & 8 \\
\hline Identification to SM level & 10 & 4 & 5 & 19 \\
\hline Other profile & 12 & 5 & 13 & 30 \\
\hline Total & 145 & 54 & 51 & 250 \\
\hline $\begin{array}{l}\text { SA, S.anginosus; SC, S.constellatus; SI, S.intermedius; SM, S.milleri } \\
*: \text { excellent, very good, good, and acceptable profiles }\end{array}$ & \\
\hline
\end{tabular}


Both identification systems correctly identified the reference strains and were reproducible. Visual reading of the Rapid ID 32 Strep system required some experience due to the different colors of the test results and the compact lay-out of the result sheet. Complementary tests were suggested by the APILAB Computer Program in 6 profiles but results of these tests did not allow more acceptable identification profiles.

\section{Discussion}

Strains belonging to the "S.milleri" group are notoriously difficult to recognize (9). In addition, they seemed to be refractory to classification until they were allocated into three redefined species (12). Together with other newly described species within the viridans streptococci (1), they await reliable phenotypic tests for identification in the clinical laboratory. The Rapid ID 32 Strep system claims to identify the redefined S.anginosus, S.constellatus and S.intermedius (4). We challenged the system with a collection of heterogeneous clinical strains and compared it to the reference identification method. Commercial kits designed for identification of streptococci tend to agree moderately when strains belonging to the "S.milleri" group are tested $(6,8)$. The two identification systems used by us have in common only three reactions ( $\beta$-glucosidase, $\beta$-galactosidase and $N$-acetyl- $\beta$-D-glucosaminidase) and it is known that glycosidase activities detected with different reagents may not necessarily agree (1). In addition, it is possible that electronic reading (e.g., with the ATB 1520 reader) would generate fewer doubtful profiles than visual reading.

Taking these limitations into account, we feel that both systems agreed reasonably well. Overall agreement within the good, very good or 
excellent identifications of the Rapid ID 32 Strep system was $56.4 \%$, and this value increased to $70.8 \%$ when doubtful profiles were included for comparison. The highest agreement was reached with S.anginosus $(71.7 \%$; with inclusion of doubtful profiles, $82 \%)$. We did not find any test in the Rapid ID 32 Strep system for which a change in the test result could have augmented the number of acceptable identifications or the level of agreement with the scheme of Whiley et al.(11). Discrepancies occurred most frequently with S.intermedius, 10/51 strains of this species being allocated to S.anginosus by the Rapid ID 32 Strep system. This is remarkable because S.intermedius can be clearly delineated in the fluorogenic system due to its production of multiple glycosidases, of which sialidase might be related to pathogenicity (7).

"Other profiles" in Table 3 represent doubtful or unacceptable profiles referring to identifications limited to the genus Streptococcus or related genera. An exception within these profiles were those coding for good or very good identification of Lactococcus lactis/cremoris $(\mathrm{n}, 9)$. These profiles represent poorly reactive strains in the Rapid ID 32 system. Five of these strains carried Lancefield group $F$, the other strains were nongroupable. It is possible that revision of the traditional inclusion criteria for. "S.milleri" can further elucidate this problem.

\section{Acknowledgement}

We thank Mrs. Vriese for excellent technical assistance. 


\section{References}

1. Beighton D, Hardie JM, Whiley RA. A scheme for the identification of viridans streptocci. J Med Microbiol 1991;35: 367-72.

2. Coykendall AL. Classification and identification of the viridans streptococci. Clin Microbiol Rev 1987; 2: 315-28.

3. Facklam RR, Washington JAII. Streptococcus and related catalasenegative gram-positive cocci. In Balows $A$, Herrmann $\mathrm{KL}$, Isenberg HD, Shadomy HJ eds. Manual of clinical microbiology. 5th ed., Washington DC: American Society for Microbiology, 1991.

4. Freney J, Bland S, Etienne J, Desmonceaux M, Boeufgras JM, Fleurette J. Description and evaluation of the semiautomated 4-hour Rapid ID 32 Strep method for identification of streptococci and members of related genera. J Clin Microbiol 1992; 30: 2657- 61.

5. Gossling J. Occurrence and pathogenicity of the Streptococcus milleri group. Rev Infect Dis 1988;10:257-85.

6. Hinnebusch CJ, Nikolai DM, Bruckner DA: Comparison of API Rapid Strep, Baxter MicroScan Rapid Pos ID Panel, BBL Minitek Differential Identification System, IDS RapID STR System and Vitek GPI to conventional biochemical tests for identification of viridans streptococci. Am. J Clin Pathol 1991;91:459-63.

7. Manafi M, Kneifel W, Bascomb S. Fluorogenic and chromogenic substrates used in bacterial diagnostics. Microbiol Rev 1991; 55: 335-48.

8. Peterson EM, Shigei JT, Woolard A, De La Maza L. Identification of viridans streptococci by three commercial systems. Amer J Clin Pathol 1988; 90: 87-91.

9. Ruoff KL. Streptococcus anginosus ("Streptococcus milleri"): the unrecognized pathogen. Clin Microbiol Rev 1988;1:102-8.

10. Smith RF, Willett NP. Rapid plate method for screening hyaluronidase and chondroitin sulfatase-producing microorganisms. Appl Microbiol 1968; 16:1434-6.

11. Whiley RA, Fraser H, Hardie JM, Beighton D. Phenotypic differentiation of Streptococcus intermedius, Streptococcus constellatus, and Streptococcus anginosus strains within the "Streptococcus milleri" group. J Clin Microbiol 1990;28:1497-501.

12. Whiley RA, Beighton D. Emended descriptions and recognition of Streptococcus constellatus, Streptococcus intermedius and Streptococcus anginous as distinct species. Int J Syst Bacteriol $1991 ; 41: 1-5$. 
Rapid species identification of "Streptococcus milleri" strains by line blot hybridization: identification of a distinct $16 \mathrm{~S}$ ribosomal population closely related to Streptococcus constellatus 


\section{Rapid species identification of "Streptococcus milleri" strains by line blot hybridization: identification of a distinct $16 \mathrm{~S}$ ribosomal RNA population closely related to Streptococcus constellatus.}

Jan A.Jacobs, M.D. ${ }^{\text {** }}$, Corrie S.Schot ${ }^{2}$, Annelies E. Bunschoten² and Leo M.Schouls, Ph.D.?

Department of 'Medical Microbiology, University Hospital of Maastricht, P.O.Box. 5800, 6202 AZ Maastricht, The Netherlands.

${ }^{2}$ Research laboratory for infectious diseases, National Institute of Public Health and Environmental Protection, P.O.Box 1, 3720 BA Bilthoven, The Netherlands

\section{Abstract}

A collection of 399 "Streptococcus milleri" strains was identified to the species level in a line blot assay: PCR amplified $16 \mathrm{~S}$ ribosomal RNA gene was hybridized with species-specific 5'biotinylated oligonucleotide probes homologous to the 213-231 base region of the $16 \mathrm{~S}$ rRNA gene sequences of the type strains Streptococcus anginosus ATCC 33397, Streptococcus constellatus ATCC 27823 and Streptococcus intermedius ATCC 27335. The hybridization results were compared with the reference phenotypic identification (R.A.Whiley, H.Fraser, J.M.Hardie and D.Beighton, J.Clin.Microbiol. 28: 1497-1501, 1990). Most strains $(357 / 399,89.5 \%)$ reacted unambiguously with only one probe. However, $42 / 399$ ( $10.5 \%$ ) strains reacted with both the S. constellatus and S. intermedius specific probes, 4.1 of them were phenotypically identified as $S$. constellatus. These dually reactive strains hybridized with a 5 'biotinylated probe based on the 213-231 base region of the 16S rRNA gene sequence of one of them. Analysis of the 5 ' end of the I6S rRNA gene sequence ( $487 \mathrm{bp}$ ) demonstrated that the dual reactive strains represent a distinct rRNA population sharing $98.1 \%$ sequence similarity with S. constellatus. Phenotypic consistency between the dual reactive strains and the $S$. constellatus strains was not demonstrated. Line blot hybridization proved to be a simple and inexpensive method to screen large numbers of strains for genetic relatedness, and allowed detection of a distinct 16S rRNA type within the "S. milleri" group. 


\section{Introduction}

In contrast to other viridans species, organisms belonging to the "Streptococcus mill'ri" group are notable as agents of purulent infections (5). They are difficult to recognize because they exhibit heterogeneous biochemical, hemolytic and serologic characteristics $(10,12)$. Moreover, two classification schemes - one European and one American coexisted from 1977 to 1987 , and added to the difficulties concerning the identification and the nomenclature of these organisms. On the basis of DNA-DNA reassociation studies, Whiley and coworkers (18) divided the "S. milleri" group into three distinct species ( $S$. anginosus, $S$. constellatus and $S$. intermedius). The phylogenetic validity of the current taxonomy has been confirmed by comparisons of rRNA gene restriction patterns (4) and of $16 \mathrm{~S}$ rRNA sequences (1). However, within the $S$. milleri group, distinct rRNA populations (2) have been recognized. Phenotypic differentiation of

\section{Materials and Methods}

\section{Bacterial strains}

The streptococci studied were recovered during the period July 1991 - October 1995 from clinical specimens submitted for culture at the microbiological laboratory of the University Hospital of Maastricht. Streptococci were included in the study if they were identified as "Streptococcus milleri" by the API 20 Strep system supplied with the data base 4.0 (bioMérieux, Marcy-l'Etoile, France). Hemolysis was assessed by observation of the subsurface growth in stabbed sheep blood agar plates (12). Lancefield grouping was performed on all isolates (Streptex, Murex Diagnostics, Dartford, U.K.). The isolates were stored at $-70^{\circ} \mathrm{C}$ on porous beads in cryopreservative (Microbank, Pro-Lab Diagnostics, Richmond Hill, Canada). Assignment of strains to the three species is performed by detection of glycosidase activities using fluorogenic substrates (17).

Nucleotide sequences found in the $16 \mathrm{~S}$ ribosomal RNA gene yield valuable information on the phylogenetic interrelationships of microorganisms (19), and can be studied by the use of DNA amplification technology (15). In a preliminary study, we hybridized the PCR products of the $16 \mathrm{~S}$ ribosomal RNA gene of small numbers of "S. milleri" strains with species-specific oligonucleotide probes. During that study, we found that a few strains hybridized with both the probe specific for the $S$. constellatus species and the probe specific for the S. intermedius species. Because we recently collected a large number of clinical "S. milleri" strains, we wanted to study the prevalence of these dually reactive strains, their phylogenetic interrelationships and their phenotypic properties.

either $S$. anginosus, S. constellatus or S. intermedius was determined by the scheme of Whiley and coworkers (16). Briefly, strains were tested for a panel of seven glycosidase reactions using 4-methylumbelliferyl-linked fluorogenic substrates (Sigma, St.Louis, M.O., U.S.A.) in flat-bottomed microtiter plates, and for the production of hyaluronidase (Sigma) in a plate assay. Strains that were phenotypically identified as $S$. intermedius $(\mathrm{n}=63)$ were all included in the study, the $S$. anginosus $(\mathrm{n}=$ $200)$ and $S$. constellatus $(\mathrm{n}=136)$ strains were randomly selected from the entire collection recovered during the study period (approximately 700 strains). Strains were assigned to broad anatomic and clinical categories as previously described (5). One strain per species per patient was included, unless 
the strains differed in hemolytic pattern or Lancefield group or unless they were recovered from distinct body sites. Reference strains were the type strains $S$. anginosus: ATCC 33397, S. constellatus: ATCC 27823 and S. intermedius: ATCC 27335.

\section{PCR amplification}

The isolates were retrieved on blood agar base (Oxoid, Basingstoke, U.K.) supplemented with sheep blood $5 \% \mathrm{v} / \mathrm{v}$, checked for purity and streaked on secondary plates. The cells were removed from the plates and transferred to a microcentrifuge tube. They were spun twice, first in a $100 \mu \mathrm{l}$ volume and subsequently in a $900 \mu \mathrm{l}$ volume of $10 \mathrm{mM}$ Tris/ $150 \mathrm{mM} \mathrm{NaCl}$ buffer $\mathrm{pH}$ 8.0. The supernatant was discarded, and the cells were resuspended in $100 \mu \mathrm{l}$ TE buffer ( $10 \mathrm{mM}$ Tris HCl/ $1 \mathrm{mM}$ EDTA buffer $\mathrm{pH}$ 8.0 ) and heated at $99^{\circ} \mathrm{C}$ for $10 \mathrm{~min}$.

Primers based on the highly conserved regions of the eubacterial 16S rRNA gene were used to amplify the 5 ' end of the 16S rRNA gene sequence. These primers correspond to residues $8-27$ (primer 16S1F) and 575-556 (16S1RR) of the Escherichia coli 16S rRNA gene sequence (3) (Table 1). Amplification was done in $25 \mu 1$ reaction volumes, in an OmniGene Thermal Cycler (Hybaid, Teddington, U.K.). Each sample contained 1 pmol of both primers, 0.25 units of super Tth DNA polymerase (HT Biotechnology, Cambridge, U.K.) and standard amounts of amplification reagents $(200 \mu \mathrm{M}$ [each] deoxynucleoside triphosphate, $50 \mathrm{mM}$. Tris- $\mathrm{HCl}[\mathrm{pH}$ 9.0], $50 \mathrm{mM} \mathrm{KCl}, 1.5 \mathrm{mM} \mathrm{MgCl}_{2}, 0.01 \%$ gelatin, $0.1 \%$ Triton X-100). A $25 \mu$ l overlay of sterile mineral oil was added to the tubes. The PCR program used was $3 \mathrm{~min}$ at $95^{\circ} \mathrm{C}$, followed by 25 cycles of amplification that consisted of $20 \mathrm{sec}$ at $95^{\circ} \mathrm{C}, 30 \mathrm{sec}$ at $55^{\circ} \mathrm{C}$, and $30 \mathrm{sec}$ at $72^{\circ} \mathrm{C}$.

Table 1. Oligonucleotide sequences of primers and probes wad in PCR, scruencing and line blot hybridization.

\begin{tabular}{|l|l|l|l|l|}
\hline Designation & Target & Nucleotide sequence & $\begin{array}{l}\text { Position on the } \\
165 \text { rRNA gene }\end{array}$ & Reference \\
\hline I6SIF & Eubacterial 16S rRNA & TGTAAAACGACGGCCAGTAGAGTTTGATC(A/C)TGG(T/C)TCAG & $8-27$ & 3 \\
\hline I6SIRR & Eubacterial 16S rRNA & CAGGAAACAGCTATGACCCTTTACGCCCA(A/G)T(G/A)A(A/T)TC & $575-556$ & 3 \\
\hline SA & S. anginosus 16S rRNA & ATGCAATTGCATCGCTAGT & $213-231$ & This study \\
\hline SC & S. constellatus I6S rRNA & GTGCAAGAGCATCACTACC & $213-231$ & This study \\
\hline SI & S. intermedius I6S rRNA & GTGCAAATGCATCACTACC & $213-231$ & This study \\
\hline SCI & CI strain 16S rRNA & GTGCAAAAGCATCACTACC & $213-231$ & This study \\
\hline
\end{tabular}

Line blot hybridization of $P C R$ products

Hybridization was performed in a line blot assay based on the reverse line blot assay described by Kaufhold and coworkers (7). Species-specific 5' biotinylated oligonucleotide probes were designed homologous to the 213-231 base region of the $16 \mathrm{~S}$ rRNA gene of the ATCC type strains $S$. anginosus, $S$. constellatus and $S$. intermedius respectively and a probe was designed based on the 213-231 region $16 \mathrm{~S}$ rRNA sequence of a dually reactive strain (Table 1 ). A volume of $300 \mu \mathrm{l}$ of $2 \times \mathrm{SSPE}$ ( $360 \mathrm{mM} \mathrm{NaCl}, 20$ $\mathrm{mM} \mathrm{Na}_{2} \mathrm{HPO}_{4} * \mathrm{H}_{2} \mathrm{O}, 2 \mathrm{mM}$ EDTA) was added to the amplification products. After a 5 min denaturation step at $99^{\circ} \mathrm{C}$, the mixtures were immediately placed on ice and $140 \mu l$ of each sample was loaded into a separate channel of a Miniblotter 45 (Immunetics, 
Cambridge, M.A., U.S.A.), in which device a nylon membrane (Hybond- $\mathrm{N}^{+}$, Amersham, 'sHertogenbosch, The Netherlands) was mounted. After a 10 min incubation at room temperature, the samples were removed by aspiration and the membrane was taken from the Miniblotter. The PCR products ( 43 samples in separate lanes on one single membrane) were fixed by placing the membrane for 5 min on a pad of adsorbent filter paper soaked in $0.4 \mathrm{M} \mathrm{NaOH}$.

The membrane containing PCR products was washed twice at $50^{\circ} \mathrm{C}$ for $10 \mathrm{~min}$ in $150 \mathrm{ml}$ of $2 \times \mathrm{SSPE}$ and $0.5 \%$ SDS and then placed again in the Miniblotter, rotated 90 degrees from its original orientation (Figure 1). The oligonucleotide probes were diluted in 2x SSPE and $0.1 \%$ SDS to a concentration of 0.02 $\mathrm{pmol} / \mathrm{l}$ and a volume of $140 \mu \mathrm{l}$ of these suspensions was injected in separate channels of the Miniblotter Hybridization was done in the Miniblotter for $45 \mathrm{mir}$ at $50^{\circ} \mathrm{C}$, after which the channels were emptied by aspiration. The membrane was removed from the Miniblotter and subjected to two 10-min washing steps at either $50^{\circ} \mathrm{C}$ or $56^{\circ} \mathrm{C}$ with $150 \mathrm{ml}$ of $2 \mathrm{x} \mathrm{SSPE}$ and $0.5 \%$ SDS. Subsequently, the membranes wer incubated with 1:4000 diluted streptavidin peroxidase conjugate (Boehringer Mannheim Mannheim, Germany) for $45 \mathrm{~min}$ at $42^{\circ} \mathrm{C}$ in $10 \mathrm{ml} o$ $2 \mathrm{x}$ SSPE and $0.5 \%$ SDS and then washed twice (10 min each) with $150 \mathrm{ml}$ of $2 \times \mathrm{SSPE}$ and $0.5 \%$ SDS a $42^{\circ} \mathrm{C}$. After a final 5 -min wash step with $2 \times$ SSPE the membranes were incubated with ECL detection reagents (Amersham) for $1 \mathrm{~min}$ and used to expose an ECL. hyperfilm (Amersham) for 5 min to visualize hybridization.
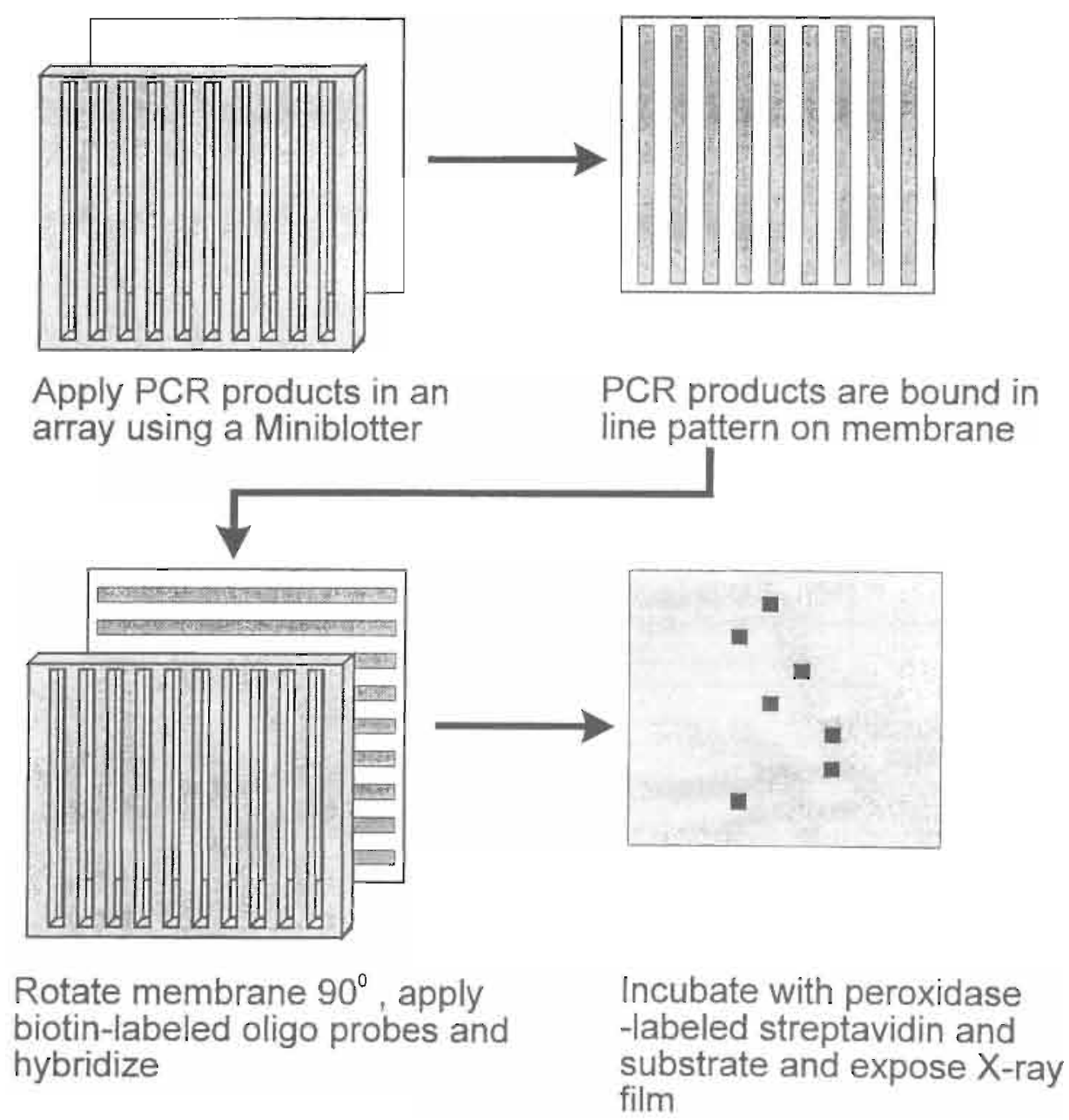

Figure 1. Diagram of the essential features of the line blot hybridization assay.

For simplicity, only 9 of 45 channels are depicted. 
Determination and analysis of 16S rRNA gene sequence

The partial sequences of the 16S rRNA gene of various "S. milleri" strains were determined by direct sequencing of the PCR products obtained by amplification with the broad host range primers 16SIF and 16S1RR (3). Briefly, PC R fragments were separated on agarose gel, cut out of the gel and purified by the QIAquick PCR purification kit (Qiagen, Hilden, Germany) according to the manufacturer's instructions. The PCR products were sequenced directly using the fluorescent dye terminator cycling sequencing system (Applied Biosystems/Perkin-Elmer, Gouda, The Netherlands). The primers used for sequencing were the primers $16 \mathrm{~S} 1 \mathrm{~F}$ and $16 \mathrm{~S} 1 \mathrm{RR}$. The sequencing data were

\section{Results}

Bacterial strains - identifications

Three hundred and ninety nine strains were included in this study. Both the phenotypic identification method and the line blot hybridization assay proved to be reproducible. When tested with the method of Whiley and coworkers $(16), 350 / 399(87.7 \%)$ strains fit the identification exactly or differed in only one test reaction from the reference identification scheme. Thirty nine (9.8\%) and $10(2.5 \%)$ strains differed in two respectively three test results from the scheme. They were designated as $S$. anginosus $(\mathrm{n}=6), S$. constellatus $(\mathrm{n}=32)$ and S. intermedius $(\mathrm{n}=11)$.

When hybridized with the oligonucleotide probes specific for $S$. anginosus, S. constellatus and $S$. intermedius in the line blot assay, the majority (357/ $399,89.5 \%$ ) of the strains displayed an unequivocal compared with all other known DNA sequences in the EMBL nucleotide sequence data base (release 37) using the Fast A DNA comparison program (9). Multiple alignment and construction of the phylogenetic tree was performed using the megalign module of the DNAStar program (DNAStar, Madison, Wisconsin, U.S.A.).

\section{Reproducibility - Statistical evaluation}

Reproducibility of the species identifications was assessed by testing 20 strains on three consecutive days. When strains gave discrepant results in the two identification methods, they were retested by both the phenotypic identification and the line blot hybridization. For statistical evaluation, proportions were compared by means of the chi-square test.

signal with one of the three oligonucleotide probes, but the remaining strains $(42 / 399,10.5 \%)$ gave faint signals with both the $S$. constellatus and the $S$. intermedius specific probes, these dually reactive strains will be referred to as CI strains (Figure 2A). Table 2 lists the results of the two identification methods, matched with each other. Most strains (22/ $32,68.8 \%$ ) that displayed discrepant results when tested by the two identification schemes belonged to the $S$. constellatus species as identified by the phenotypic scheme, and were identified by line blot hybridization as $S$. intermedius. Fourteen of the 32 strains that displayed discrepant results differed in more than one test reaction from the reference phenotypic profile as described by Whiley and coworkers $(16)(p<0.001)$. 
Table2. Species identification within the "S. miller" strains: comparison of phenotypic identification (according reference No. 17) and identification obtained by fine blot hybridization of 165 ribosomal RNA gene with species-specific oligonucleotide probes.

Identification obtained by $16 S$ ribosomal RNA gene line blot hybridization.

S. anginosus S. constellatus Cl strains ${ }^{\star} \quad$ S. intermedius Total

Pherotypic identification

$$
\text { S.anginosus }
$$

S.constellatus

Sintermedius

Total
199

0

2

201
1

73

7

81
0

41

1

42
0

22

53

75
200

399

+ Cl strains: strains that hybridized with both $S$. constellatus and S. intermedius specific probes.

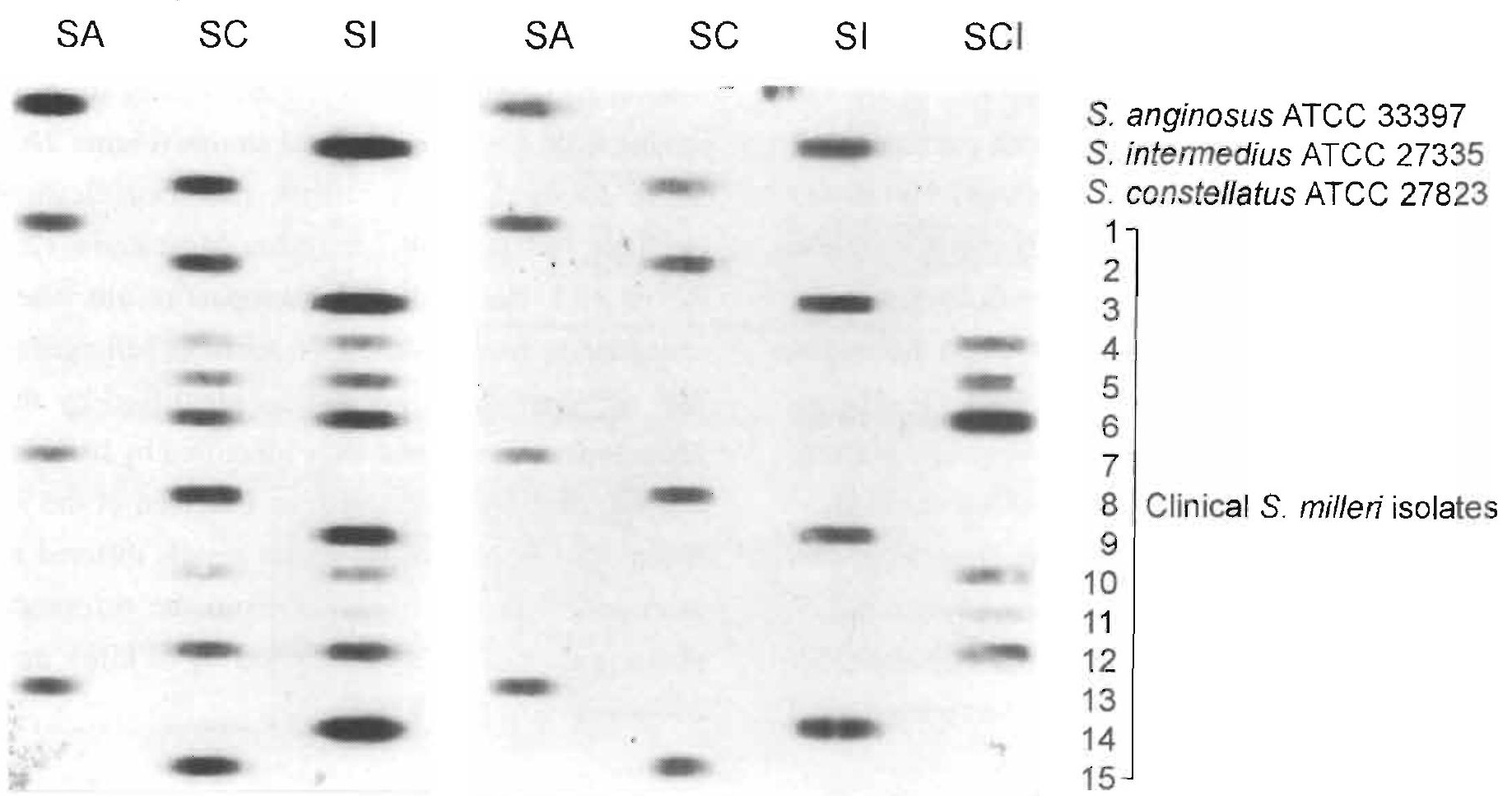

A.

B.

Figure 2. Hybridization patterns of the PCR products of the "S. milleri" strains with oligonucleotide probes specific for $S$. anginosus (SA), S. constellatus (SC), S. intermedius (SI) and the dually reactive CI strains (SCI). Post-hybridization washing temperatures of $50^{\circ} \mathrm{C}$ (fig. $\left.2 \mathrm{~A}\right)$ and $56^{\circ} \mathrm{C}$ (fig. $2 \mathrm{~B}$ ). 
16S rRNA gene sequence analysis of PCR products hybridization with the SCI probe

In order to further study the nature of the dually reactivity $\mathrm{Cl}$ strains, the 5 ' end of the $16 \mathrm{~S}$ rRNA gene sequences (487 bp) of three CI strains (strain 259 , 268 and 372) were determined. These three sequences were shown to be identical. Comparison with the $S$. anginosus, S. constellatus and S. intermedius 16S rRNA gene sequences present in the EMBL and GenBank databases revealed that the CI strains were closely related to $S$. constellatus. However, the $16 \mathrm{~S}$ rRNA sequences of S. anginosus, S. constellatus and S. intermedius in the EMBL and GenBank contained too many ambiguous bases, making accurate comparison difficult. Therefore, we also sequenced the 5' end of the 16S rRNA gene of the three ATCC strains and those of a randomly picked $S$. anginosus, $S$. constellatus and $S$. intermedius strain present in our collection and identified as such by both genotypic and phenotypic methods.

Multiple alignment and the construction of a phylogenetic tree were performed and showed that the Cl strains were indeed closely related to $S$. constellatus, differing in only 4 bases of the 487 bp sequenced. A phylogenetic tree sequence similarity, the genetic distances and part of the 16S rRNA gene sequences are shown in figure 3.

A 5 'biotinylated probe SCI homologous to the 213 231 base region of the $16 \mathrm{~S}$ rRNA gene sequence of the three dually reactive CI strains was designed. PCR products of the $\mathrm{CI}$ strains $(\mathrm{n}=36)$ and of the three "S. milleri" species ( $\mathrm{n}=20$ for each spécies) were hybridized with this newly designed probe and the species-specific probes. All samples gave unequivocal signals restricted to their corresponding probe when the post-hybridization washing temperature was increased to $56^{\circ} \mathrm{C}$ (Fig. 2B).

A
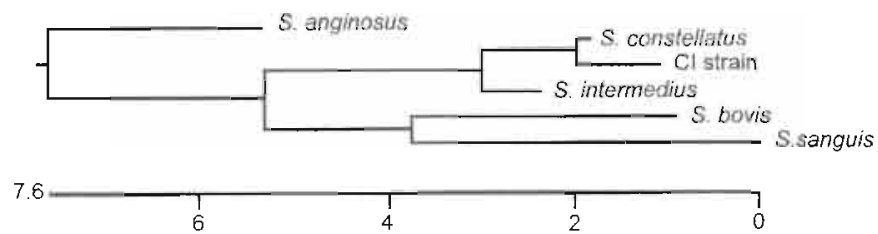

B
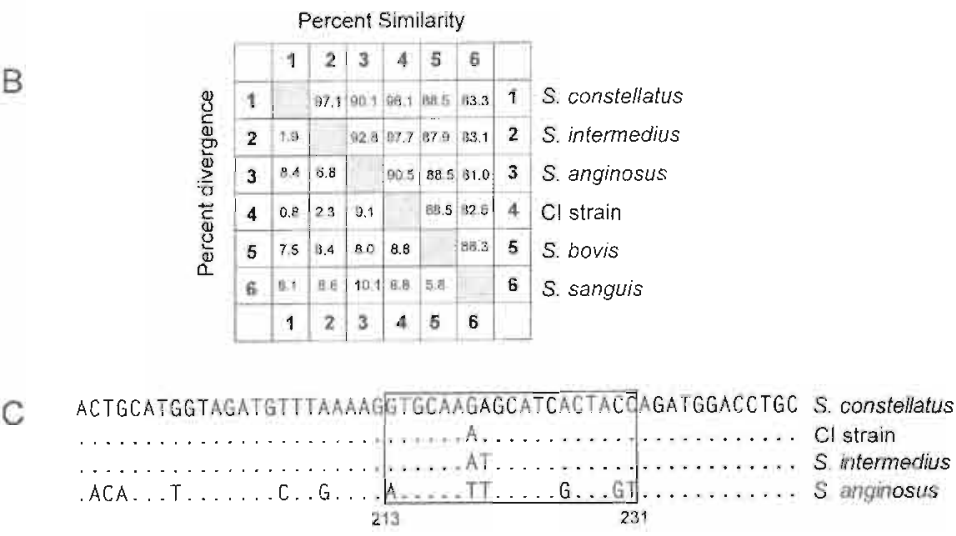

Figure 3. Genetic interrelationships between S. anginosus, S. constellatus, S. intermedius and the dially reactive Cl strains based on the partial sequence of the 16 S ribosomal RNA gene sequences ( 487 bp).

fig 3A. Unrooted phylogenetic tree showing the interrelationships between S. anginosus, S. constellatus, $S$. intermedius, the dually reactive $C I$ strains and related taxa.

fig 3B. Levels of I6S RNA sequence relatedness of S. anginosus, S. constellatus, S. intermedius, the dually, reactive $C I$ strains and related taxa.

fig 3C. Alignment of the partial $16 S$ ribosomal RNA sequences of $S$. anginosus, S. constellatus, S. intermedius and the dually reactive $C I$ strains which will be available in the EMBL and GenBank under accession numbers Z69038, Z69041, Z69040, and Z69037, respectively. The boxed region indicated the 213-231 bp segment on which the species-specific oligonucleotide probes were based. 


\section{CI strains - phenotypic characteristics}

The CI strains closely resembled the $S$. constellatus species. Twenty seven out of 42 strains $(64.3 \%)$ were B-hemolytic. They belonged to Lancefield groups $\mathrm{F}$ $(n=18)$ or $C(n=2)$ or were non-groupable $(n=22)$. Physiological characteristics of the CI strains, as determined by the API 20 Strep system were as follows: all 42 strains gave positive reactions for production of acetoin, alkaline phosphatase, and leucine arylamidase. All of the isolates were negative for hydrolysis of hippurate, production of pyrrolidonyl arylamidase, $\alpha$-galactosidase, $\beta$ galactosidase, $\beta$-glucuronidase, and acidification of ribose, arabinose, mannitol, sorbitol, inulin and glycogen. Table 3 shows the results of API 20 Strep tests for which variable reactions were observed and the results for tests included in the scheme of Whiley and coworkers. The CI strains were assigned to API biotype $1(\mathrm{n}=29)$ or biotype $2(\mathrm{n}=12)$, only one strain was assigned to biotype 3 . No single phenotypic characteristic, nor any combination of characteristics was found to be predictive for the CI strains. The CI strains shared anatomic distribution and clinical significance with the $S$. constellatus strains, with $22 /$ $42(52.3 \%)$ of the CI strains recovered from infectionor abscess-related samples, and a proportionally high number of CI strains recovered from the thorax $(\mathrm{n}=$ 9) and head and neck $(n=8)$ area.

Table 3. Variable phenotypic characteristics of the dually reactive $\mathrm{Cl}$ strains $(n=42)$

Test

Number of strains positive (\%)

Test characteristics determined by the AP 20 Strep system

Hydrolysis of esculin

$23(54.8)$

Arginine dihydrolase

$38(90.5)$

Acidification of lactose

Acidification of trehalose

$35(83.3)$

Acidification of raffinose

$1(2.4)$

Acidification of starch

$1(2.4)$

Test characteristics determined by the scheme of Whiley et al. (reference No 16)

B-D-fucosidase

$N$-acetyl- $\beta$-D-glucosaminidase

$N$-acetyl- $\beta$-D-galactosaminidase

sialidase

$\beta$-galactosidase

$\beta$-glucosidase

$\alpha$-glucosidase

hyaluronidase
0

$3(7.1)$

$1(2.4)$

$3(7.1)$

$7(16.7)$

$2(4.8)$

$37(88.0)$

$41(97.6)$ 


\section{Discussion}

In this study, we identified 399 clinical "S. milleri" strains to the species level by phenotypic tests and by $16 \mathrm{~S}$ rRNA gene hybridization with speciesspecific oligonucleotide probes in a line blot hybridization assay. In the initial experiments, we used oligonucleotide probes specific for the $16 \mathrm{~S}$ rRNA gene sequences of $S$. anginosus, $S$. constellatus and $S$. intermedius. A relative high number of strains reacted with both the $S$. constellatus and the $S$. intermedius probe. Analysis of the 16S rRNA gene of three of these dually reactive CI strains revealed minor differences with the 16S rRNA sequence of $S$. constellatus. Subsequently, an oligonucleotide probe specific for this subset of strains was developed and used in a slightly modified line blot assay. Hybridization reactions resulted in the unequivocal genotypic identification of all strains studied. Phenotypic consistency of the CI strains was not demonstrated.

The CI strains represented nearly one third (41/136, $30.1 \%$ ) of the phenotypically identified $S$. constellatus strains. Their hybridization pattern (faint signal with both $S$. constellatus and $S$. intermedius specific probes and uniform reaction with the probe designed to the CI strain) argued their inclusion in a single genetic group. Comparison of the partial 16S rRNA gene sequence ( $487 \mathrm{bp}$ ) of the three $S$. milleri species and the CI strains revealed that the dually reactive $\mathrm{CI}$ strains and the $S$. constellatus species displayed a sequence similarity of $98.1 \%$.

At such a high level of 16S rRNA gene sequence similarity, DNA-DNA reassociation studies are needed to decide whether the CI strains represent a distinct species or not (14).

The anatomic distribution and clinical significance as well as the phenotypic profile of the CI strains confirmed the close relatedness with $S$. constellatus. These findings actually do not support the existence of a distinct species. However, the phenotypic reference system is based on tests for only eight enzyme activities and most $S$. constellatus strains are known to display positive reactions for only two of them ( $\alpha$-glucosidase and hyaluronidase) (17): increasing the number of enzyme activities tested for may demonstrate more subtle phenotypic differences among the strains studied. The biochemical gallery of the API 20 Strep system was originally tailored to the American classification scheme and does not include appropriate tests to differentiate the three currently described "S. milleri" species (7). More expanded tests galleries such as the Rapid ID 32 Strep system may be used for further screening of biochemical markers. In addition, a more detailed clinical study might reveal minor but significant differences between the clinical pictures associated with the CI strains and those associated with the $S$. constellatus strains.

Apart from the dually reactive CI strains, both the phenotypic and the genotypic identifications agreed well. The relative high proportion of $S$. constellatus strains that showed atypical tests results in the phenotypic identification scheme suggests a possible heterogeneity within this species. At present, we did not attempt to characterize the genetic and phenotypic properties of the 22 strains that were identified as $S$. constellatus by the phenotypic method and as $S$. intermedius by the line blot assay. Close relatedness between $S$. constellatus and $S$. intermedius has been observed in DNA-DNA reassociation studies (16) and in 16 S rRNA gene sequence analysis (1). In this study, the use of the line blot hybridization assay enabled us to hybridize PCR samples originating from 43 different strains against 4 species-specific probes on. a single membrane. Reverse line blot hybridization. may be an even more labor-friendly and economical alternative (8). In the latter assay, probes are first fixed to the membranes and 5'biotinylated PCR products are added thereafter: the membranes with 
the fixed probes can be reused at least twenty times. In addition, this assay seems a promising technique to detect and differentiate amplified rRNA gene of fastidious growing organisms directly from clinical or environmental samples (11).

In summary, we identified a distinct $16 \mathrm{~S}$ rRNA population within the "S. milleri" group that encompassed strains closely related to $S$. constellatus and represented one third of the phenotypically identified $S$. constellatus strains. In the present series, phenotypic consistency of these strains was not demonstrated. DNA-DNA reassociation studies are needed to confirm the taxonomic position of this rRNA population. Further investigations are needed to devise a rapid phenotypic identification scheme and to define the clinical significance of these strains. 


\section{References}

1. Bentley, R.W., J.A. Leigh, and M.D. Collins. 1991. Intrageneric structure of Streptococcus based on comparative analysis of small-subunit rRNA sequences. Int. J. Syst. Bacteriol. 41:487494.

2. Bergman, S., M. Selig, M.D. Collins, J.A.E. Farrow, E.J. Baron, G.R. Dickersin and K.L. Ruoff. 1995. "Streptococcus milleri" strains displaying a gliding type of motility. Int. J. Syst. Bacteriol. 45:235-239.

3. Bergmans A.M.C., J. Groothedde, J.F.P. Schellekens, J.D.A. van Embden, J.M. Ossewaarde and L.M. Schouls. 1995. Etiology of cat scratch disease: comparison of polymerase chain reaction detection of Bartonella (formerly Rochalimaea) and Afipiafelis DNA with serology and skin tests. J. Infect. Dis. 171:916923.

4. Doit, C., F. Grimont, R.A. Whiley, B. Regnault, P.A.D. Grimont, J.M. Hardie and A. Bouvet. 1994. Ribotypes of the "Streptococcus millerigroup" allow discrimination between Streptococcus constellatus, Streptococcus intermedius and Streptococcus anginosus, p. 531-532. In A.Totolian (ed.), Pathogenic Streptococci: present and future. Lancer Publication, St.Petersburg, Russia.

5. Gossling, J. 1988. Occurrence and pathogenicity of the Streptococcus milleri group. Rev. Infect. Dis. 10:257-285.

6. Jacobs, J.A., H.G. Pietersen, E.E. Stobberingh and P.B. Soeters. 1995. Streptococcus anginosus, Streptococcus constellatus and Streptococcus intermedius. Clinical relevance, hemolytic and serologic characteristics. Am. J. Clin. Pathol. 104:547-553.

7. Jacobs, J.A., H.C. Schouten, E.E. Stobberingh and P.B. Soeters. 1995. Viridans streptococci isolated from the bloodstream. Relevance of species identification. Diagn. Microbiol. Infect. Dis. 22:267-273.

8. Kaufhold A., A. Potbielski, G. Baumgarten, M. Blokpoel, J. Top and L. Schouls. 1994. Rapid typing of group A streptococci by use of DNA amplification and nonradioactive allele-specific oligonucleotide probes. FEMS Microbiol. Lett. 119:19-26.
9. Pearson W.R. and D.J. Lipman. 1988. Improved tools for biological sequence comparison. Proc. Natl. Acad. Sci. USA 85:2444-2448.

10. Piscitelli, S.C., J. Shwed, P. Schreckenberger and L.H. Danziger.1992. Streptococcus milleri group: renewed interest in an elusive pathogen. Eur. J. Clin. Microbiol. Infect. Dis. 11:491-498.

11. Rijpkema S.G.T., M.J.C.H. Molkenboer, L.M. Schouls, F. Jongejan and J.F.P. Schellekens. 1995. Simultaneous detection and genotyping of three genomic groups of Borrelia burgdorferi sensu lato in Dutch Ixodes ricinus ticks by characterization of the amplified intergenic spacer region between $5 \mathrm{~S}$ and $23 \mathrm{~S}$ rRNA genes. J. Clin. Microbiol. 33:3091-3095.

12. Ruoff K.L., L.J. Kunz and M.J. Ferraro. 1985. Occurrence of Streptococus milleri among betahemolytic Streptococi isolated from clinical specimens. J. Clin. Microbiol. 22:149-151.

13. Ruoff, K.L. 1988. Streptococcus anginosus ("Streptococcus milleri"): the unrecognized pathogen. Clin. Microbiol. Rev. 1:102-108.

14. Stackebrandt E. and B.M. Goebel. 1994. Taxonomic note: a place for DNA-DNA reassociation and $16 \mathrm{~S}$ rRNA sequence analysis in the present species definition in bacteriology. Int. J. Syst. Bacteriol. 44:846-850.

15. Weisburg, W.G., S.M. Barns, D.A. Pelletier, and D.J. Lane. 1991. 16S Ribosomal DNA amplification for phylogenetic study. J. Clin. Microbiol. 173:697-703.

16. Whiley R.A. and J.M. Hardie. 1989. DNA-DNA hybridization studies and phenotypic characteristics of strains within the "Streptococcus milleri" group. J. Gen. Microbiol. 28: 1497-1501.

17. Whiley, R.A., H. Fraser, J.M. Hardie, and D. Beigthon D. 1990. Phenotypic differentiation of Streptococcus intermedius, Streptococcus constellatus and Streptococcus anginosus strains within the "Streptococcus milleri group". J. Clin. Microbiol. 28:1497-1501.

18. Whiley, R.A., and D. Beighton. 1991. Emended descriptions and recognition of Streptococcus constellatus, Streptococcus intermedius and Streptococcus anginosus as distinct species. Int. J. Syst. Bacteriol. 41:1-5.

19. Woese, C.R. 1987. Bacterial evolution. Microbiol. Rev. 51:221-271. 


\section{CHAPTER VII Hydrolytic enzymes of Streptococcus anginosus, Streptococcus constellatus and Streptococcus intermedius in relation to infection}

J.A.Jacobs and E.E.Stobberingh.

European Journal of Clinical Microbiology and Infectious

Diseases 1995; 9: 818-820. 
Hydrolytic Enzymes of

Streptococcus anginosus, Streptococcus constellatus and Streptococcus intermedius in Relation to Infection

\section{J.A. Jacobs*, E.E. Stobberingh}

A collection of 518 'Streptococcus milleri' strains was tested for the presence of hydrolytic enzymes, and the results were related to the clinical significance of the strains. Ribonuclease activity was equally distributed among the three species while hyaluronidase activity was linked to Streptococcus intermedius and Streptococcus constellatus. Both enzymes were not significantly associated with infection-related strains. Deoxyribonuclease and chondroitin sulfatase activity tended to be present more frequently in Streptococcus intermedius and Streptococcus constellatus and was associated with infection-related strains $(p<0.001)$

Strains belonging to the 'Streptococcus milleri' group have a tendency to cause abscess formation (1). Three newly defined species have been described - Streptococcus anginosus, Streptococcus constellatus and Streptococcus intermedius (2) the pathogenic mechanisms of which remain unclear (1). Hydrolytic enzymes are generally considered to be potential virulence factors (3), and some of them have been demonstrated in the 'Streptococcus milleri' group (3-9). However, most of these studies predated current taxonomy and made no distinction between the currently recognized species. Moreover, only one study evaluated the correlation between the enzyme activity tested for and the clinical significance of the strains investigated (9). As we were interested in the pathogenic potential of these organisms, we screened a collection of 'Streptococcus milleri' group strains for the production of hydrolytic enzymes. We looked for correlations between enzyme activity on one hand and species and clinical significance on the other.

Department of Medical Microbiology, University Hospital of Maastricht. PO Box 5800, 6202 AZ Maastricht. The Netherlands.
Materials and Methods. Five hundred and eighteen strains were consecutively recovered over a three-year period (July 1991-June 1994) from clinical specimens submitted for culture. Strains were selected irrespective of their hemolytic activity and identified as 'Streptococcus milleri' with the API 20 Strep system (bioMérieux, France). They were stored at $-70^{\circ} \mathrm{C}$. Species identification was performed using the methods of Whiley et al. (10). According to CDC definitions (11), strains were considered infection related on the basis of the opinion of the clinician treating the patient. If clinical evidence was not conclusive or if the culture specimen might have been contaminated by saprophytic flora, the strain was categorized as being of questionable clinical significance.

The panel of enzymes included chondroitin sulfatase, hyaluronidase, deoxyribonuclease (DNase) and ribonuclease (RNase). Unless otherwise stated, media were purchased from Oxoid, UK. Chondroitin sulfatase and hyaluronidase were assayed according to Smith and Willett (12) with biochemicals (chondroitin sulfate $A$ from bovine trachea, bovine albumin fraction $\mathrm{V}$, and hyaluronic acid from bovine trachea) obtained from Sigma, USA. For the DNase test, DNase agar supplemented with brain heart infusion (BHI) broth was used. RNase activity was tested with BHI agar to which yeast RNA (Boehringer Mannheim, Germany) was added (6). Strains were retrieved on blood agar base supplemented with $5 \% \mathrm{v} / \mathrm{v}$ sheep blood. After overnight incubation, they were transferred to Todd-Hewitt broth and incubated for $4 \mathrm{~h}$ at $35^{\circ} \mathrm{C}$. From these suspensions, the substrate plates were inoculated with $10^{4} \mathrm{cfu} / \mathrm{spot}$ via a multipoint inoculator (Denley, UK). They were incubated at $35^{\circ} \mathrm{C}$ in the presence of $5 \% \mathrm{CO}_{2}$ and read after $48 \mathrm{~h}$. All reactions were developed and read according to the cited investigations, and the recommended control strains were used. Proportions were compared with the chi-square test.

Results and Discussion. Table 1 lists the distribution of the enzymes among the clinical categories and the three species. Streptococcus intermedius was proportionally the species most frequently related to infection $(\mathrm{p}<0.001)$. RNase activity was equally distributed among the species and the clinical categories, making a pathogenic role for this enzyme unlikely.

Hyaluronidase activity was more strongly linked to Streptococcus intermedius and Streptococcus constellatus $(\mathrm{p}<0.001)$, in agreement with the findings of Whiley et al. (10), who noted the tax- 
Table 1: Enzyme activity related to species and clinical significance of the strains.

\begin{tabular}{|c|c|c|c|c|c|c|c|c|c|}
\hline & \multirow{2}{*}{$\begin{array}{l}\text { No of } \\
\text { strains }\end{array}$} & \multicolumn{2}{|c|}{ DNase } & \multicolumn{2}{|c|}{ RNase } & \multicolumn{2}{|c|}{ Hyaluronidase } & \multicolumn{2}{|c|}{$\begin{array}{l}\text { Chondroitin } \\
\text { sulfatase }\end{array}$} \\
\hline & & Positive & Negative & Positive & Negative & Positive & Negative & Positive & Negative \\
\hline \multicolumn{10}{|l|}{ Infection related } \\
\hline S. anginosus & 163 & 117 & 46 & 90 & 73 & 11 & 152 & 1 & 162 \\
\hline S. constellatus & 82 & 48 & 34 & 30 & 52 & 80 & 2 & 3 & 79 \\
\hline S. intermedius & 44 & 38 & 6 & 36 & 8 & 42 & 2 & 32 & 12 \\
\hline Total & 289 & 203 & 86 & 156 & 133 & 133 & 156 & 36 & 253 \\
\hline \multicolumn{10}{|c|}{ Questionable clinical significance } \\
\hline S. anginosus & 144 & 77 & 67 & 84 & 60 & 14 & 130 & 0 & 144 \\
\hline S. constellatus & 75 & 43 & 32 & 33 & 42 & 71 & 4 & 1 & 74 \\
\hline S. intermedius & 10 & 4 & 6 & 2 & 8 & 8 & 2 & 2 & 8 \\
\hline Total & 229 & 124 & 105 & $11 \overline{9}$ & 110 & 93 & $13 \overline{6}$ & 3 & 226 \\
\hline \multicolumn{10}{|c|}{ Both clinical categories } \\
\hline S. anginosus & 307 & 194 & 113 & 174 & 133 & 25 & 282 & 1 & 306 \\
\hline S. constellatus & 157 & 91 & 66 & 63 & 94 & 151 & 6 & 4 & 153 \\
\hline S. intermedius & 54 & 42 & 12 & 38 & 16 & 50 & 4 & 34 & 20 \\
\hline Total & 518 & 327 & 191 & 275 & 243 & 226 & 292 & 39 & 479 \\
\hline
\end{tabular}

onomic value of this enzyme. Hyaluronidase activity has been reported to occur mainly in $\beta$ hemolytic 'Streptococcus milleri' group strains (4, $9)$; in the present study the association between hyaluronidase production and $\beta$-hemolysis ( $p<0.001$. data not shown) was related to the high proportion of Streptococcus constellatus among the $\beta$-hemolytic strains. Furthermore, we found no associations between hyaluronidase activity and clinical significance. This suggests that hyaluronidase activity represents a cophenomenon associated with Streptococcus intermedius and Streptococcus constellatus rather than a pathogenic factor on its own. Unsworth et al. (9) noted a correlation between hyaluronidase activity and abscess-related strains. In addition, it was demonstrated that strains from dental plaque and from abscesses both produced the same serotype of this enzyme, which suggested an oral origin for abscess-related strains (P.F. Unsworth et al., Proceedings of the Pathological Society of Great Britain and Ireland, 1980, Abstract no. 31). In that study, the aforementioned strains were not identified to species level, but their characteristics and origin (dental plaque and brain and liver abscesses) correspond to those of Streptococcus intermedius: the reported correlation might be due to the preponderance of Streptococius intermedius strains in their collection.

DNase and chondroitin sulfatase activity were mostly found in Streptococcus constellatus and Streptococcus intermedius, and the association of Streptococcus intermedius with chondroitin sulfatase was statistically significant $(p<0.0(01)$. In- fection-related strains demonstrated DNase and chondroitin sulfatase activity more frequently ( $p<0.001$ ). Strains that possessed both types of activity were found exclusively among Streptococcus intermedius; the majority of them (31/33, $93.9 \%$ ) were infection related. DNase activity has been reported in 52 of 69 'Streptococcus milleri' group strains (5). In a previous report, chondroitin sulfatase activity was only demonstrated in Streptococcus intermedius (10).

The present data provide indirect evidence for the pathogenic potential of DNase and chondroitin sulfatase activity among the 'Streptococcus milleri' group in general and Streptococcus intermedius in particular. The present observations may aid in dirccting further investigations on the pathogenic properties of the 'Streptococcus milleri' group.

\section{References}

1. Piscitelli SC, Shwed J, Schreckenberger P, Danziger $\mathrm{LH}$ : Streptococcus milleri group: renewed interest in an elusive pathogen. European Journal of Clinical Microbiology \& Infectious Diseases 1992, 11: 491-498.

2. Whiley RA, Beighton D: Emended descriptions and recognition of Streptococcus anginosus, Streptococcus intermedius, and Streptococcus anginosus as distinct species. International Journal of Systematic Bacteriology 1991, 41: 1-5.

3. Homer KA, Denbow L. Whiley RA, Beighton D: Chondroitin sulfate depolymerase and hyaluronidase activities of viridans streptococci determined by a sensitive spectrophotometric assay. Journal of Clinical Microbiology 1993, 31: 1648-1651. 
4. Poole PM, Wilson G: Occurrence and cultural features of Streptococcus milleri in various body sites. Journal of Clinical Pathology 1979, 32: 764-768.

5. Pulliam L, Porschen RK, Hadley WK: Biochemical properties of $\mathrm{CO}_{2}$-dependent streptococci. Journal of Clinical Microbiology 1980, 12: 27-31.

6. Marshall R, Kautman AK: Production of deoxyribonuclease, ribonuclease, coagulase and hemolysins by anaerobic gram-positive cocci. Journal of Clinical Microbiology 1981, 13: 787-788.

7. Ruoff KL, Ferraro MJ: Hydrolytic enzymes of "Streptococcus milleri". Journal of Clinical Microbiology 1987, 25: $1645-1647$.

8. Osano E, Hibi E, Ozeki M, Fuji Y, Moriyama T: Chon droitin sulfate-depolymerizing activity in Streptococcus intermedius and other streptococci. Microbiology and Immunology 1987, 31: 1127-1130.
9. Unsworth PF: Hyaluronidase production in Streptococcus milleri in relation to infection. Journal of Clinical Pathology 1989, 42: 506-510

10. Whiley RA, Fraser H, Hardie JM, Beighton D: Phenotypic differentiation of Streptococcus intermedius, Streptococcus constellatus and Streptococcus anginosus strains within the "Streptococcus milleri" group. Journal of Clinical Microbiology 1990, 28: 1497-1501.

11. Garner JS, Jarvis WR, Emori TG, Horan TC, Hughes JM: CDC definitions for nosocomial infections. American Journal of Infection Control 1988, 16: 128-140.

12. Smith RF, Willett NP: Rapid plate method for screening hyaluronidase and chondroitin sulfatase-producing microorganisms. Applied Microbiology 1968, 16: 14341436. 


\section{CHAPTER VIII In-vitro antimicrobial}

susceptibility of the "Streptococcus milleri" group (Streptococcus anginosus, Streptococcus constellatus and Streptococcus intermedius) 


\title{
In-vitro antimicrobial susceptibility of the 'Streptococcus milleri' group (Streptococcus anginosus, Streptococcus constellatus and Streptococcus intermedius)
}

\author{
Jan A. Jacobs* and Ellen E. Stobberingh \\ University Hospital of Maastricht, Department of Medical Microbiology, P.O. Box 5800, \\ NL-6202, AZ Maastricht, The Netherlands
}

\begin{abstract}
A collection of 423 clinical 'Streptococcus milleri' strains was speciated and tested for susceptibilities to twelve antibiotics. Only $1.4 \%$ of the strains were of intermediate susceptibility to penicilin. None of the strains exhibited high-level resistance to gentamicin. Strains resistant to erythromycin, roxithromycin and clindamycin were found with a frequency of $2.6 \%, 2.4 \%$ and $2.4 \%$ respectively. Doxycycline resistance was found in $5.7 \%$ of the strains and occurred most frequently in Streptococcus anginosus. All the strains were susceptible to cefotaxime, vancomycin and teicoplanin. The results of this study do not indicate changing antibiotic resistance in strains of the ' $S$. milleri' group, but local differences in antibiotic susceptibilities may occur.
\end{abstract}

\section{Introduction}

Strains belonging to the 'Streptococcus milleri' group are distinct among the viridans streptococci because of their tendency to cause suppurative infections (Gossling, 1988). At present, three newly defined species are recognised: Streptococcus anginosus, Streptococcus constellatus and Streptococcus intermedius (Whiley \& Beighton, 1991). Strains belonging to the ' $S$. milleri' group are considered uniformly susceptible to the antibiotics usually employed for streptococcal infections (Gossling, 1988). However, anecdotal reports (Quinn et al.. 1988) as well as studies on strain collections (Gómez-Garcés, Alós \& Cogollos, 1994) have demonstrated the presence of resistant strains. Moreover, an increasing antimicrobial resistance among viridans streptococci has been noted (Potgieter et al., 1992). Apart from one study (Gómez-Garcés et al., 1994), all studies on antibiotic susceptibility of the 'S. milleri' group were done before 1990 and pre-dated current taxonomy.

For these reasons, we were interested in the current susceptibility patterns of the ' $S$. milleri' group in general and in the differences in susceptibilities between the three species in particular. We retrospectively identified a collection of clinical 'S milleri' isolates to the species level and determined susceptibilities to a range of antibiotics in current use.

*Phone: +31-43-3874644; Fax: +31-43-3876643 


\section{Methods}

The isolates were recovered over a three-year period (July 1991-June 1994) from clinical specimens received by the microbiology laboratory of the University Hospital of Maastricht. Four hundred and twenty three isolates were collected, $224(53.0 \%)$ of which were infection-related and the remaining $199(47.0 \%)$ were considered of questionable clinical significance. The isolates were recovered from the abdominal cavity $(n=118)$, the urogenital tract $(105)$, head and neck area (56), the thoracic cavity including the respiratory tract (74), the skin and soft tissues (42), and the blood (28). They were stored at $-70^{\circ} \mathrm{C}$ on porous beads in cryopreservative (Microbank, Pro-Lab Diagnostics, Richmond Hill, Ontario, Canada). Before inclusion in the study, their identification was confirmed with the API 20 Strep system supplied with the data base 4.0 (API System, bioMérieux, Marcy-l'Etoile, France). Isolates were identified as $S$. anginosus, $S$. constellatus or $S$. intermedius using the scheme described by Whiley et al. (1990).

Antimicrobial susceptibility tests were carried out by the agar dilution method (NCCLS, 1994) on Mueller-Hinton agar (Oxoid, Basingstoke, UK) supplemented with $5 \%$ (vol vol) sheep blood and containing doubling dilutions of the different antibiotics. The antibiotics were obtained as standard reference powders of defined potency from their respective manufacturers in The Netherlands and included: penicillin (Yamanouchi, Leiderdorp), amoxycillin (Smith-Klinc Beecham, Rijswijk), cefotaxime (Hoechst-Roussel, Hoevelaken), clindamycin (Upjohn, Ede), erythromycin (Abbott, Amsterdam), roxithromycin (Roussel, Hoevelaken), doxycycline (Pfizer, Rotterdam), gentamicin (Essex-Schering, Amstelveen), vancomycin (Eli Lilly, Nieuwegein), teicoplanin (Yamanouchi, Leiderdorp), ciprofloxacin (Bayer, Mijdrecht), and ofloxacin (Hoechst, Amsterdam). The plates were inoculated with $10^{4} \mathrm{cfu} / \mathrm{spot}$ with a multipoint inoculator and incubated in $7 \% \quad \mathrm{CO}_{2}$ at $35^{\circ} \mathrm{C}$ for $18 \mathrm{~h}$. Control organisms were Staphylococcus aureus ATCC 29213 and Enterococcus faecalis ATCC 29212. The susceptibility breakpoint concentrations were as recommended by the National Committee for Clinical Laboratory Standards (NCCLS, 1994):

\section{Results}

The $\mathrm{MIC}_{50}, \mathrm{MIC}_{90}$ and the $\mathrm{MIC}$ range of the three species for the different antibiotics are presented in the Table.

For penicillin, $6 / 423(1.4 \%)$ isolates were moderately susceptible, and were randomly distributed among the three species. None of the isolates tested exhibited high-level resistance (MIC $\geq 500 \mathrm{mg} / \mathrm{L}$ ) to gentamicin.

Overall resistance rates to macrolide antibiotics were limited to $2.6 \%$ (11 isolates) for erythromycin and to $2.4 \%$ (ten isolates) for both clindamycin and roxithromycin. Resistance was found exclusively among the isolates of $S$. anginosus and $S$. constellatus. Resistance to all three aforementioned antibiotics was found in nine isolates, combined erythromycin and clindamycin resistance in another two and combined roxithromycin and clindamycin resistance in one. Overall, 351/423 $(83.0 \%)$ of the organisms studied were susceptible to doxycycline, and $24(5.7 \%)$ were resistant to this agent. Of the three species, $S$. anginosus was most frequently resistant. 


\section{Discussion}

Strains belonging to the ' $S$. milleri' group encompass a heterogencous collection of viridans streptococci. Two classification schemes coexisted from 1977 to 1987: one British and one American. The American scheme distinguished between three species, that were named (in the final version), S. anginosus, S. constellatus and S. intermedius. From 1987 to 1991, all strains were integrated into one single species, S. anginosus. Recently, molecular techniques delineated three species (Whiley \& Beighton, 1991). For reasons of nomenclature (the principle of priority of publication), they were given the same names as those used by the American scheme. The name ' $S$. milleri' was used by British taxonomists, who unified all strains into one species. The name is not legitimate but is still used because of its association with abscesses and other purulent infections. Although surgery constitutes the cornerstone of effective treatment of such infections, prolonged antibiotic therapy may be required (Jacobs et al., 1994).

Recent studies on antimicrobial susceptibilities of the ' $S$. milleri' group are rare and only one report gives details of the susceptibilities of the three species described here (Gómez-Garcés et al., 1994). The literature on 'S. milleri' up to 1988 has been reviewed by Gossling, who noted a wide variety in the results of susceptibility determinations, making comparisons difficult (Gossling, 1988).

In the present study, penicillin was shown to be intrinsically more active than amoxycillin, as reported by others (Gossling. 1988; Gómez-Garcés et al., 1994). The number of isolates moderately susceptible to penicillin $G$ was comparable with the data reviewed by Gossling (1988) and to the results reported in recent studies (LePennec \& Bérardi-Grassias, 1989; Gómez-Garcés et al., 1994). As many life-threatening infections due to 'S milleri' are empirically treated with an antibiotic regimen including a $\beta$-lactam antibiotic (Jacobs et al., 1994), resistance to these agents may have serious consequences. Quinn et al. (1988) report on a fatal case of post-neurosurgical meningitis due to a penicillin-resistant ' $S$. milleri' strain $(\mathrm{MIC} 4 \mathrm{mg} / \mathrm{L}$ ); resistance in this strain was shown to be mediated by alterations of penicillin-binding proteins.

The MIC values for gentamicin in the present study are in line with those found in previous studies that used comparable methodologies (Gossling, 1988). To our knowledge, high-level resistance to aminoglycosides has not yet been demonstrated in ' $S$. milleri'.

The susceptibilities to clindamycin, erythromycin, and roxithromycin in the present study were similar to the data reviewed by Gossling (1988). Resistance to the erythromycin-lincomycin-clindamycin group is transferable among the streptococci (Horaud, Le Bouguenec \& Pepper, 1985). One recent study from Spain reported resistance rates of $14.3 \%$ and $12.8 \%$ for erythromycin and clindamycin respectively (Gómez-Garcés et al., 1994). Although the authors did not specify the number of isolates that displayed combined resistance to these agents, these findings argue for periodic review of susceptibilities and invite a study of the mechanisms responsible for the resistance.

The MIC concentrations of doxycycline for the present collection of isolates are in line with the data compiled for the tetracycline antibiotics (Gossling, 1988). Local differences in susceptibility are again illustrated by the above-cited Spanish report (Gómez-Garcés et al., 1994), that quoted a resistance rate of $37.1 \%$ for tetracycline. As in the present study, $S$. anginosus was noted to be more frequently resistant to tetracycline. 
As reported in other studies (LePennec \& Berardi-Grassias, 1989; Gómez-Garcés et al., 1994), the MIC values for ciprofloxacin and ofloxacin were close to the breakpoint susceptibility concentration.

The glycopeptide antibiotics have been shown to possess excellent in-vitro activity (LePennec \& Berardi-Grassias, 1989; Gómez-Garcés et al., 1994) and the in-vitro

Table. Activity of the antibiotics tested against the three species of the 'S. milleri' group

\begin{tabular}{|c|c|c|c|c|}
\hline $\begin{array}{l}\text { Species }(n) / \\
\text { antibiotic }\end{array}$ & $50 \%$ & $\begin{array}{l}\text { MIC }(\mathrm{mg} / \mathrm{L}) \\
\quad 90 \%\end{array}$ & range & $\begin{array}{l}\text { Percentage of } \\
\text { strains susceptible } \\
\text { at breakpoint } \\
\text { concentration }^{a}\end{array}$ \\
\hline \multicolumn{5}{|c|}{$S$. anginosus $(n=252)$} \\
\hline Penicillin & 0.06 & 0.06 & $\leq 0.015-0.5$ & 99.2 \\
\hline Amoxycillin & 0.125 & 0.25 & $\leq 0.06-0.5$ & 77.3 \\
\hline Cefotaxime & 0.25 & 0.25 & $\leq 0.06-1$ & 100 \\
\hline Erythromycin & 0.125 & 0.25 & $\leq 0.125->256$ & 97.2 \\
\hline Roxithromycin & 0.25 & 0.25 & $\leq 0.25->256$ & 95.6 \\
\hline Clindamycin & 0.06 & 0.125 & $\leq 0.125->256$ & 97.2 \\
\hline Doxycycline & 0.25 & 8 & $\leq 0.25-32$ & 76.2 \\
\hline Gentamicin & 16 & 32 & $\leq 4-32$ & 4.0 \\
\hline Vancomycin & 1 & 1 & $\leq 0.125-1$ & 100 \\
\hline Teicoplanin & 0.06 & 0.125 & $\leq 0.06-0.5$ & 100 \\
\hline Ciprofloxacin & 1 & 2 & $\leq 0.5-4$ & 73.0 \\
\hline Ofloxacin & 1 & 2 & $\leq 0.5-4$ & 99.6 \\
\hline \multicolumn{5}{|c|}{ S. constellatus $(n=130)$} \\
\hline Penicillin & 0.06 & 0.125 & $\leq 0.015-0.5$ & 97.7 \\
\hline Amoxycillin & 0.25 & 0.25 & $\leq 0.06-1$ & 41.5 \\
\hline Cefotaxime & 0.25 & 0.5 & $\leq 0.06-1$ & 100 \\
\hline Erythromycin & 0.125 & 0.125 & $\leq 0.125->256$ & 96.9 \\
\hline Roxithromycin & 0.25 & 0.25 & $\leq 0.25->256$ & 97.7 \\
\hline Clindamycin & 0.06 & 0.125 & $\leq 0.06-32$ & 96.9 \\
\hline Doxycycline & 0.25 & 4 & $\leq 0.25-16$ & 80.1 \\
\hline Gentamicin & 16 & 32 & $\leq 4-32$ & 16.2 \\
\hline Vancomycin & 1 & 1 & $\leq 0.25-1$ & 100 \\
\hline Teicoplanin & 0.06 & 0.125 & $\leq 0.06-0.5$ & 100 \\
\hline Ciprofloxacin & 1 & 1 & $\leq 0.5-2$ & 93.0 \\
\hline Ofloxacin & 1 & 1 & $\leq 0.5-1$ & 100 \\
\hline \multicolumn{5}{|c|}{ S. intermedius $(n=41)$} \\
\hline Penicillin & 0.06 & 0.06 & $\leq 0.015-0.25$ & 97.6 \\
\hline Amoxycillin & 0.125 & 0.25 & $\leq 0.06-0.25$ & 85.4 \\
\hline Cefotaxime & 0.125 & 0.25 & $<0.06-0.5$ & 100 \\
\hline Erythromycin & 0.125 & 0.125 & $\leq 0.125-0.125$ & 100 \\
\hline Roxithromycin & 0.25 & 0.25 & $\leq 0.25-0.25$ & 100 \\
\hline Clindamycin & 0.06 & 0.125 & $\leq 0.06-0.25$ & 100 \\
\hline Doxycycline & 0.25 & 0.5 & $\leq 0.25-16$ & 90.2 \\
\hline Gentamicin & 16 & 32 & $\leq 4-64$ & 22.0 \\
\hline Vancomycin & 1 & 1 & $\leq 0.25-1$ & 100 \\
\hline Teicoplanin & 0.06 & 0.125 & $\leq 0.06-0.125$ & 100 \\
\hline Ciprofloxacin & 1 & 2 & $\leq 0.5-4$ & 82.9 \\
\hline Ofloxacin & 1 & 2 & $\leq 0.5-4$ & 100 \\
\hline
\end{tabular}

"See text for details. 
activity of teicoplanin has been reported to be superior to that of vancomycin (LePennec \& Berardi-Grassias, 1989).

In conclusion, for the antibiotics studied, we found resistance amongst ' $S$. milleri' group rare. However, as uniform susceptibility cannot be assumed and as these organisms may be implicated in life-threatening infections, susceptibility studies should be done on isolates recovered from normally sterile body sites. Resistance to clindamycin and erythromycin was limited to $S$. anginosus and $S$. constellatus, and doxycycline resistance was more frequently found among $S$. anginosus. The high resistance rates to erythromycin, clindamycin and doxycycline reported by others (Gómez-Garcés et al., 1994) contrast with the data in the present study but warrant periodic review of local antimicrobial susceptibility of ' $S$. milleri'.

\section{References}

Gómez-Garcés, J. L., Alós, J. I. \& Cogollos, R. (1994). Bacteriologic characteristics and antimicrobial susceptibility of 70 clinically significant isolates of Streptococcus milleri group. Diagnostic Microbiology and Infectious Diseases 19, 69-73.

Gossling, J. (1988). Occurrence and pathogenicity of the Streptococcus milleri group. Rerie's of Infectious Diseases 10, 257-85.

Horaud, T., Le Bouguenec, C. \& Pepper, K. (1985). Molecular genetics of resistance to macrolides, lincosamides and streptogamin B (MLS) in streptococci. Journal of Antimicrobial Chemotherapy 16, Suppl. A, 111-35.

Jacobs, J. A., Pietersen, H. G., Stobberingh, E. E. \& Soeters, P. B. (1994). Bacteremia involving the "Streptococcus milleri" group: analysis of 19 cases. Clinical Infectious Diseases 19, 704-13.

LePennec, M. P. \& Berardi-Grassias, L. (1989). In-vitro activity of 13 antibiotics against clinical isolates of Streptococcus milleri. Journal of Antimicrobial Chemotherapy 24, 618-9.

National Committee for Clinical Laboratory Standards. (1994). Methods for Dilution Antimicrobial Susceptibility Test for Bacteria that Grow Aerobically, 3rd edition; Approted Standard M7-A3. NCCLS, Villanova, PA.

Potgieter, E., Carmichael, M., Koornhof, H. J. \& Chalkley, L. J. (1992). In vitro antimicrobial susceptibility of viridans streptococci isolated from blood cultures. European Journal of Clinical Microbiology and Infectious Diseases 11, 543-6.

Quinn, J. P., DiVincenzo, C. A., Lucks, D. A., Luskin, R. L., Shatzer, K. L. \& Lenner, S. A. (1988). Serious infections due to penicillin-resistant strains of viridans streptococci with altered penicillin-binding proteins. Journal of Infectious Diseases 157, 764-9.

Whiley, R. A. \& Beighton, D. (1991). Emended descriptions and recognition of Streptococcus anginosus, Streptococcus intermedius and Streptococcus anginosus as distinct species. International Journal of Systematic Bacteriology 41, 1-5.

Whiley, R. A., Fraser, H., Hardie, J. M. \& Beighton, D. (1990). Phenotypic differentiation of Streptococcus intermedius, Streptococcus constellatus, and Streptococcus anginosus strains within the "Streptococcus milleri" group. Journal of Clinical Microbiology 28, 1497-501.

(Received 22 March 1995; accepted 12 September 1995) 


\section{CHAPTER IX General Discussion}




\section{GENERAL DISCUSSION}

Although the incidence of bacteraemia due to $S$. milleri was rare $(0.33$ per 1,000 admissions, Chapter I), it exceeded that of the pyogenic streptococci. Moreover, S. milleri represented nearly half (43\%) of the streptococcal species isolated from blood in non-neutropenic patients. S. milleri strains grew fastidiously in blood cultures and were invariably associated with clinical significance. These observations argue for identification of all streptococci recovered from the blood stream, irrespective of the number of blood cultures grown and the delay of growth detection.

The detailed clinical description of the episodes of bacteraemia (Chapter II) extended the previously reported findings. S. milleri frequently caused nosocomial bacteraemia and the majority of infected patients had underlying diseases. To our knowledge, the organism has never been cultured from the hospital environment and it is generally accepted that virtually all infections due to $S$. milleri arise from endogeneous sources (Whitworth, 1990). In addition, the incidence of severe infections due to $S$. milleri did not increase with age, as was demonstrated in Chapter IV. For these reasons, S. milleri should not be considered a hospital-related opportunistic pathogen. The term "local opportunist" would better fit its behaviour, as a local disruption of the mucosal barrier preceded the majority of the episodes of bacteraemia described in Chapter III as well as in those previously reported.

The distribution of the three species among the strains implicated in the study of bacteraemia did not allow to establish possible associations between species on the one hand and clinical picture on the other (Chapter III). With regard to the phenotypic characteristics of the implicated $S$. milleri strains, the number of strains carrying Lancefield group $\mathrm{C}$ was significantly higher in blood as compared to other locations. This finding was not observed in previous studies, although it should be noted that in the present study (Chapter IV) 4 out of the 9 strains that carried Lancefield group $\mathrm{C}$ were non-haemolytic, and Lancefield grouping with group $\mathrm{C}$ and $\mathrm{G}$ antisera is generally not recommended for the diagnostic work-up of nonhaemolytic streptococci (Facklam, 1991).

The streptococci included in Chapter IV were consecutive isolates that were recovered irrespectively of their haemolytic pattern. This allowed conclusions with regard to the relative distribution of the three species: $S$. anginosus outnumbered the two other species, whereas $S$. intermedius accounted for only $10 \%$ of the S. milleri strains. In addition, based on clinical data, we were able to demonstrate $S$. intermedius as the species that was proportionally more often recovered from infection- and abscess-related culture specimens. Two points can be underlined. First, we noticed that the isolation rate of $S$. milleri in our laboratory increased along with the progression of the collection period. Of course, this reflected increased microbiological experience with these organisms, but it also influenced the ultimate composition of the strain collection by adding more strains of questionable clinical significance to the collection. Or, in terms of species distribution: the number of $S$. anginosus strains that was added to the collection increased faster than the number of e.g. clearly abscess-related $S$. intermedius strains. Second, for accurate comparison of the causative role of the disitinct species in infections and abscesses, there is a need to investigate the distribution of the three $S$. milleri species colonising the non-hospitalised, healthy host.

Chapter VIII deals with the susceptibilities of the three $S$. milleri species to a panel of currently used 
antibiotics. Overall, the strains conformed to the expected susceptibility patterns. The combined resistance rates to erythromycin and clindamycin were rare but they are important, as this resistance pattern is chromosome-borne and transferable among the streptucocci and related genera (Horaud, 1985). Tetracycline resistance genes $t e t(M)$ and tet( $O)$ have been demonstrated in $S$. milleri strains (Charpentier, 1994), and the tet $(M)$ gene is known as a broad-host range conjugative transposon commonly found among enterococci and streptococci. (Clermont, 1990). The potential of transfer of these resistance patterns, coupled with differences in antibiotic selection pressure might explain for the discrepancy in antibiotic susceptibilities between the present collection and those reported from Spain (GómezGarcés, 1994): in fact. Spain is one of the many countries outside North America and Northern Europe where antibiotics are available without prescription. It has the dubious distinction of one of the highest rates in the world of Streptococcus pneumoniae resistant to penicillin, tetracycline, chloramphenicol and erythromycin. (Fenoll, 1991). Although the exact resistance mechanisms of the $S$. milleri strains described by Gómez-Garcés and coworkers have not been determined (Gómez-Garcés, 1994), the message must be clear: indiscriminate use of antibiotics has to be avoided.

With regard to immediate patient care, we demonstrated no clinical benefit in species identification of the $S$. milleri strains. Between the three species, the differences in ecology and antimicrobial susceptibilities are too small to be of any predictive value in the management of the individual patient. Despite the existence of certain associations between particular species and specific anatomic sites or clinical conditions, these associations were not exclusive, with the result that for instance in the case of a $S$. constellatus strain isolated from the blood, any conclusion regarding the original source of the infection must be questionable. The same conclusions can be made with regard to the serologic and haemolytic properties of the strains. The Rapid ID 32 Strep system was useful to distinguish the $S$. milleri strains within the other viridans streptococci and proved to be satisfactory for identification of the other $S$. viridans species (Chapter II). Species identifications of S. anginosus, S. constellatus and S. intermedius obtained by the Rapid ID 32 Strep system agreed reasonably well with those obtained by the reference phenotypic identification scheme (Chapter V). However, correlations were not perfect, and this fact, coupled with the limited need for species identification of the $S$. milleri strains, raises questions concerning the place of this identification kit in the daily routine of the clinical laboratory. A thorough discussion must include recent data on the performance of other commercial systems in identification of streptococcal and enterococcal species, and this is beyond the scope of this thesis. With regard to the S. milleri strains in the diagnostic setting, we suggest the VogesProskauer test, the tests for hydrolysis of arginine and for fermentation of sorbitol (referred to in Chapter IV) to be performed on suspected colonies, regardless of the type of haemolysis. In our experience, the minute colony appearance, the small zone of haemolysis and the caramel odour are helpful screening criteria but they are not always present. Strains displaying doubtful or inconclusive test reactions should be further examined, and for this purpose we still rely upon the API 20 Strep system. As stated in Chapter II, this system is not valuable to differentiate between the three $S$. milleri species. However, the API 20 Strep is a potent and reproducible system to delineate $S$. milleri strains from the other streptococcal species and has the advantage of its biotyping capacity. These factors contribute to its continued use (in the version 4.0) by prominent authors in the field (Coykendall, 1989; Flynn, 1995; Bergman, 1995). We tried to modify its 
database to correct for the high proportion of $S$. anginosus strains that were incorrectly assigned to the $S$. intermedius species by the database 5.1., but this modification resulted in a high number of incorrectly identified $S$. intermedius strains. We concluded that the API 20 Strep system did not contain appropriate tests to discriminate among the three species (Chapter I) and we adopted the following approach: we decode the API 20 Strep digit number with the database 5.1 , and when the system identifies the strain tested as $S$. anginosus, $S$. constellatus or $S$. intermedius, we report it as " $S$. milleri" instead of using its particular species name. At present, we do not use the Rapid ID 32 Strep system in daily practice. For optimal performance, we presumed that the system has to be coupled to an automatic reader, and we experienced the visual reading and recording as complicated (Chapter III). For taxonomic or epidemiologic studies however, it is of interest to realise that the system generates an eleven-digit numerical profile. The Fluo-Card Milleri (Flynn, 1995) seems a promising tool for instant species differentiation of clinical $S$. milleri strains. The simplicity and reproducibility of the system probably allows its occasional use in those (rare) situations where species differentiation of a clinical S. milleri strain is required. When the system is released in Europe, we will certainly consider an evaluation.

Lancefield grouping is of minor importance for the identification of the S. milleri strains, as far as individual patient care is concerned. It may give relevant information for studies regarding the pathogenicity or epidemiology of these strains, provided that grouping is performed on all strains, regardless of their haemolytic pattorn.

In Chapter VI, we demonstrated a distinct ribosomal RNA population (the "Cl strains") closcly related to $S$. constellatus. From a purely taxonomic perspective, the question whether the CI strains represent a distinct species or not awaits a decisive answer from DNADNA reassociation studies, as the latter technique is superior over RNA gene sequencing for delimiting species among highly related taxa (Stackebrandt, 1994). Independently from the result of these DNADNA reassociation studies, the question will further be governed by a practical approach, namely the phenotypic consistency (Wayne, 1987). As long as the $\mathrm{CI}$ strains and $S$. constellatus strains remain phenotypically and clinically indistinguishable, they will not be allocated to distinct nomenspecies even when DNA-DNA reassociation studies might reveal less than 70\% homology between the two groups. Assays such as the line blotting assay used in Chapter VI allow screening of large collections of strains, and techniques for sequencing the ribosomal RNA have become less cumbersome than they were a decade ago (Amman, 1994). As a result, the chances of detecting subpopulations at the genetic level are expected to augment, and some of them (even if they will proven to be genospecies) will lack phenotypic characteristics that allow correct phenotypic identification. Recently, a taxonomic note has been proposed to resolve this problem (Ursing, 1995): nomenspecies should be allowed to include more than one genomic group and the term "genomovars" should apply to those genomic groups that await reliable and applicable identification schemes to be phenotypically distinguished from each other.

Chapter VII provides indirect evidence for the production of deoxyribonuclease and chondroitin sulfatase as potential pathogenic factors of the $S$. milleri strains. These enzymes were mostly found in $S$. constellatus and S. intermedius. Further studies should include quantitative measurements of the enzyme production, as described by Homer and coworkers (Homer, 1993). Properties such as inducibility of the enzymes are to be investigated and in-vivo studies should be done to provide direct evidence of these enzymes as virulence determinants. 


\section{References}

Amann R, Ludwig $\mathrm{W}$ and Schleifer KH. Identification of uncultured bacteria: a challenging task for molecular taxonomists. ASM News 1996; 66: 358-365.

Bergman S, Selig M, Collins MD, Farrow JAE, Baron EJ, Dickersin GR and Ruoff KL. "Streptococcus milleri" strains displaying a gliding type of motility. Int J Syst Bacteriol 1995: 45: 235-239.

Charpentier E, Gerbaud G and Courvalin P. Presence of Listeria tetracycline resistance gene tet(S) in Enterococcus faecalis. Antimicrob Agents Chemother 1994; 38: 2330-2335.

Clermont D and Horaud T. Identification of chromosomal antibiotic resistance genes in Streptococcus anginosus ("S. milleri"). Antimicrob Agents Chemother 1990; 34: 1685-1690.

Coykendall A, Wesbecher PM and Gustafson KB. "Streptococcus milleri", Streptococcus constellatus, and Streptococcus intermedius are later synonyms of Streptococcus anginosus. Int J Syst Bacteriol 1987 ; 37: 222-228.

Facklam RR and Washington JA. Streptococcus and related catalase-negative gram-positive cocci. In Balows A, Hausler WJ, Herrmann KL, Isenberg HD and Shadomy HJ. Manual of Clinical Microbiology. 5th ed., 1991. American Society for Microbiology, Washington DC. pp238-257).

Fenoll A, Martín Bourgon C, Muñóz R, Vicioso D and Casal J. Serotype distribution and antimicrobial resistance of Streptococcus pneumoniae isolates causing systemic infections in Spain, 1979-1989. Rev Infect Dis, 1991: 13: 56-60.
Flynn CE and Ruoff KL. Identification of "Streptococcus milleri" group isolates to the species level with a commercially available rapid test system. J Clin Microbiol 1995; 33: 27042706.

Homer KA, Dendow L, Whiley RA and Beighton D. Chondroitin sulfate depolymerase and hyaluronidase activities of viridans streptococci determined by a sensitive spectrophotometric assy. J Clin Microbiol 1993; 31: 1648-1651.

Stackebrandt E and Goebel BM. Taxonomic note: a place for DNA-DNA reassociation and 16S rRNA sequence analysis in the present species definition in bacteriology. Int J Syst Bacteriol 1994; 44: 846-850.

Ursing JB, Rosselló-Mora RA, García-Valdés E and Lalucat J. Taxonomic note: a pragmatic approach to the nomenclature of phenotypically similar genomic groups. Int J Syst Bacteriol 1995; 45: 604.

Wayne LG, Brenner DJ, Colwell RR, Grimont PAD. Kandler O, Krichievsky MI, Moore LH, Moore WEC, Murray RGE, Stackebrandt E, Starr MP and Trüper HG. Report of the Ad Hoc Committee on Reconciliation of Approaches to Bacterial Systematics. Int J Syst Bacteriol 1987; 37: 463-464.

Whitworth JM. Lancefield group F and related streptococci. J Med Microbiol 1990; 33: 135-151. 


\section{SUMMARY}

Strains belonging to the Streptococcus milleri group are notorious among the viridans streptococci because of their assocation with purulent infections. Unfortunately, they are difficult to recognise in the laboratory due to their serologic and biochemical heterogeneity. Furthermore, a long standing dispute on the classification of these organisms has caused confusion on their nomenclature, which, in turn, has added to the difficulties of identification. At present, three species are recognised within the $S$. milleri group: Streptococcus anginosus, Streptococcus constellatus and Streptococcus intermedius.

In Chapter I, a literature review on $S$. milleri and $S$. anginosus, S. constellatus and S. intermedius is given. The different issues regarding the taxonomy of these strains are revicwed: classification, nomenclature and identification. The clinical picture, the pathogenic potential and the antimicrobial susceptibilities of $S$. milleri and the three species are presented.

From these compiled data, it is clear that many questions regarding these organisms remain open. We were particularly interested in (i) the clinical relevance of species identification of the $S$. milleri strains, (ii) the genomic diversity of these organisms, (iii) the performance of the Rapid ID 32 Strep system and (iv) the presence of hydrolytic enzyme activities in relation to infection.

In Chapter II, a collection of viridans streptococci isolated from the blood was identified to the species level according to recently established criteria. Streptococcus milleri outnumbered the other species among those strains that were recovered from the general hospital population. The $S$. milleri strains isolated from the blood were invariably associated with clinical significance and they tended to grow fastidiously in blood culture media.
In Chapter III, the clinical and microbiological aspects of nineteen episodes of bacteraemia due to S. milleri (including 20 strains) were studied in detail. $S$. anginosus was the most prevalent species, and eight strains carried Lancefield group C. Underlying diseases were present in nearly $60 \%$ of the patients studied, and local trauma to the mucosal barrier was an important risk factor. Abscess formation was present in nine cases, and repeated drainage procedures were required in half of these cases. The associated mortality of bacteraemia due to $S$. milleri was $26.3 \%$.

Chapter IV depicts the clinical and phenotypic profile of a collection of $518 \mathrm{~S}$. milleri strains recovered from clinical specimens routinely submitted for culture. $S$. anginosus was the most frequently isolated species $(59.3 \%)$, followed by S. constellatus $(30.3 \%)$ and $S$. intermedius $(10.4 \%)$. Most of the $S$. constellatus strains were B-haemolytic. S. intermedius, although predominantly recovered from the head and neck area, was also isolated from the abdomen and the skin, bone and soft tissues. Non-haemolytic strains and $S$. intermedius were proportionally more frequently recovered from abscess-related specimens.

In Chapter V, the Rapid ID 32 Strep system was challenged with a collection of clinical $S$. milleri strains, in order to study its performance in differentiation S. milleri strains to the species level. The results were compared with those obtained by the reference identification scheme. Both systems agreed reasonably weli, the best agreement was reached with $S$. anginosus, while most discrepancies occurred with S. intermedius.

The study presented in Chapter VI describes the phylogenetic interrelationships between the $S$. milleri 
strains at the level of the $16 \mathrm{~S}$ ribosomal RNA gene. PCR-amplified 16S rRNA gene was hybridised with species-specific 5'biotinylated oligonucleotide probes in a line blot assay. Strains that hybridised with both the $S$. constellatus and the $S$. intermedius specific probes accounted for nearly one third of those strains that were phenotypically identified as $S$. constellatus. Comparison of the partial 16S rRNA sequence of these dually reactive strains showed that they represented a distinct rRNA population sharing 98.1\% sequence similarity with $S$. constellatus type strain. In addition, the dually reactive strains hybridised with a 5'biotinylated probe based on the partial $16 \mathrm{~S}$ rRNA sequence of one of them. Phenotypic consistency of the dually reactive strains was not observed.

In Chapter VII, the three $S$. milleri species were tested for the presence of hydrolytic enzymes by a qualitative plate method. The results were related to the clinical significance of the strains. Deoxyribonuclease and chondroitin sulfatase activities were significantly associated with infection- related strains, and these enzyme activities tended to be more often present in $S$. intermedius and $S$. constellatus.

In Chapter VIII the in-vitro susceptibilities of the three $S$. milleri species to a panel of currently used antimicrobial agents are described. Only $1.4 \%$ of the strains were intermediate susceptible to penicillin. Strains resistant to erythromycin, roxithromycin, and clindamycin were found in a frequency of $2.6 \%$, $2.4 \%$, and $2.4 \%$, repectively. Doxycycline resistance was found in $5.7 \%$ of the strains and occurred most frequently in $S$. anginosus. Comparison of these results with recent data from Spain warrant periodic review of local antimicrobial susceptibilities of the S. milleri strains.

In Chapter IX the results presented in the previous chapters are discussed. It is concluded that there is no clinical benefit for immediate patient care in differentiation the $S$. milleri strains to the species. Furthermore, strategies for the identification of the S. milleri strains in the diagnostic setting are outlined. 


\section{SAMENVATTING}

Stammen die tot de Streptococcus milleri groep behoren onderscheiden zich van de andere vergroenende streptococcen door hun relatie met purulente infecties. Jammer genoeg worden deze bacteriën vanwege hun heterogene serologische en biochemische eigenschappen moeilijk herkend in het laboratorium. Bovendien heeft de langdurige discussie over de taxonomie van deze bacteriën onduidelijkheden veroorzaakt aangaande hun benaming, en dit resulteerde dan weer in problemen rondom de identificatie. Op dit ogenblik worden er drie species onderscheiden in de $S$. milleri groep: Streptococcus anginosus, Streptococcus constellatus en Streptococcus intermedius.

In Hoodfstuk I wordt de literatuur over S. milleri, $S$. anginosus, S. constellatus en S. intermedius samengevat. De verschillende aspecten met betrekking tot de taxonomie van deze stammen worden belicht: classificatie, nomenclatuur en identificatie. Het klinisch beeld, het pathogeen vermogen en de antimicrobiële gevoelighcid van $S$. milleri en de drie species worden beschreven. Uit deze gegevens wordt duidelijk dat vele vragen betreffende deze bacteriën onbeantwoord blijven. Ons intereseerde in het bijzonder (i) de klinische relevantie van de speciesidentificatie van de S. milleri stammen, (ii) de genetische diversiteit van deze organismen, (iii) de waarde van het Rapid ID 32 Strep systeem en (iv) het verband tussen de productie van hydrolytische enzymes en infectie.

In Hoofdstuk II worden de resultaten beschreven van een collectie vergroenende streptococcen die volgens recent gepubliceerde criteria geïdentificeerd werden. De species behorende tot de Streptococcus milleri groep waren de meest voorkomende specics tussen de stammen die bij de niet-neutropene ziekenhuis- populatie gekweekt werden. De S. milleri stammen die uit bloed gekweekt werden waren zonder uitzondering klinisch relevant en vertoonden soms een langzame groei in de bloedkweekmedia.

In Hoofdstuk III werden de klinische en microbiologische aspecten van negentien episodes van bacteriëmie veroorzaakt door $S$. milleri (in het totaal 20 stammen) in detail bestudeerd. S. anginosus was de meest voorkomende species, en acht stammen behoorden tot Lancefield groep C. Onderliggende aandoeningen waren aanwezig in bijna $60 \%$ van de bestudeerde patiënten, en lokaal trauma aan de mucosa was een belangrijke risicofactor. Abcessen waren aanwezig in negen episodes, en herhaalde drainage was vereist in bijna de helft van deze gevallen. De mortaliteit geassocieerd aan S. milleri bacteriëmie bedroeg $26.3 \%$.

Hoofdstuk IV beschrijft de klinische en fenotypische eigenschappen van een collectie van 518 S. milleri stammen die gekweekt werden uit klinische monsters. $S$. anginosus was het meest voorkomende species $(59.3 \%)$, gevolgd door S. constellatus (30.3\%) en S. intermedius $(10.4 \%)$. Het merendeel van de $S$. constellatus stammen vertoonde B-hemolyse. Hoewel $S$. intermedius vooral uit het hoofd- en halsgebied gekweekt werd, werd dit species ook gekweekt uit monsters afkomstig uit het abdomen en de huid, het skelet en de weke delen. De niet-hemolytische stammen en $S$. intermedius werden in verhouding het meest frequent gekweekt uit abcessen.

In Hoofdstuk V werd het Rapid ID 32 Strep getest met een collectie klinische $S$. milleri stammen, met het oog op de prestatie van het systeem in het onderscheiden van de drie species. De resultaten werden vergeleken met deze verkregen met het 
referentie identificatieschema. De overeenkomst tussen beide systemen was aanvaardbaar goed, de beste overeenkomst werd bereikt met $S$. anginosus, de $S$. intermedius stammen leverden de meeste discrepanties.

De studie in Hoofdstuk VI beschrijft de fylogenetische verwantschap tussen de $S$. milleri stammen in het gebied van het 16 S ribosomaal RNA. Het 16 S ribosomaal RNA werd door een polymerase ketting reactie geamplificeerd en vervolgens gehybridiseerd met species-specifieke gebiotinyleerde oligonucleotide probes in een zgn. 'line blot assay'. Van de in fenotypische tests als $S$. constellatus geïdentificeerde stammen hybridiseerde bijna één derde met zowel de voor $S$. constellatus specifieke probe als met de $S$. intermedius specifieke probe. Vergelijking van een deel van de $16 \mathrm{~S}$ ribosomale nucleotidensequentie toonde aan dat deze stammen een aparte groep vormen die $98.1 \%$ gelijkenis in nucleotidensequentie vertoont met de S. constellatus type stam. Specifiek onderscheidende fenotypische kenmerken van deze stammen werden niet aangetoond.

In Hoofdstuk VII wordt de produktie van hydrolytische enzymen bij de drie S. milleri species bepaajd door een kwalitatieve plaatmethode. De resultaten werden vergeleken met de klinische relevantie van de stammen. Deoxyribonuclease en chondroïtinesulfatase activiteiten kwamen significant meer voor bij stammen die afkomstig waren uit infectieuze monsters, en deze enzymatische activiteiten kwamen ook meer voor bij $S$. intermedius en $S$. constellatus.

Hoofdstuk VIII beschrijlt de in vitro gevoeligheid van de drie S. milleri species aan een aantal antimicrobiële middelen. Slechts $1.4 \%$ van de onderzochte stammen was matig gevoelig aan penicilline. Resistentie voor erythromycine, roxithromycine en clindamycine werd aangetoond bij respectievelijk $2.6 \%, 2.4 \%$ en $2.4 \%$ van de onderzochte stammen. Resistentie voor doxycycline werd aangetoond in $5.7 \%$ van de onderzochte stammen en werd het vaakst vastgesteld bij $S$. constellatus. Een vergelijking van deze cijfers met recente cijfers uit Spanje onderstreept het belang van het regelmatig opvolgen van de lokale antmicrobiële gevoeligheden van de $S$. milleri stammen.

In Hoofdstuk IX worden de resultaten van de vorige hoofdstukken besproken. Besluit is dat voor directe patiëntenzorg de spcciesdifferentiatie van S. milleri stammen niet relevant is. Daarnaast worden er strategieën voor de identificatie van S. milleri stammen in het diagnostisch laboratorium uiteengezet. 


\section{DANKWOORD}

Mijn oprechte dank gaat naar elkeen van de talrijke mensen die aan dit proefschrift meegeholpen hebben. Zonder iemand te kort te willen doen, wil ik een aantal van hen hier vermelden.

Mijn promotor, Prof. dr. Peter Soeters wens ik te bedanken voor zijn synthetische inbreng: die van ervaren clinicus en doordachte wetenschapper. Daarnaast waardeer ik enorm het vertrouwen dat hij stelt in jonge collega's als ik, en zijn bekommernis dat dit proefschrift mijn persoonlijke vorming en kennis zou vernieuwen en uitbreiden.

Mijn copromotor, dr. Ellen Stobberingh dank ik voor de kans die zij mij destijds bood om los van de toen lopende onderzoekslijnen dit onderwerp aan te vatten, en voor de mogelijkheden die zij mij ter beschikking stelde. Het ontwapenende optimisme dat ze uitstraalt en haar doordrijvend karakter hebben me steeds weer gemotiveerd.

Mijn copromotor, Prof. dr. Jan Verhaegen dank ik voor de degelijke en constructieve inbreng vanuit dit specifieke gezichtspunt dat kliniek en patiëntenzorg benadert vanuit de bacterie op de laboratoriumtafel. Deze visie heeft dit onderzoek doorvlochten en werd met rustige kennis door Jan uitgedragen.

De medewerkers van het Bacteriologisch Laboratorium van het azM vergaarden op korte tijd een uitzonderlijk grote collectie $S$. milleri stammen: ik dank hen van harte omwille van hun speurzin en systematiek, maar ook voor de aandacht en de roulerende betrokkenheid bij dit onderzoek. In het bijzonder dank ik Wanda Vriese en Monique Coomans voor de korte maar vruchtbare samenwerking.

Dr. Jan van Embden dank ik voor de dagen die ik op het RIVM (Bilthoven) doorbracht, en die voor mij een verrijking geweest zijn. Dr.Leo Schouls ben ik erkentelijk voor zijn grondige begeleiding bij het moleculair werk. Daarnaast heb ik zijn geestdrift voor het vak en zijn aanstekelijke humor erg op prijs gesteld. Corrie Schot, Annelies van Bunschoten, Janetta Top en de overige medewerkers dank ik voor hun inzet en belangstelling, en voor de sfeer van kennisoverdracht en gastvrijheid op de werkvloer.

Mijn vriend drs. Henk Pietersen heeft als werker van het eerste uur alles van nabij gevolgd: van de eerste casusbeschrijving tot zijn betrokkenheid als paranymf. Ik dank hem voor zijn degelijke en voortdurende ondersteuning: hij zette de database op en construeerde onvermoeibaar de vorm en presentatie van de resultaten. Daarnaast zullen onze discussies me bijblijven: discussies over het vak, de "milleries" en over nog veel meer: te vergelijken met mijn beste college- en studentenjaren.

Dr. Maarten Visser (AZU) en drs. Ton van den Bogaard dank ik voor de waardevolle suggesties die me op het goede ogenblik bereikten en me hielpen het onderzoek te structureren. Dr. Harry Schouten wens ik te bedanken voor zijn vlotte en efficiënte bijdrage aan het eerste hoofdstuk.

De leden van de beoordelingscommissie, in het bijzonder de voorzitter Prof. dr. Frans Ramaekers dank ik voor de bekwame spoed waarmee zij dit manuscript hebben beoordecld. Hierdoor bleef de wachttijd tot de promotiedatum beperkt, met ongetwijfeld gunstige weerslag op de jaarlijkse vakantie van de familie Jacobs aan de Belgische kust.

De collega's op de afdeling ben ik erkentelijk voor hun begrip en goede wil in drukke dagen. De medewerkers van de secretariaten medische microbiologie (in bijzonder Resi Hoogenboom) en chirurgie (Esther ten Hoor) wens ik te bedanken voor de vriendelijke energie waarmee de adminstratie bekwaam geregeld werd. 
Bovendien zijn er vele mensen geweest die ik niet zozeer voor hun microbiologische dan wel voor hun psychologische bijdrage wil danken: mijn diensthoofd Prof. dr. Cathrien Bruggeman, dr. Geert Wälenkamp, dr. Frank van Tiel, dr. Frans Stals als paranymf en dr. Nico Meessen als bondgenoot op het laatste trajekt van dit proefschrift.

Mijn vader en wijlen mijn moeder dank ik voor de stimulans tot voortdurende vorming en studie die ze mij bijbrachten. Mijn schoonouders wil ik bijzonder danken voor hun polyvalente inzet thuis.

Mijn lieve echtgenote Chris ontplooide vanuit eigen ervaring een goed gedoseerde houding van steun, belangstelling en relativering. Dit droeg enorm bij aan mijn zelfvertrouwen en innerlijke rust, waarvoor ik mijn dank en waardering wil uitspreken. Onze kinderen Bart, An, Liesbet, Karel en Koen wil ik bedanken voor de pret en de gezellige geborgenheid die ze samen met ons maken. Ik hoop dat ze dezelfde kansen mogen krijgen als wijzelf gehad hebben. 


\section{LIST OF PUBLICATIONS}

J. Jacobs, G. Tricot, and R.L.Verwilghen. Pseudotrombocytopenie door trombocytagglutinaten (EDTAthrombocytopenie). Ned.Tijdschr.Geneesk. 1986; 130: 1643-1646.

J. Jacobs, J. Van Lierde, A. Nevelsteen, J. Vermylen, and L. Verbist. Campylobacter fetus subspecies fetus infection of an abdominal aneurysm. Act.Clin.Belg. 1989; 44: 123-128.

J. Jacobs, M. Smeets, E. Eggermont, and J. Vandepitte. Yersinia enterocolitica associated diarrhoea in a neonate (Letter). Eur.J.Clin.Microbiol.Infect.Dis. 1989; 8: 1005-1006.

J. Jacobs, D. Jamaer, J. Vandeven, M. Wouters, C. Vermylen, and J. Vandepitte. Yersinia enterocolitica in donor blood: a case report and a review. J.Clin.Microbiol.1989; 27: 1119-1121.

J. Jacobs, K. Garmyn, J. Verhaegen, H. Devlieger, and E. Eggermont. Neonatal sepsis due to Streptococcus pneumoniae. Scand.J.Infect.Dis. 1990; 22: 493-497.

J. Jacobs, J. Verhaegen, G. Verhoef, and M. Boogaerts. Rare nosocomial pathogen isolated from two patients. Clin.Microbiol.Newsl.1990; 12: 6-7.

L. Verbist, I. Jacobs, and K. Hens. Comparative antimicrobial activity of Ceftibuten against multipy-resistent microorganisms from Belgium. Diagn.Microbiol.Infect.Dis. 1991: 14: 53-61.

J.A. Jacobs, E.E. Stobberingh, and H.C. Schouten. Fatal infection due to Alcaligenes xylosoxidans subsp.xylosoxidans in a neutropenic host. Clin.Microbiol.Newsl.1992; 14: 182-184.

J.A. Jacobs and E.E. Stobberingh. Naamverandering van bacteriën. I.Classificatie. Ned.Tijdschr. Geneesk. 1992; 136: $1799-1802$.

J.A. Jacobs and E.E. Stobberingh. Naamverandering van bacteriën. II.Nomenclatuur en identificatie. Ned.Tijdschr.Geneesk. 1992; 36: 1803-1807.

M. Maes, H. Metzler, J. Jacobs, E. Suy, J. Calabrese, B. Minner, and J. Raus. Autoimmunity in depression: increased antiphospholipid autoantibodies. Acta Psychiatr. Scand. 1993; 87: 160-166.

J.A. Jacobs, G.D. Algie, G.H. Sie, and E.E. Stobberingh. Association between Eikenella corrodens and Streptococci (Letter). Clinical Infectious Diseases 1993; 16: 173.

J.A. Jacobs, J.J.E. Hendriks, P.D.M.M. Verschure, A.M. van der Wurff, G. Freling, G.D. Vos, and E.E. Stobberingh. Meningitis due to Fusobacterium necrophorum subspecies necrophorum. Case report and review of the literature. Infection 1993; 21: 57-63. 
J.A. Jacobs and E.E. Stobberingh. Infection due to a contaminated thoracic drainage system. J.Hosp.Infection 1993; 24: 23-28.

J.A. Jacobs and E.E. Stobberingh. Pseudomeningitis: how clean are pre-cleaned slides? (Letter) Lancet 1993; i: 446-447.

J.T.C. Kellens, J.A. Jacobs, W.J. Peumans, and E.E. Stobberingh. The agglutination of ß-haemolytic streptococi by lectins. J.Med.Microbiol. 1993,39: 440-445.

J.A. Jacobs, M.C.T. de Krom, J.T.C. Kellens, and E.E. Stobberingh. Meningitis and sepsis due to group G Streptococcus (Letter). Eur.J.Clin.Microbiol.Infect.Dis. 1993; 12: 223-224.

J.A. Jacobs, J.L. Verhagen, J.J.P. Schrander, and E.E. Stobberingh. Pneumokokken (Letter). Ned.Tijdschr.Geneesk. 1993; 137: 674.

J.C.J.M. Veraart, J.A. Jacobs, and H.A.M. Neumann. Arcanobacterium haemolyticum isolated from pompholyx lesions. Eur.J.Dermatol.1994; 4: 315-316.

H.G. Pietersen, J.A. Jacobs, P.B. Soeters, and E.E. Stobberingh. Een Bulla uit Bolivië. Tijdschr.voor Geneeskunde 1994; 50: 811-814.

J.T.C. Kellens, J.A. Jacobs, W.J. Peumans, and E.E. Stobberingh. Agglutination of "Streptococcus milleri" by lectins. J.Med.Microbiol.1994; 41: 14-19.

J.A. Jacobs, H.G. Pietersen, G.H.I.M. Walenkamp, E.E. Stobberingh, and P.B. Soeters. Intervertebral infection caused by Streptococcus milleri. Clin.Orthop.Rel.Res. 1994; 302: 183-188.

J.A. Jacobs, and E.E. Stobberingh. Species identification of "Streptococcus milleri" with the Rapid ID 32 Strep system. Med.Microbiol.Lett. 1994; 3: 315-322.

J.A. Jacobs, M.G.R. Hendrix, and E.E. Stobberingh. Pseudobacteraemia: stowaways in commercial culture media (Letter). J.Hosp.Infection 1994; 27: 242-243.

J.A. Jacobs, H.G. Pietersen, E.E. Stobberingh, and P.B. Soeters. Bacteremia due ot the "Streptococcus milleri" group: analysis of 19 cases. Clin.Infect.Dis. 1994; 19: 704-713

F.H. van Tiel, B. Slangen, H.C. Schouten, and J.A. Jacobs. Stomatococcus mucilaginosus bacteremia in neutropenic patients. Eur.J.Clin.Microbiol.Infect.Dis.1995; 14: 193-198. 
M. Drent, M.J.M. Bonten, and J.A. Jacobs. Diagnostiek nosocomiale pneumonie bij mechanisch geventileerde patiënten. In Bakker J, de Lange B., Rommes J.H.(eds). Intensive Care Capita Selecta, Stichting Venti-Care, Utrecht 1995: pp127-138.

J.A. Jacobs, H.C. Schouten, E.E. Stobberingh, and P.B. Soeters. Viridans streptococci isolated from the bloodstream. Relevance of species identification. Diagn.Microbiol.Infect.Dis. 1995; 22: 267-273.

J.A. Jacobs, J.L.N. Stappers, and J.P. Sels. Endocarditis due to Streptococcus oralis in a patient with a colon tumor (Letter). Eur.J.Clin.Microbiol.Infect.Dis.1995; 14: 557-558.

J.A. Jacobs and E.E. Stobberingh. Hydrolytic enzymes of Streptococcus anginosus, Streptococcus constellatus and Streptococcus intermedius in relation to infection. Eur.J.Clin.Microbiol.Infect.Dis 1995; 14: 818-820.

J.A. Jacobs and E.E. Stobberingh. In-vitro antimicrobial susceptibility of clinical isolates of the Streptococcus milleri group (Streptococcus anginosus, Streptococcus constellatus and Streptococcus intermedius). J.Antimicrob.Chemother. 1996; 37: 371-375.

J.A. Jacobs, H.G. Pietersen, E.E. Stobberingh, and P.B. Soeters. Streptococcus anginosus, Streptococcus constellatus and Streptococcus intermedius. Clinical relevance, hemolytic and serologic characteristics. Am.J.Clin.Pathol. 1995; 104: 547-553.

J.A. Jacobs, C.S. Schot, A.E. Bunschoten, P.B. Soeters, and L.M. Schouls. "Streptococcus milleri " : line blot hybridization of $16 \mathrm{~S}$ rRNA gene reveals distinct rRNA population closely related to Streptococcus constellatus. J.Clin.Microbiol., accepted with minor modification. 


\section{CURRICULUM VITAE}

Jan Jacobs werd geboren op 23 oktober 1959 te Leuven. Hij volgde Latijns-Griekse Humaniora aan het StRomboutscollege te Mechelen. Vervolgens studeerde hij Geneeskunde aan de Katholieke Universiteit Leuven, het kandidaatsdiploma werd met grote onderscheiding behaald in 1980, het artsdiploma met grote onderscheiding in 1984. Van 1984 tot 1989 doorliep hij de opleiding Klinische Biologie aan de K.U.Leuven. Tijdens zijn opleiding voltooide hij de vorming Medische en Veterinaire Mycologie aan het Instituut voor Tropische Geneeskunde te Antwerpen (diploma 1986, grote onderscheiding) en de Aggregatie voor het Hoger Secundair Onderwijs en het Hoger Onderwijs van het Korte Type in de Geneeskunde (K.U.Leuven, diploma 1988, grote onderscheiding). In 1989 en 1990 werkte hij aan het Dr.L.Willems-Instituut te Diepenbeek, België. In 1990 verkreeg hij het getuigschrift ziekenhuishygiëne (K.U.Leuven). In 1991 volgde registratie als Medisch Microbioloog en begon hij zijn werkzaamheden op de afdeling Medische Microbiologie aan het Academisch Ziekenhuis Maastricht. Sinds begin 1993 werkt hij aan het onderzoek dat in dit proefschrift beschreven is.

Jan is gehuwd met Christel Van Geet, kinderarts aan de Universitaire Ziekenhuizen te Leuven. Zij zijn de ouders van Bart, An, Liesbet, Karel en Koen. 
